Universidade de São Paulo

Instituto de Física

\title{
Teletransporte de informação quântica entre campos de cores distintas
}

\author{
Igor Konieczniak
}

Orientador: Prof. Dr. Paulo Alberto Nussenzveig

Dissertação de mestrado apresentada ao Instituto de Física da Universidade de São Paulo para obtenção do título de Mestre em Ciências

Banca Examinadora:

Prof. Dr. Paulo Alberto Nussenzveig (IFUSP)

Prof. Dr. Antonio Martins Figueiredo Neto (IFUSP)

Prof. Dr. Stephen Patrick Walborn (UFRJ) 


\section{FICHA CATALOGRÁFICA}

Preparada pelo Serviço de Biblioteca e Informação do Instituto de Física da Universidade de São Paulo

\section{Konieczniak, Igor}

Teletransporte de informação quântica entre campos de cores distintas - São Paulo, 2013.

Dissertação (Mestrado) - Universidade de São Paulo. Instituto de Física - Depto. de Física Experimental

Orientador: Prof Dr Paulo Alberto Nussenzveig

Área de Concentração: Física

Unitermos: 1. Informação quântica; 2. Física experimental; 3. Feixes ópticos. 


\section{Agradecimentos}

Agradeço a Paulo e ao Marcelo pela oportunidade de estudar e pesquisar em ambientes tão agradáveis, culturalmente ricos e intelectualmente estimulantes como são o LMCAL e a USP. Ao Marcelo, em especial, pela paciência, pela motivação e pelas inúmeras oportunidades de aprendizado. À todos os colegas de jornada do LMCAL, em especial à Paula, pelo companheirismo no trabalho em conjunto e pelo livre compartilhamento de pontos de vista, mesmo quando divergentes. À Rayssa e a Klara, pela amizade e disposição para ouvir nos poucos momentos de crise. Ao Antônio, Felipe e Renné, pelos ensinamentos, soluções salvadoras quando nada mais funcionava e pelos bons momentos de descontração. Neste sentido, bônus especial ao Antônio pela apelidagem generalizada.

Agradeço à Juliane, à Edi e à Maria Izabel, pela solicitude e simpatia no trato com a burocracia nossa de cada dia.

Agradeço ao Sr. Wilson, Sr. Alex e Sr. Zé Roberto, pela agilidade e esmero na fabricação das peças mecânicas.

Agradeço à Adilma, Dna. Graça e Edilsa, por ajudar a manter nossos ambientes habitáveis e pelo cuidado com os equipamentos.

Agradeço à todos os amigos, aos novos que encontrei São Paulo, aos de mais longa data, que já me acompanham a mais tempo. Em especial, agradeço ao Eduardo, ao Cláudio, ao Douglas e ao Daniel, pela amizade.

Agradeço à Tereza, pela disposição em ouvir.

Agradeço à Tamires, pela companhia e pelos bons momentos.

Agradeço à meus pais, Fred e Rosi, e minhas irmãs, Carla e Júlia por estarem sempre ao meu lado mesmo à quilômetros de distância.

Agradeço por fim, ao CNPQ pelo suporte financeiro através da bolsa de mestrado. 
Sempre instigantes, às vezes assustadores, dedico este trabalho aos desconhecidos: $a$ natureza, $o$ outro, $o$ eu. 


\section{Resumo}

KONIECZNIAK, I. Teletransporte de informação quântica entre campos de cores distintas. 2013. 67 f. Dissertação (Mestrado) - Instituto de Física, Universidade de São Paulo, São Paulo, 2013.

Em 1993, Bennett et al. [1] postularam o processo de teletransporte de um estado quântico através do uso de dois canais de comunicação, um canal clássico e outro formado por um par de sistemas emaranhados. Na área de óptica quântica, várias realizações experimentais deste teletransporte foram relatadas $[2,3,4]$, tanto no domínio de variáveis contínuas como discretas. Recentemente, foi medido emaranhamento no domínio de variáveis contínuas entre feixes de luz intensos de cores distintas [5, 6, 7]. Utilizando feixes com estas características como canal de comunicação quântico, apresentamos uma proposta para o primeiro teletransporte de informação quântica com troca de informação no domínio de variáveis contínuas entre campos de cores distintas. Resultados experimentais em direção à realização da proposta foram alcançados. Os moduladores eletro-ópticos, necessários na construção e reconstrução dos estados quânticos da luz, foram caracterizados. Quatro cavidades ópticas foram construídas, com requerido pelo protocolo para feixes de luz de cores distintas. Um oscilador paramétrico óptico (OPO) foi construído para a gerar os feixes correlacionados. No entanto, ele apresentou resultados insatisfatórios, atribuídos a um defeito no cristal não linear. Por isso, um OPO com novo cristal e novos espelhos foi projetado e se encontra em fase de construção. Por fim, um tratamento teórico adequado às particularidades da proposta experimental é apresentado.

Palavras-chave: Teletransporte Quântico, Emaranhamento, Oscilador Paramétrico Óptico. 


\section{Abstract}

KONIECZNIAK, I. Quantum information teleport with distinct color fields. 2013. 67 f. Dissertation (Master) - Instituto de Física, Universidade de São Paulo, São Paulo, 2013.

In 1993, Bennett et al. [1] postulated teleportation of quantum states by means of two communication channels, one classical and the other formed by a pair of entangled systems. In quantum optics, several experimental realizations of this teleportation process have been reported $[2,3,4]$, both in the continuous and discrete variables domains. Recently, entanglement in the continuous variables domain between brigth beams of light with different colors were measured $[5,6,7]$. Using beams with these characteristics as a quantum comunication channel, we present a proposal for the first quantum information teleportation with exchange of information in the continuous variables domain between different color fields. Experimental results towards the proposal's accomplishment have been achieved. The electro-optic modulators, needed in the preparation and reconstruction of quantum states of light, were characterized. Four optical cavities were built, as required by the protocol for multicolored light beams. An optical parametric oscillator (OPO) was built to generate the correlated beams. However, it showed unsatisfactory results, attributed to a defect in the nonlinear crystal. Therefore, an OPO with new crystal and new mirrors was designed and is under construction. Finally, a theoretical treatment appropriate to the particularities of the experimental proposal is presented.

Keywords: Quantum Teleportation, Entanglement, Optical Parametric Oscilator. 


\section{Sumário}

1 Introdução 1

2 Teletransporte de Informação Quântica 3

2.1 Os transportes, as telecomunicações e o teletransporte . . . . . . . . . 3

2.2 Teletransporte em variáveis discretas . . . . . . . . . . . . . . . 6

2.2.1 Medida de Bell em variáveis discretas $\ldots \ldots \ldots \ldots \ldots \ldots$

2.2 .2 O efeito do canal quântico . . . . . . . . . . . . . . 10

2.3 Teletransporte em variáveis contínuas . . . . . . . . . . . . . 11

2.3.1 Variáveis contínuas do campo eletromagnético . . . . . . . . . . . 11

2.3.2 Teletransporte de um único modo . . . . . . . . . . . . . . . . . . 12

2.3.3 Medida de Bell em variáveis contínuas . . . . . . . . . . . . . 13

2.3.4 O efeito do canal quântico . . . . . . . . . . . . . . . 14

2.4 Critérios para verificação do teletransporte . . . . . . . . . . . . . . 15

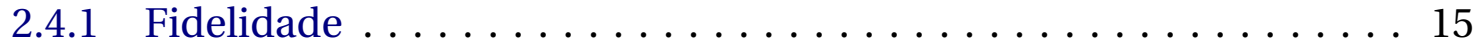

2.4 .2 O limite Clássico $\ldots \ldots \ldots \ldots \ldots \ldots \ldots \ldots \ldots$

2.4 .3 O limite de Não clonagem . . . . . . . . . . . . . . . . 17

3 Componentes do Teletransporte Multicor $\quad 19$

3.1 Cavidades Ópticas . . . . . . . . . . . . . . . . . . . . . . . . 19

3.1.1 Teoria do funcionamento das cavidades ópticas . . . . . . . . . 20

3.1 .2 O projeto das cavidades ópticas . . . . . . . . . . . . . 20

3.1.3 Construção e caracterização preliminar das cavidades ópticas . . . . 22

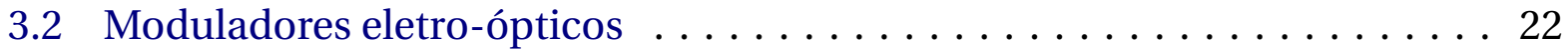

3.2.1 Teoria de funcionamento de um EOM . . . . . . . . . . . . . . . 23

3.2.2 Procedimento de caracterização dos EOMs . . . . . . . . . . . . . . 24

3.3 A fonte de estados EPR . . . . . . . . . . . . . . . . . . . . . 29

3.3.1 Teoria clássica do OPO Duplamente Ressonante . . . . . . . . . . . 31

3.3.2 Construção e caracterização do DROPO . . . . . . . . . . . . . . . . 34

3.3 .3 O projeto do novo $\mathrm{OPO} \ldots \ldots \ldots \ldots \ldots \ldots \ldots$

4 O Projeto de Teletransporte do LMCAL $\quad 43$

4.1 Teoria do teletransporte com bandas laterais . . . . . . . . . . . . . 43 
viii SUMÁRIO

4.1.1 Descrição do campo eletromagnético com bandas laterais . . . . . . 43

4.1 .2 Produção dos feixes EPR . . . . . . . . . . . . . . . . . . . . 47

4.1.3 Preparação do estado a ser teletransportado . . . . . . . . . . . . . 47

4.1.4 Medida de Bell com bandas laterais . . . . . . . . . . . . . . 48

4.1 .5 O efeito do canal quântico . . . . . . . . . . . . . . . . . . 49

5 Conclusão 


\section{Capítulo 1}

\section{Introdução}

"Teletransporte" é uma palavra bastante chamativa, que tão logo pronunciada lembra o ouvinte desavisado de ficção científica. Neste contexto, o termo diz respeito ao transporte desencarnado de matéria, um desafio que está longe de ser superado experimentalmente. O termo foi, no entanto, emprestado pela física, que o utilizou para nomear um processo de transposição de um estado quântico no espaço através de dois canais de comunicação, um clássico e outro quântico. Este canal de comunicação quântico é inerente ao processo e é genericamente formado por pares de sistemas emaranhados como, por exemplo, sistemas com correlações entre as posições e os momentos de duas partículas que interagiram previamente, como descrito por Einstein, Podolsky e Rosen (EPR) em 1935 [8]. Por causa destas características o processo foi chamado de teletransporte de informação quântica, não envolvendo, portanto, o transporte de matéria. O teletransporte de informação quântica foi teoricamente proposto em 1993 por Bennett et al. [1] e já foi realizado experimentalmente em vários laboratórios [2, 3, 4].

Desde a proposição do fenômeno do emaranhamento em 1935 por EPR [8], como uma crítica à mecânica quântica, o emaranhamento têm sido demonstrado experimentalmente em vários sistemas físicos. Cito alguns exemplos, começando em 1982, com o experimento de Aspect et al. [9], que emaranhou estados de polarização de pares de fótons, passando por Rowe et al. [10], que em 2001 mediu as correlações quânticas em íons de Berílio e ainda o experimento de Hasegawa et al. [11], que em 2003 mediu correlações quânticas entre dois graus de liberdade de nêutrons únicos. Um experimento que ainda vale ressaltar é o realizado por Ou et al. em 1992 [12]. Neste experimento, foi demonstrado pela primeira vez o uso de um Oscilador Paramétrico Óptico - OPO para produzir estados emaranhados de vácuo. Nosso laboratório têm estudado o oscilador paramétrico óptico operando acima do limiar de oscilação, demonstrando que existe emaranhamento bi e tripartite entre os feixes de diferentes cores do OPO [5, 6, 7].

Com o domínio da técnica de produção do recurso do emaranhamento $[13,3,5]$, passamos a desenvolver um projeto de teletransporte de informação quântica em campos de cores distintas, com o uso dos feixes emaranhados produzidos entre as bandas laterais de feixes de luz intensos de um OPO, tomando como base o experimento realizado por Furusawa et al. [3] e apresentado teoricamente por [14].

Apresentaremos a proposta do teletransporte nos próximos capítulos, começando, no capítulo 2, com uma introdução do teletransporte de informação quântica, primeiro de forma conceitual e depois utilizando o formalismo da mecânica e da óptica quânticas.

Após esta introdução teórica, o capítulo 3 mostra o trabalho realizado na construção e/ou caracterização de três componentes fundamentais para o projeto: cavidades 
ópticas, moduladores eletro-ópticos e o oscilador paramétrico óptico.

Por fim, o capítulo 4 apresenta uma descrição final de nossa proposta de teletransporte numa abordagem teórica mas integrando particularidades experimentais do projeto. 


\section{Capítulo 2}

\section{Teletransporte de Informação Quântica}

Para esclarecer o conceito de teletransporte, iniciaremos com uma abordagem conceitual na seção 2.1. Através de uma análise dos vários tipos de transporte imagináveis, dos mais simples aos mais elaborados, diferenciaremos o teletransporte de informação quântica de outros tipos de transporte e comunicação. Na seção 2.2, apresentaremos o teletransporte de informação quântica utilizando o formalismo da mecânica quântica e seguindo de perto o artigo pioneiro de Bennett et al. [1]. Os autores utilizaram uma base de estados com auto-valores discretos para esta descrição teórica. Detalhes sobre a medida de Bell, um dos processos fundamentais no teletransporte quântico, que não se encontram no artigo de 1993, são esclarecidos. No entanto, o primeiro experimento de teletransporte incondicional utilizou estados com auto-valores contínuos da luz [3]. Este também é o caso de nosso experimento e, por isso, na seção 2.3, descrevemos o teletransporte de informação quântica em variáveis contínuas, ainda sem levar em conta particularidades experimentais. Por fim, com a teoria do teletransporte bem desenvolvida, abordamos a necessidade de conferir o sucesso do teletransporte, através da definição do conceito de fidelidade na seção 2.4.

\subsection{Os transportes, as telecomunicações e o teletransporte}

Suponha que tenhamos o objetivo de fazer surgir num lugar do espaço um objeto que está inicialmente em outro. O processo mais simples que atinge a este objetivo é, obviamente, o transporte, pois envolve o simples deslocamento do objeto. Nesse processo o objeto sai de uma origem e é transportado a seu destino. Somente a operação de deslocamento espacial é necessária. Um primeiro passo de sofisticação seria o de copiar o objeto original, como num fax. Com isso, a cópia seria deslocada até o destino, e o original ficaria na origem. Para copiar um objeto, precisamos ler suas características essenciais, aquelas características que o definem, ou, ao menos, as características cuja existência seja útil no destino. É preciso medir estas informações no objeto e, então, imprimi-las em um novo material, de preferência indistinguível do material que constitui o original. A codificação da informação do objeto pode então nos levar ao próximo passo conceitual.

No processo de cópia, a informação fica codificada, separada do objeto original, para depois ser impressa no novo material, formando a cópia. Surge então a alternativa de, ao invés de transportar a cópia do original, transportar apenas as informações que definem o objeto. Com isso, apenas no destino é que essa informação será agregada à matéria-prima, formando uma cópia do objeto original. Vários processos de telecomu- 
nicação atuais podem ser sintetizados dessa forma. A transmissão de um documento por fax é um dos exemplos mais ilustrativos. As informações do documento original são lidas pelo aparelho e codificadas em sinais elétricos. Os sinais elétricos contendo a informação desejada são transmitidos via linhas telefônicas até o aparelho no destino. Ali, esta informação é impressa sobre novo papel, usando nova tinta, formando uma cópia no destino do documento que permanece na origem.

No entanto, os processos de telecomunicação não podem ser chamados de teletransporte. Ainda que envolvam também um transporte de informações, existem diferenças entre os conceitos. A primeira diferença é que a telecomunicação é um processo de cópia, enquanto que o teletransporte, não. Isso é muito interessante do ponto de vista da criptografia e segurança da informação, pois o processo de teletransporte assegura a existência de uma única versão autêntica.

Se pensarmos no transporte de objetos macroscópicos, surgem diferenças importantes com relação à viabilidade de cada processo, devido à quantidade de informação envolvida. Quando um objeto é simples, e suas características essenciais são poucas, a dificuldade é pequena. Uma bola de plástico vermelha é facilmente copiada e representa pouca informação, pois, essencialmente, é apenas uma bola vermelha de plástico. Já objetos mais complexos, especialmente aqueles cujas características microscópicas são essenciais para a caracterização, podem representar uma enorme quantidade de informação. Se o detalhamento envolver a composição em átomos e moléculas, o montante de informação atinge algo da ordem de $10^{32}$ bits de informação, que levariam mais de um bilhão de séculos para serem transmitidos pelas melhores fibras ópticas disponíveis hoje em dia [15]. Com isso, o teletransporte de objetos complexos está muito distante de se tornar realidade. Ainda assim, mesmo para objetos simples existem outros desafios a serem superados. Na ficção científica, é possível entender que a própria matéria é desintegrada em energia, transportada e depois reconvertida em matéria no destino. Como isso envolveria a desintegração dos próprios núcleos dos átomos, estamos falando em reações de fissão nuclear, e, portanto, em dois grandes extremos: a gigantesca quantidade de energia envolvida e nossa enorme incapacidade de manipular a matéria nesse nível. Se algum dia o teletransporte de objetos macroscópicos ocorrer, não envolverá em primeiro lugar o teletransporte da matéria em si, mas apenas das informações que são essenciais na descrição do objeto teletransportado. Também não é fácil de imaginar que o teletransporte ocorra sem que não exista alguma espécie de máquina no destino.

E há ainda uma última diferença entre as telecomunicações e o teletransporte da ficção científica, que vem do fato da matéria possuir uma natureza intrinsecamente quântica. Se as características essenciais do objeto a ser teletransportado compreenderem algum tipo de estado quântico, teremos problemas em utilizar os processos de telecomunicação. Isso porque há um limite sobre as informações que se pode obter de um estado quântico. Este limite é definido pelo princípio de incerteza de Heisenberg. No exemplo em que as informações em questão são a posição e o momento de uma partícula, o princípio se expressa através da incerteza mínima na medida destas duas grandezas,

$$
\triangle x \triangle p \geqslant \hbar / 2
$$

Esta relação impõe limites fundamentais na precisão da informação que se pode obter sobre duas grandezas conjugadas entre si. O mesmo problema também pode ser posto de outra forma, através do teorema da não clonagem, que afirma que a cópia de estados quânticos é impossível segundo a teoria quântica [16]. Como dito anteriormente, os processos de telecomunicação atuais envolvem a cópia da informação do 
objeto, algo impossível para estados quânticos.

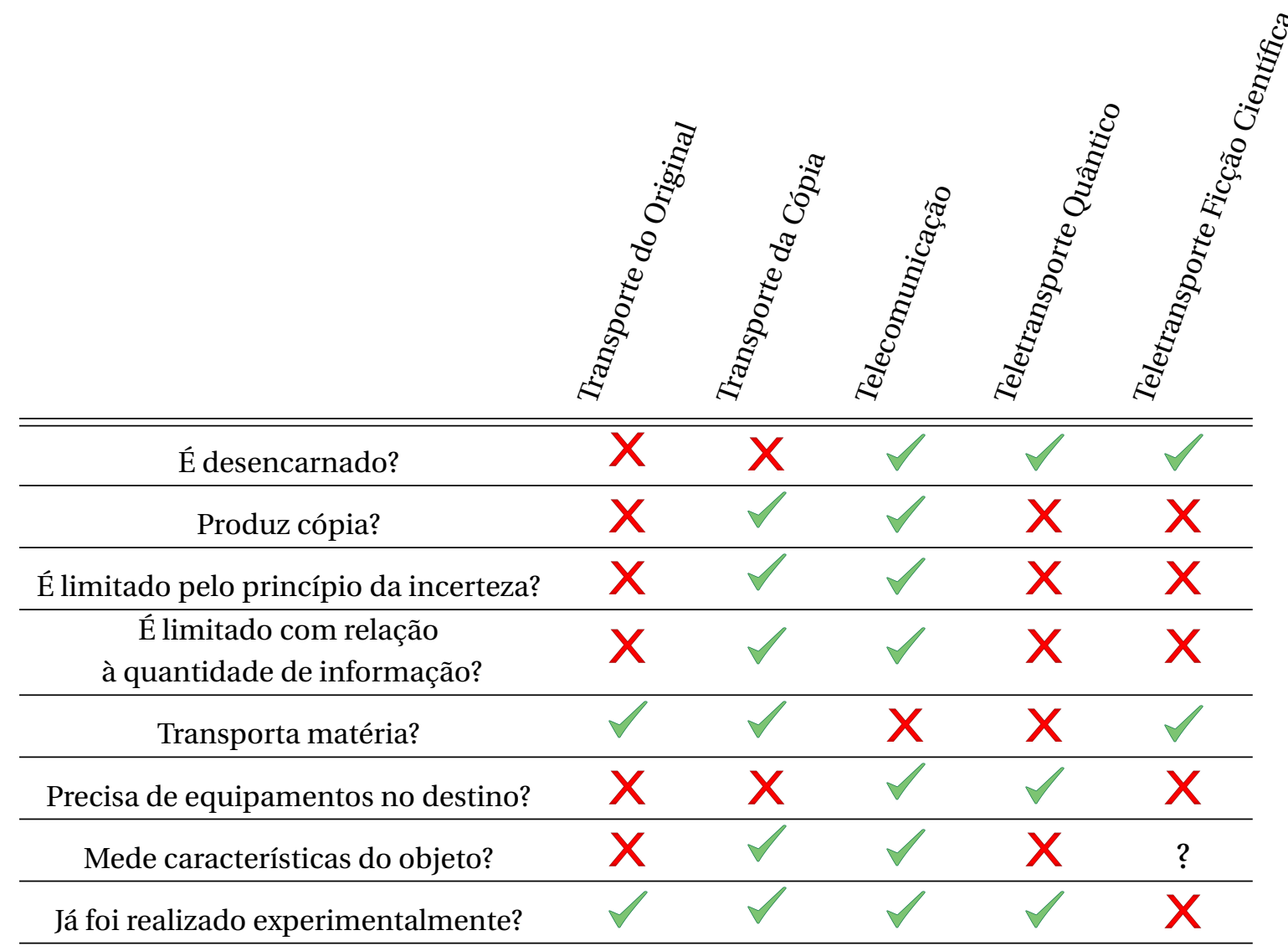

Tabela 2.1: Resumo das características que diferem os transportes, as telecomunicações e o teletransporte da ficção científica, do teletransporte de informação quântica.

O teletransporte de informação quântica é um processo que busca superar estas barreiras, pois em essência não realiza medidas das características do objeto e não procura copiar o objeto original. O estado é simplesmente destruído durante o processo na origem e é reconstruído no destino, sendo que as suas características essenciais ficam desconhecidas durante todo o processo. A destruição do estado quântico na origem é parte inevitável do processo de teletransporte. Mas então fica a questão de como transmitir informação sem que se possa conhecê-la. A resposta, encontrada por C. H. Bennett, G. Brassard, C. Crépeau, R. Jozsa, A. Peres e W. K. Wootters em 1993 [1] , faz uso de um recurso chamado emaranhamento quântico. O emaranhamento entre dois sistemas é utilizado como canal de comunicação quântico entre a origem e o destino. Um dos sistemas é enviado para o destino e o outro para a origem. O teletransporte envolve uma medida conjunta entre um dos sistemas do estado emaranhado e o estado a ser teletransportado. Nessa medida conjunta, os dois objetos são combinados e medida de duas grandezas conjugadas da combinação ${ }^{1}$ é realizada. Esta informação medida é passada para o destino, de forma clássica (cabos elétricos, ondas de rádio, etc.). Sozinha, não revela nada sobre o estado original que continua desconhecido após a medida. No destino, a informação clássica é utilizada para operar sobre o estado do outro sistema emaranhado. As operações com base nas informações clássicas eliminam as diferenças que haviam entre o estado inicial e o estado do sistema emaranhado que foi enviado ao

\footnotetext{
${ }^{1}$ Considera-se que uma combinação é um processo reversível. Após a medida, no entanto, as informações dos dois sistemas deixam de formar uma combinação e passando a ser uma mistura, irreversível.
} 


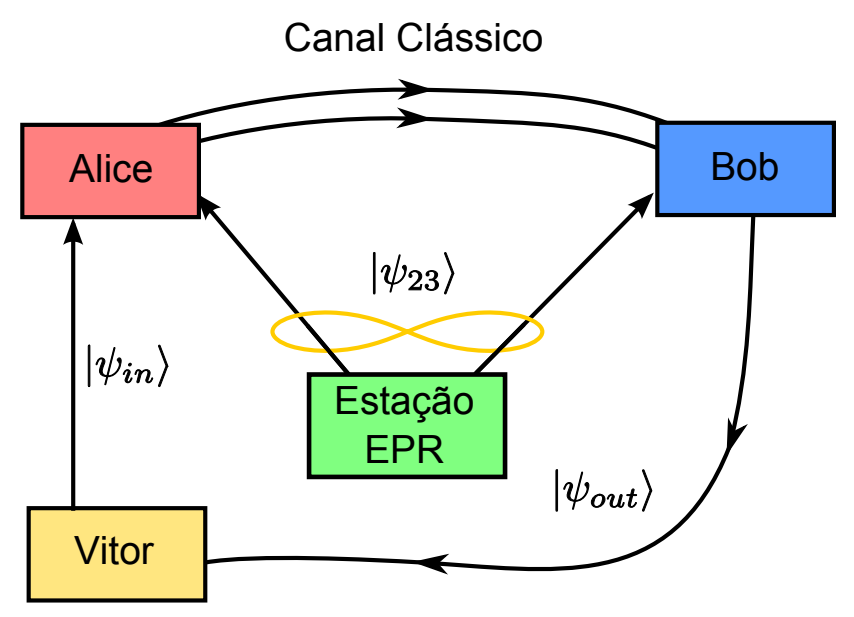

Figura 2.1: Esquema geral do teletransporte de informação quântica.

destino. Com isso, o estado quântico original é reconstruído em outro lugar sobre um novo material, idealmente, sem alterações.

Na tabela 2.1 encontra-se um quadro que sintetiza várias características dos processos de transporte, comunicação e teletransporte, ressaltando as similaridades e diferenças entre eles.

Vamos agora estudar formalmente o processo de teletransporte quântico com o uso do formalismo da mecânica quântica.

\subsection{Teletransporte em variáveis discretas}

Primeiramente, vamos apresentar na figura 2.1 um esquema geral do teletransporte quântico, e explicar a nomenclatura usualmente utilizada.

Vitor é o nome que daremos à estação que construirá o estado a ser teleportado. Somente ele conhece este estado, por saber as condições utilizadas em sua preparação. Por isso, é também Vitor o encarregado de verificar se o processo foi bem sucedido, comparando o estado de saída com o estado de entrada.

Estação EPR No caso do teletransporte quântico, é a estação responsável por gerar os sistemas emaranhados, e enviar uma para a origem e a outra para o destino.

Alice é o nome usual da estação emissora, localizada, portanto, na origem. Alice fará a medida conjunta de seu sistema EPR com o estado de entrada e enviará o resultado para o destino de forma clássica.

Bob é o nome da estação receptora. Bob recebe a outra partícula EPR e aplica, ou imprime, sobre ela as informações clássicas enviadas por Alice, obtendo neste processo o estado de saída, idealmente idêntico ao estado de entrada. Bob entrega então o estado para Vitor, que fará a conferência do grau de identidade entre os dois estados. 
Como existem diferentes tipos de estados quânticos, existem diferentes formas de realizar o teletransporte quântico. Uma primeira diferenciação é com relação à continuidade das variáveis que descrevem os estados. Neste sentido, os estados podem ser classificados como discretos ou contínuos. Como a computação atual é baseada em sistemas discretos binários, estes são largamente estudados na área de informação quântica. Apresentaremos nesta seção a teoria de teletransporte quântico em variáveis discretas, da forma como o teletransporte foi primeiramente proposto por Bennett et al. [1].

Vitor prepara uma partícula (1) num estado quântico específico a ser teletransportado. Matematicamente, o estado é descrito como:

$$
\left|\psi_{\text {in }}\right\rangle=a\left|0_{1}\right\rangle+b\left|1_{1}\right\rangle
$$

O estado acima é chamado de qubit. Em comparação ao bit clássico, que deve ter, ou um valor igual a 1 , ou um valor igual a 0 , o qubit pode estar em uma superposição destes dois estados. Ou seja, na equação acima, os coeficientes $a$ e $b$ pode assumir valores diferentes de 0 e 1 . No entanto, devido a natureza quântica, os estados em questão só podem fornecer duas opções de resposta quando sofrem uma medida, “0” ou " 1 ”. Os coeficientes a e b estão associados às probabilidades de se encontrar os valores 0 e 1 , respectivamente:

$$
\begin{aligned}
& P(0)=|a|^{2} \\
& P(1)=|b|^{2}
\end{aligned}
$$

Apenas Vitor conhece o estado, pois é ele que conhece os coeficientes $a$ e $b$. Este estado é enviado para Alice. Na estação EPR, duas partículas (2 e 3) são emitidas num estado emaranhado,

$$
\left|\psi_{23}\right\rangle=\sqrt{1 / 2}\left(\left|0_{2}\right\rangle\left|0_{3}\right\rangle+\left|1_{2}\right\rangle\left|1_{3}\right\rangle\right)
$$

A partícula 2 é enviada para Alice e a partícula 3 para Bob. Alice precisa fazer uma medida sobre as duas partículas que recebe. Para que possamos entender como isso acontece, observe-se o sistema global como está.

$$
\begin{gathered}
\left|\Upsilon_{123}\right\rangle=\left|\psi_{i n}\right\rangle\left|\psi_{23}\right\rangle \\
\left|\Upsilon_{123}\right\rangle=\left(a\left|0_{1}\right\rangle+b\left|1_{1}\right\rangle\right)\left(\left|0_{2}\right\rangle\left|0_{3}\right\rangle+\left|1_{2}\right\rangle\left|1_{3}\right\rangle\right) / \sqrt{2} \\
\left|\Upsilon_{123}\right\rangle=\frac{a}{\sqrt{2}}\left(\left|0_{1}\right\rangle\left|0_{2}\right\rangle\left|0_{3}\right\rangle+\left|0_{1}\right\rangle\left|1_{2}\right\rangle\left|1_{3}\right\rangle\right)+ \\
+\frac{b}{\sqrt{2}}\left(\left|1_{1}\right\rangle\left|0_{2}\right\rangle\left|0_{3}\right\rangle+\left|1_{1}\right\rangle\left|1_{2}\right\rangle\left|1_{3}\right\rangle\right)
\end{gathered}
$$

Como as partículas 1 e 2 são enviadas para Alice e a partícula 3 para Bob, é conveniente isolar os estados das partículas 1 e 2 da partícula 3, no estado global. Manipulando a equação 2.3, obtém-se: 


$$
\begin{aligned}
& \left|\Upsilon_{123}\right\rangle=\frac{1}{2 \sqrt{2}} \quad\left[\left(\left|0_{1}\right\rangle\left|0_{2}\right\rangle+\left|1_{1}\right\rangle\left|1_{2}\right\rangle\right)\left(a\left|0_{3}\right\rangle+b\left|1_{3}\right\rangle\right)+\right. \\
& +\quad\left(\left|0_{1}\right\rangle\left|0_{2}\right\rangle-\left|1_{1}\right\rangle\left|1_{2}\right\rangle\right)\left(a\left|0_{3}\right\rangle-b\left|1_{3}\right\rangle\right)+ \\
& +\quad\left(\left|0_{1}\right\rangle\left|1_{2}\right\rangle+\left|1_{1}\right\rangle\left|0_{2}\right\rangle\right)\left(b\left|0_{3}\right\rangle+a\left|1_{3}\right\rangle\right)+ \\
& \left.+\quad\left(\left|0_{1}\right\rangle\left|1_{2}\right\rangle-\left|1_{1}\right\rangle\left|0_{2}\right\rangle\right)\left(-b\left|0_{3}\right\rangle+a\left|1_{3}\right\rangle\right)\right]
\end{aligned}
$$

Cada um dos quatro estados em vermelho, referente às diferentes possibilidades que Alice pode receber e medir, é chamado de um estado de Bell. Os estados de Bell são estados maximamente emaranhados que formam uma base com quatro estados ortogonais entre si. Se representarmos os estados de Bell da forma:

$$
\begin{aligned}
& \left|\Phi_{12}^{+}\right\rangle=\left(\left|0_{1}\right\rangle\left|0_{2}\right\rangle+\left|1_{1}\right\rangle\left|1_{2}\right\rangle\right) / \sqrt{2} \\
& \left|\Phi_{12}^{-}\right\rangle=\left(\left|0_{1}\right\rangle\left|0_{2}\right\rangle-\left|1_{1}\right\rangle\left|1_{2}\right\rangle\right) / \sqrt{2} \\
& \left|\Psi_{12}^{+}\right\rangle=\left(\left|0_{1}\right\rangle\left|1_{2}\right\rangle+\left|1_{1}\right\rangle\left|0_{2}\right\rangle\right) / \sqrt{2} \\
& \left|\Psi_{12}^{-}\right\rangle=\left(\left|0_{1}\right\rangle\left|1_{2}\right\rangle-\left|1_{1}\right\rangle\left|0_{2}\right\rangle\right) / \sqrt{2}
\end{aligned}
$$

Então o estado global $\left|\Upsilon_{123}\right\rangle$ fica da forma:

$$
\begin{aligned}
\left|\Upsilon_{123}\right\rangle= & \frac{1}{2} \quad\left[\left|\Phi_{12}^{+}\right\rangle\left(a\left|0_{3}\right\rangle+b\left|1_{3}\right\rangle\right)+\right. \\
& +\left|\Phi_{12}^{-}\right\rangle\left(a\left|0_{3}\right\rangle-b\left|1_{3}\right\rangle\right)+ \\
& +\left|\Psi_{12}^{+}\right\rangle\left(a\left|1_{3}\right\rangle+b\left|0_{3}\right\rangle\right)+ \\
& \left.+\left|\Psi_{12}^{-}\right\rangle\left(a\left|1_{3}\right\rangle-b\left|0_{3}\right\rangle\right)\right]
\end{aligned}
$$

Atentando-se para a equação 2.4, nota-se primeiramente que nada foi feito por Alice até aqui. O resultado acima é apenas um rearranjo do estado global. Alice, ao receber as partículas 1 e 2, precisa realizar uma medida de Bell.

\subsubsection{Medida de Bell em variáveis discretas}

Dadas as duas partículas, uma vinda do par EPR e a outra a ser teletransportada, Alice precisa discernir qual estado de Bell os estados conjuntos delas formam. Ou seja, para cada estado de Bell, possível de ser obtido, Alice precisa medir um valor diferente. Podemos associar um número de 0 a 3 para cada estado de Bell. Se representarmos estes números em notação binária, deveremos obter sempre uma das seguintes respostas, $\{00,01,10,11\}$. Em termos lógicos, Alice precisa realizar duas operações sobre as duas partículas, uma operação CNOT e uma operação Hadamard $[17,18]$.

A porta lógica CNOT, ou Controlled-Not, atua sobre dois qubits. Um deles é o controle, ou seja, só haverá operação pela porta se este qubit for 1 . O outro é o qubit que sofrerá a ação de inversão. Se este qubit entrar 1, e o controle for 1, ele sairá da porta 0 . Se este qubit entrar como 0 , e o controle for 1 , ele sairá 1 . 


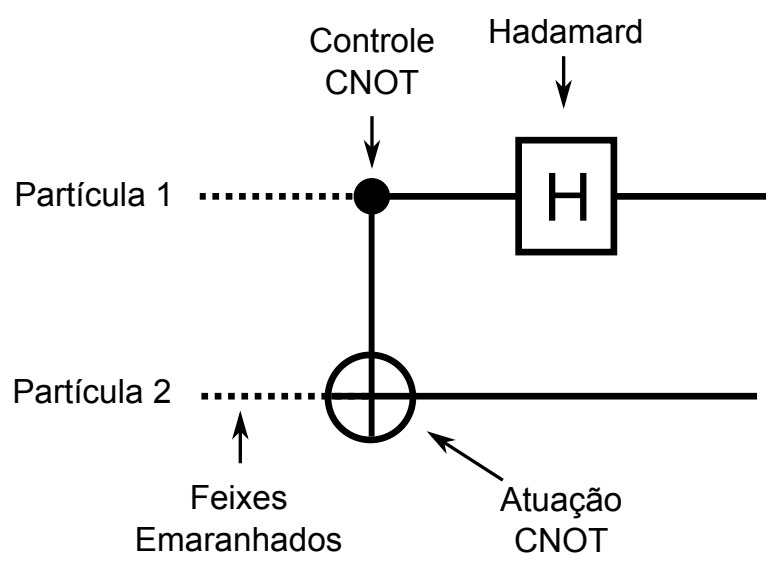

Figura 2.2: Esquema lógico de uma medida de Bell em variáveis discretas.

De forma matricial, se consideramos a base:

$$
\left|0_{1}\right\rangle\left|0_{2}\right\rangle=\left(\begin{array}{l}
1 \\
0 \\
0 \\
0
\end{array}\right),\left|0_{1}\right\rangle\left|1_{2}\right\rangle=\left(\begin{array}{l}
0 \\
1 \\
0 \\
0
\end{array}\right),\left|1_{1}\right\rangle\left|0_{2}\right\rangle=\left(\begin{array}{l}
0 \\
0 \\
1 \\
0
\end{array}\right),\left|1_{1}\right\rangle\left|1_{2}\right\rangle=\left(\begin{array}{l}
0 \\
0 \\
0 \\
1
\end{array}\right)
$$

a matriz que representa a porta CNOT é, considerando o primeiro qubit como controle:

$$
C N O T=\left(\begin{array}{llll}
1 & 0 & 0 & 0 \\
0 & 1 & 0 & 0 \\
0 & 0 & 0 & 1 \\
0 & 0 & 1 & 0
\end{array}\right)
$$

Assim, podemos resumir a ação da porta CNOT sobre os quatro estados de Bell na tabela :

\begin{tabular}{|c|c|}
\hline \multicolumn{2}{|c|}{ Porta CNOT } \\
\hline Entrada - Estados de Bell & Saída após CNOT \\
\hline \hline$\left|\Phi_{12}^{+}\right\rangle=\left(\left|0_{1}\right\rangle\left|0_{2}\right\rangle+\left|1_{1}\right\rangle\left|1_{2}\right\rangle\right) / \sqrt{2}$ & $\left(\left|0_{1}\right\rangle\left|0_{2}\right\rangle+\left|1_{1}\right\rangle\left|0_{2}\right\rangle\right) / \sqrt{2}=\left(\left|0_{1}\right\rangle+\left|1_{1}\right\rangle\right) \otimes\left|0_{2}\right\rangle / \sqrt{2}$ \\
\hline$\left.\Phi_{12}^{-}\right\rangle=\left(\left|0_{1}\right\rangle\left|0_{2}\right\rangle-\left|1_{1}\right\rangle\left|1_{2}\right\rangle\right) / \sqrt{2}$ & $\left(\left|0_{1}\right\rangle\left|0_{2}\right\rangle-\left|1_{1}\right\rangle\left|0_{2}\right\rangle\right) / \sqrt{2}=\left(\left|0_{1}\right\rangle-\left|1_{1}\right\rangle\right) \otimes\left|0_{2}\right\rangle / \sqrt{2}$ \\
\hline$\left.\Psi_{12}^{+}\right\rangle=\left(\left|0_{1}\right\rangle\left|1_{2}\right\rangle+\left|1_{1}\right\rangle\left|0_{2}\right\rangle\right) / \sqrt{2}$ & $\left(\left|0_{1}\right\rangle\left|1_{2}\right\rangle+\left|1_{1}\right\rangle\left|1_{2}\right\rangle\right) / \sqrt{2}=\left(\left|0_{1}\right\rangle+\left|1_{1}\right\rangle\right) \otimes\left|1_{2}\right\rangle / \sqrt{2}$ \\
\hline$\left.\Psi_{12}^{-}\right\rangle=\left(\left|0_{1}\right\rangle\left|1_{2}\right\rangle-\left|1_{1}\right\rangle\left|0_{2}\right\rangle\right) / \sqrt{2}$ & $\left(\left|0_{1}\right\rangle\left|1_{2}\right\rangle-\left|1_{1}\right\rangle\left|1_{2}\right\rangle\right) / \sqrt{2}=\left(\left|0_{1}\right\rangle-\left|1_{1}\right\rangle\right) \otimes\left|1_{2}\right\rangle / \sqrt{2}$ \\
\hline
\end{tabular}

É importante notar que a porta CNOT elimina o emaranhamento, permitindo que os estados das duas partículas ( 1 e 2) sejam escritos como um produto tensorial entre um estado superposto (partícula 1) e um estado simples (partícula 2). A segunda porta é a chamada Hadamard e é aplicada na partícula 1, que foi o controle para o CNOT. Esta porta atua gerando estados superpostos a partir de estados simples.

$$
H: \begin{aligned}
& |0\rangle \rightarrow(|0\rangle+|1\rangle) / \sqrt{2} \\
& |1\rangle \rightarrow \quad(|0\rangle-|1\rangle) / \sqrt{2}
\end{aligned}
$$

A transformação de Hadamard pode ser representada de forma matricial, conside- 
rando a base, $|0\rangle=\left(\begin{array}{l}1 \\ 0\end{array}\right), \mathrm{e}|1\rangle=\left(\begin{array}{l}0 \\ 1\end{array}\right)$ :

$$
H=1 / \sqrt{2}\left(\begin{array}{cc}
1 & 1 \\
1 & -1
\end{array}\right)
$$

Aplicando a porta Hadamard nos estados de saída da porta CNOT, temos:

\begin{tabular}{|c|c|}
\hline \multicolumn{2}{|c|}{ Porta Hadamard sobre o estado 1 } \\
\hline Entrada & Saída \\
\hline \hline$\left(\left|0_{1}\right\rangle+\left|1_{1}\right\rangle\right) / \sqrt{2}$ & $\left(\left(\left|0_{1}\right\rangle+\left|1_{1}\right\rangle\right)+\left(\left|0_{1}\right\rangle-\left|1_{1}\right\rangle\right)\right) / 2=\left|0_{1}\right\rangle$ \\
\hline$\left(\left|0_{1}\right\rangle-\left|1_{1}\right\rangle\right) / \sqrt{2}$ & $\left(\left(\left|0_{1}\right\rangle+\left|1_{1}\right\rangle\right)-\left(\left|0_{1}\right\rangle-\left|1_{1}\right\rangle\right)\right) / 2=\left|1_{1}\right\rangle$ \\
\hline
\end{tabular}

A porta Hadamard permite então que os estados que eram superpostos passem a ser estados simples. Assim, o resultado final é:

\begin{tabular}{|c|c|c|c|c|}
\hline \multirow{2}{*}{ Entrada } & \multicolumn{4}{|c|}{ Saída } \\
\cline { 2 - 5 } & Estado 1 & Estado 2 & Binário & Decimal \\
\hline \hline$\left|\Phi_{12}^{+}\right\rangle=\left(\left|0_{1}\right\rangle\left|0_{2}\right\rangle+\left|1_{1}\right\rangle\left|1_{2}\right\rangle\right) / \sqrt{2}$ & $\left|0_{1}\right\rangle$ & $\left|0_{2}\right\rangle$ & 00 & 0 \\
\hline$\left.\Phi_{12}^{-}\right\rangle=\left(\left|0_{1}\right\rangle\left|0_{2}\right\rangle-\left|1_{1}\right\rangle\left|1_{2}\right\rangle\right) / \sqrt{2}$ & $\left|1_{1}\right\rangle$ & $\left|0_{2}\right\rangle$ & 10 & 2 \\
\hline$\left.\Psi_{12}^{+}\right\rangle=\left(\left|0_{1}\right\rangle\left|1_{2}\right\rangle+\left|1_{1}\right\rangle\left|0_{2}\right\rangle\right) / \sqrt{2}$ & $\left|0_{1}\right\rangle$ & $\left|1_{2}\right\rangle$ & 01 & 1 \\
\hline$\left.\Psi_{12}^{-}\right\rangle=\left(\left|0_{1}\right\rangle\left|1_{2}\right\rangle-\left|1_{1}\right\rangle\left|0_{2}\right\rangle\right) / \sqrt{2}$ & $\left|1_{1}\right\rangle$ & $\left|1_{2}\right\rangle$ & 11 & 3 \\
\hline
\end{tabular}

Dessa forma, fica demostrado que se for possível construir um sistema físico que realize as operações equivalentes às portas lógicas CNOT e Hadamard, é possível para Alice discernir entre os quatro estados de Bell que ela pode receber.

\subsubsection{O efeito do canal quântico}

Alice, ao fazer uma medida de Bell, possui $25 \%$ de chance de obter cada um dos 4 estados de Bell, independente do estado de entrada. Assim, quando Alice faz esta medida, ela não obtém nenhuma informação sobre qual é o estado inicial. Outro aspecto fundamental é que, quando Alice faz uma medida e obtém um dos quatro estados de Bell, o estado da partícula 3 que Bob recebeu fica determinado. O canal de comunicação quântico cumpre assim o seu papel. Para que Bob possa saber qual operação realizar sobre o estado que recebeu, Alice precisa informar a ele de seu resultado. Assim, 2 bits de informação são repassados classicamente para Bob, informando qual estado de Bell Alice mediu. Com esta informação, Bob sabe qual operação deve realizar para reconstruir o estado de entrada, de acordo com a tabela abaixo:

\begin{tabular}{|c|c|c|c|}
\hline $\begin{array}{c}\text { Estado de Bell } \\
\text { medido por Alice }\end{array}$ & $\begin{array}{c}\text { Estado } \\
\text { da partícula 3 }\end{array}$ & $\begin{array}{c}\text { Operação } \\
\text { Necessária }\end{array}$ & $\begin{array}{c}\text { Resultado } \\
\left|\psi_{\text {out }}\right\rangle=\end{array}$ \\
\hline \hline$\left|\Phi_{12}^{+}\right\rangle$ & $\left(a\left|0_{3}\right\rangle+b\left|1_{3}\right\rangle\right)$ & $\hat{I}=\left(\begin{array}{cc}1 & 0 \\
0 & 1\end{array}\right)$ & $\left(a\left|0_{3}\right\rangle+b\left|1_{3}\right\rangle\right)$ \\
\hline$\left|\Phi_{12}^{-}\right\rangle$ & $\left(a\left|0_{3}\right\rangle-b\left|1_{3}\right\rangle\right)$ & $\hat{\sigma}_{z}=\left(\begin{array}{cc}1 & 0 \\
0 & -1\end{array}\right)$ & $\left(a\left|0_{3}\right\rangle+b\left|1_{3}\right\rangle\right)$ \\
\hline$\left|\Psi_{12}^{+}\right\rangle$ & $\left(b\left|0_{3}\right\rangle+a\left|1_{3}\right\rangle\right)$ & $\hat{\sigma}_{x}=\left(\begin{array}{cc}0 & 1 \\
1 & 0\end{array}\right)$ & $\left(a\left|0_{3}\right\rangle+b\left|1_{3}\right\rangle\right)$ \\
\hline$\left|\Psi_{12}^{-}\right\rangle$ & $\left(-b\left|0_{3}\right\rangle+a\left|1_{3}\right\rangle\right)$ & $\hat{\sigma}_{z} \hat{\sigma_{x}}=\left(\begin{array}{cc}0 & 1 \\
-1 & 0\end{array}\right)$ & $\left(a\left|0_{3}\right\rangle+b\left|1_{3}\right\rangle\right)$ \\
\hline
\end{tabular}


Assim, não importa qual o estado que Alice recebe de Vitor, Bob é capaz de reconstruir esse estado através das informações recebidas dos dois canais, um clássico, um quântico. É importante notar que os coeficientes $a$ e $b$, que definem o estado de entrada, permanecem desconhecidos para Alice e para Bob durante todo o processo. Por fim, Bob pode entregar o estado de saída e repassá-lo a Vitor, para que ele faça a conferência se os estados de entrada e saída são idênticos ou não e verificar o sucesso do teletransporte.

A primeira tentativa experimental de realizar o teletransporte utilizando emaranhamento em variáveis discretas foi realizada por Bouwmeester et al. em 1997 [2]. No caso, a variável discreta era o estado de polarização de fótons. Este experimento possuía uma limitação pois conseguia medir apenas um dos estados de Bell. Somente quando este estado de Bell era medido é que o teletransporte era considerado. Nas outras situações, nada se podia dizer sobre o estado final, e estes resultados eram descartados. Foi provado por Lutkenhaus et al. em 1999 que uma medida de Bell completa não é possível utilizando apenas óptica linear [19]. Assim, em 2001, Kim et al. [4] reportou um experimento onde os quatro estados de Bell eram possíveis de serem medidos com o uso de óptica não-linear. Por causa disso, o processo sofre de baixa eficiência.

\subsection{Teletransporte em variáveis contínuas}

Para a descrição do teletransporte em variáveis contínuas, uma das possibilidades é o uso da distribuição de Wigner e seu formalismo de convolução, conforme apresentado em [20]. Uma outra alternativa é a apresentação do teletransporte em termos de equações de Heisenberg para os operadores de quadratura de amplitude, como descrito em Van Loock et al. [14]. Neste formalismo, o teletransporte é expresso em variáveis contínuas de um único modo do campo eletromagnético. Esta segunda alternativa é mais adequada como um passo conceitual anterior à descrição do teletransporte com emaranhamento entre bandas laterais, que usará uma descrição semelhante. Na figura 2.3 mostramos o esquema experimental do teletransporte incondicional de informação quântica, de Furusawa et al. em 1998[3], que foi realizado dentro do domínio de variáveis contínuas. Passamos então a descrever o teletransporte em variáveis contínuas de um único modo do campo eletromagnético, utilizando o formalismo de Heisenberg.

\subsubsection{Variáveis contínuas do campo eletromagnético}

Inicialmente é necessário definir quais são as variáveis contínuas que trabalharemos. Elas são grandezas relacionadas ao campo eletromagnético, capazes de descrever suas características quânticas. Através da quantização do campo eletromagnético, podemos expressar o campo elétrico em função dos operadores de criação e aniquilação [18]:

$$
\hat{E}_{x}=\mathscr{E}_{0}\left(\hat{a} e^{-i \omega t}+\hat{a}^{\dagger} e^{i \omega t}\right) \operatorname{sen}(k z)
$$

Se definirmos os operadores de quadratura como:

$$
\begin{aligned}
& \hat{x}=\frac{1}{2}\left(\hat{a}+\hat{a}^{\dagger}\right) \\
& \hat{p}=\frac{1}{2 i}\left(\hat{a}-\hat{a}^{\dagger}\right)
\end{aligned}
$$

O campo elétrico será dado por: 


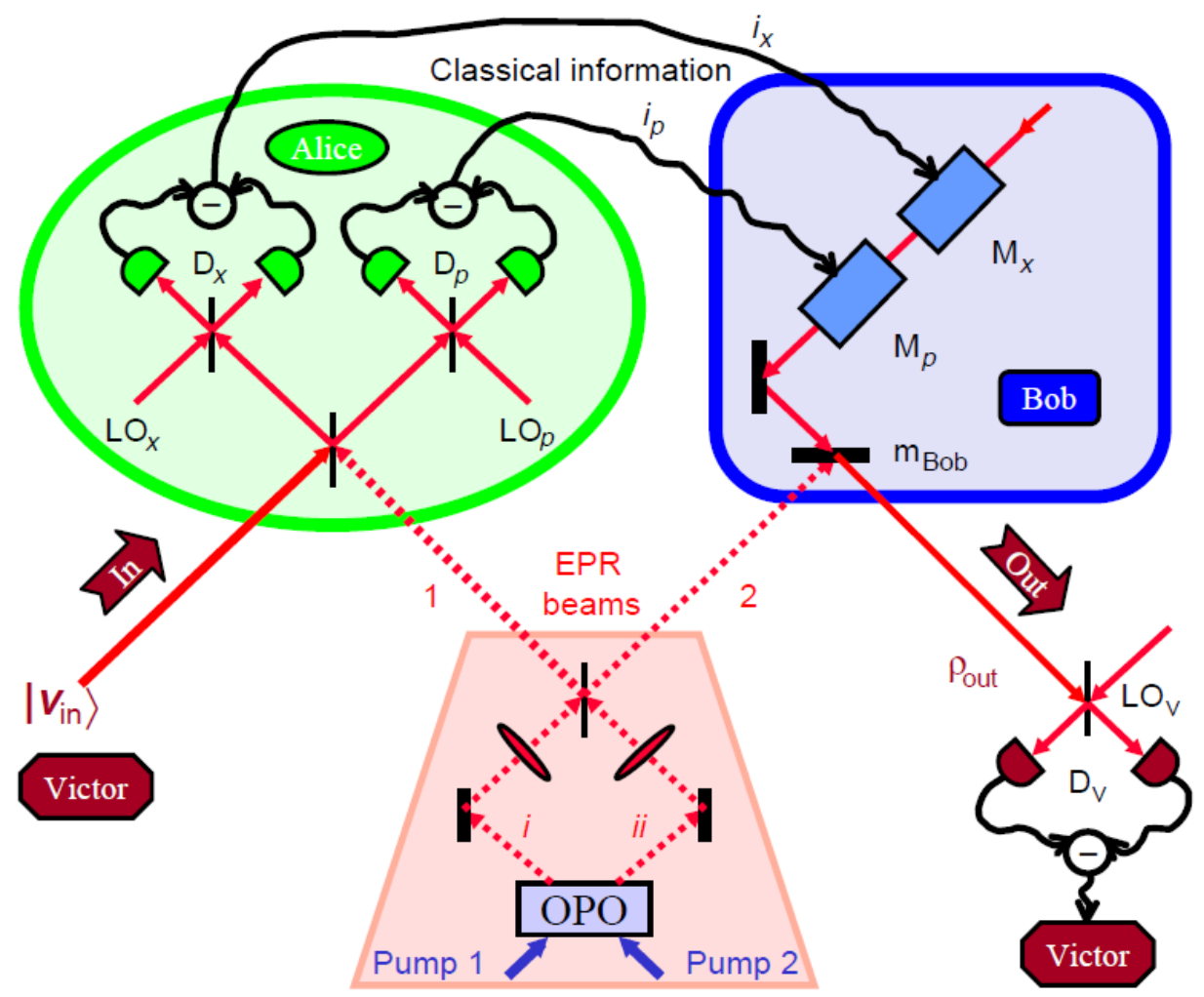

Figura 2.3: Esquema experimental do trabalho de Furusawa et al. na realização do teletransporte de informação incondicional de informação quântica . [3]

$$
\hat{E}_{x}=2 \mathscr{E}_{0} \operatorname{sen}(k z)[\hat{x} \cos (\omega t)+\hat{p} \operatorname{sen}(\omega t)]
$$

Note-se que $\hat{x}$ e $\hat{p}$ estão associados com as amplitudes do campo oscilando fora de fase em $90^{\circ}$ um em relação ao outro. Diz-se, por isso, que estão em quadratura de fase. Estes operadores satisfazem a seguinte relação de comutação:

$$
[\hat{x}, \hat{p}]=\frac{i}{2}
$$

E, por serem operadores que não comutam, estabelecem a seguinte relação de incerteza:

$$
\left\langle(\Delta \hat{x})^{2}\right\rangle\left\langle(\Delta \hat{p})^{2}\right\rangle \geqq \frac{1}{16}
$$

Utilizaremos então os operadores $\hat{x}$ e $\hat{p}$, capazes de descrever o campo elétrico da forma acima, como variáveis contínuas no teletransporte.

\subsubsection{Teletransporte de um único modo}

Em analogia ao teletransporte em variáveis discretas, o teletransporte de um único modo começa com Vitor preparando um estado a ser teletransportado. Aqui, definiremos este estado de entrada através de seus operadores de quadratura, $\hat{x}_{i n} \mathrm{e} \hat{p}_{i n}$. Estes operadores definem um único modo do campo eletromagnético, incorporado experimentalmente na forma de um feixe de luz, enviado para Alice para que seu estado seja teletranspor- 
tado.

O próximo passo é a criação do sistema EPR. Discutiremos nesta seção a criação de emaranhamento através da mistura em um divisor de feixe de dois campos de vácuo comprimidos. ${ }^{2}$ Estes campos são descritos como:

$$
\begin{array}{ll}
\hat{x}_{1}=e^{r} \hat{x}_{1}^{(0)}, & \hat{p}_{1}=e^{-r} \hat{p}_{1}^{(0)} \\
\hat{x}_{2}=e^{-r} \hat{x}_{2}^{(0)}, & \hat{p}_{2}=e^{r} \hat{p}_{2}^{(0)}
\end{array}
$$

Onde o índice (0) representa modos de vácuo, e $r$ é o parâmetro de compressão. Misturando estes campos num divisor de feixes 50:50, temos da saída:

$$
\begin{aligned}
& \hat{x}_{A}=\left(e^{r} \hat{x}_{1}^{(0)}+e^{-r} \hat{x}_{2}^{(0)}\right) / \sqrt{2}, \\
& \hat{p}_{A}=\left(e^{-r} \hat{p}_{1}^{(0)}+e^{r} \hat{p}_{2}^{(0)}\right) / \sqrt{2}, \\
& \hat{x}_{B}=\left(e^{r} \hat{x}_{1}^{(0)}-e^{-r} \hat{x}_{2}^{(0)}\right) / \sqrt{2}, \\
& \hat{p}_{B}=\left(e^{-r} \hat{p}_{1}^{(0)}-e^{r} \hat{p}_{2}^{(0)}\right) / \sqrt{2} .
\end{aligned}
$$

Os campos de saída são enviados para Alice e para Bob. Podemos conferir a existência de correlação entre eles verificando que se o parâmetro de compressão for levado ao infinito $(r \rightarrow \infty)$, as correlações serão perfeitas, da forma:

$$
\begin{aligned}
& \lim _{r \rightarrow \infty}\left[\hat{x}_{A}-\hat{x}_{B}\right]=\lim _{r \rightarrow \infty}\left[\sqrt{2} e^{-r} \hat{x}_{2}^{(0)}\right]=0, \\
& \lim _{r \rightarrow \infty}\left[\hat{p}_{A}+\hat{p}_{B}\right]=\lim _{r \rightarrow \infty}\left[\sqrt{2} e^{-r} \hat{p}_{1}^{(0)}\right]=0
\end{aligned}
$$

Neste limite, ambos os campos de saída se tornam infinitamente ruidosos, mas ao mesmo tempo, as correlações do tipo EPR entre eles se tornam ideais, como visto acima.

Seguindo o protocolo de teletransporte, Alice recebe o campo A , $\left\{\hat{x}_{A}, \hat{p}_{A}\right\}$, da fonte EPR e o campo de entrada, $\left\{\hat{x}_{i n}, \hat{p}_{i n}\right\}$, e realiza então uma medida sobre o sistema conjunto formado pelos dois campos. Esta medida é análoga à medida de estados de Bell realizada no teletransporte em variáveis discretas. Vejamos agora como esta medida é feita.

\subsubsection{Medida de Bell em variáveis contínuas}

O equivalente à porta CNOT seguida por uma porta Hadamard, no caso de variáveis contínuas, é a mistura dos dois campos que Alice recebe num divisor de feixes 50:50, seguida pela medida das duas quadraturas, $\hat{x}$ e $\hat{p}$, uma em cada saída do divisor de feixes. Para compreender o efeito desta medida, vejamos o resultado da superposição dos feixes no divisor de feixes. Ao realizar a superposição, as saídas $u$ e $v$ do divisor de feixes fornecem os seguintes campos:

$$
\begin{aligned}
& \hat{x}_{u}=\left(\hat{x}_{i n}-\hat{x}_{A}\right) / \sqrt{2}, \\
& \hat{p}_{u}=\left(\hat{p}_{i n}-\hat{p}_{A}\right) / \sqrt{2}, \\
& \hat{x}_{v}=\left(\hat{x}_{i n}+\hat{x}_{A}\right) / \sqrt{2}, \\
& \hat{p}_{v}=\left(\hat{p}_{i n}+\hat{p}_{A}\right) / \sqrt{2} .
\end{aligned}
$$

Nas saídas do divisor de feixes os detectores realizam as medidas das quadraturas. Suponhamos que na saída $u$ meçamos a quadratura $\hat{x}_{u}$, dando como resultado $x_{u}$, e

\footnotetext{
${ }^{2}$ No capítulo 4, estes campos emaranhados serão produzidos diretamente através de um OPO, sem o uso de divisores de feixes.
} 
que na saída $p$ meçamos a outra quadratura, $\hat{p}_{v}$, obtendo, $p_{v}$. Aqui é importante notar que $x_{u}$ e $p_{v}$ são valores determinados, mas que se apresentam randômicos, devido ao ruído idealmente infinito adicionado pelo campo EPR A. Estes valores fornecem uma medida da semelhança entre o campo de entrada e o campo EPR A. Esta informação é então enviada para Bob através de dois canais de comunicação clássicos, um para cada quadratura medida.

\subsubsection{O efeito do canal quântico}

Por causa do emaranhamento, o campo EPR enviado para Bob está correlacionado com o campo enviado para Alice. Para compreendermos como essa correlação faz parte do teletransporte, precisamos escrever o campo EPR de Bob, em função do campo de Alice e das medidas de Bell. Somando ao campo EPR B a seguinte equação com valor zero, deduzido das equações da medida de Bell:

$$
\begin{gathered}
0=\hat{x}_{i n}-\sqrt{2} \hat{x}_{u}-\hat{x}_{A}, \\
0=\hat{p}_{i n}-\sqrt{2} \hat{p}_{v}+\hat{p}_{A}
\end{gathered}
$$

Obtemos:

$$
\begin{aligned}
& \hat{x}_{B}=\hat{x}_{B}+\left(\hat{x}_{i n}-\sqrt{2} \hat{x}_{u}-\hat{x}_{A}\right) \\
& \hat{p}_{B}=\hat{p}_{B}+\left(\hat{p}_{i n}-\sqrt{2} \hat{p}_{v}+\hat{p}_{A}\right)
\end{aligned}
$$

Rearranjando e expressando as correlações em termos do parâmetro de compressão, $r^{3}$, temos:

$$
\begin{aligned}
& \hat{x}_{B}=\hat{x}_{i n}-\left(\hat{x}_{A}-\hat{x}_{B}\right)-\sqrt{2} \hat{x}_{u}=\hat{x}_{i n}-\sqrt{2} e^{-r} \hat{x}_{2}^{(0)}-\sqrt{2} \hat{x}_{u} \\
& \hat{p}_{B}=\hat{p}_{i n}+\left(\hat{p}_{B}+\hat{p}_{A}\right)-\sqrt{2} \hat{p}_{v}=\hat{p}_{i n}+\sqrt{2} e^{-r} \hat{p}_{1}^{(0)}-\sqrt{2} \hat{p}_{v}
\end{aligned}
$$

Caso tenhamos $r \rightarrow \infty$, obtemos:

$$
\begin{aligned}
& \hat{x}_{B}=\hat{x}_{i n}-\sqrt{2} \hat{x}_{u} \\
& \hat{p}_{B}=\hat{p}_{i n}-\sqrt{2} \hat{p}_{v}
\end{aligned}
$$

Este resultado é obtido através do emaranhamento, e representa o estado inicial entregue por Vitor para Alice, a menos de flutuações randômicas, justamente aquelas que Alice mediu e enviou para Bob através do canal clássico. Com base nestas informações vinda de Alice, Bob pode então operar sobre seu feixe EPR de forma a obter o estado inicial:

$$
\begin{aligned}
& \hat{x}_{t e l}=\hat{x}_{B}+\Gamma \sqrt{2} \hat{x}_{u} \\
& \hat{p}_{t e l}=\hat{p}_{B}+\Gamma \sqrt{2} \hat{p}_{v}
\end{aligned}
$$

Onde $\Gamma$ é o ganho envolvido na transformação da fotocorrente clássica para amplitude complexa do campo. Para $\Gamma=1$, Bob elimina as flutuações $x_{u}$ e $p_{v}$, obtendo apenas

$$
\begin{aligned}
& \hat{x}_{t e l}=\hat{x}_{i n} \\
& \hat{p}_{t e l}=\hat{p}_{i n}
\end{aligned}
$$

\footnotetext{
${ }^{3}$ O parâmetro de compressão $r$ é um dos parâmetros do operador de compressão, definido como $\hat{S}(\xi)=\operatorname{epx}\left[\frac{1}{2}\left(\xi^{*} a^{2}-\xi a^{\dagger 2}\right)\right]$, sendo que $\xi=r \mathrm{e}^{i \theta}, 0 \leqslant r<\infty$ e $0 \leqslant \theta \leqslant 2 \pi$. O parâmetro $r$ reflete a intensidade da compressão e o parâmetro $\theta$, a direção em que a compressão ocorre no espaço de fases.
} 
ou seja, o estado de entrada. Considera-se então efetuado o teletransporte. Num caso um pouco mais geral, onde levamos em conta compressão finita e ganho diferente de 1, a expressão para o campo teletransportado fica [14]:

$$
\begin{aligned}
& \hat{x}_{t e l}=\Gamma \hat{x}_{i n}-\frac{\Gamma-1}{\sqrt{2}} e^{r} \hat{x}_{1}^{(0)}-\frac{\Gamma+1}{\sqrt{2}} e^{-r} \hat{x}_{2}^{(0)} \\
& \hat{p}_{t e l}=\Gamma \hat{p}_{i n}+\frac{\Gamma-1}{\sqrt{2}} e^{r} \hat{p}_{2}^{(0)}+\frac{\Gamma+1}{\sqrt{2}} e^{-r} \hat{p}_{1}^{(0)}
\end{aligned}
$$

No caso mais geral percebemos o efeito do fator de compressão $r$ para a eficiência do teletransporte. Na medida em que ele for finito, o estado de saída se distanciará em semelhança ao estado de entrada. Podemos então compreender de que forma o teletransporte ocorre para variáveis contínuas, através de emaranhamento entre as quadraturas do campo eletromagnético, no caso simples em que o campo é descrito com apenas uma frequência.

\subsection{Critérios para verificação do teletransporte}

Após a realização do teletransporte, precisamos ser capazes de verificar se o procedimento foi bem sucedido. Alice e Bob, por não possuírem nenhuma informação sobre o estado teletransportado, não estão aptos a fazer esta conferência. Cabe então à Vitor, que criou o estado de entrada, estabelecer um procedimento para verificar o sucesso do teletransporte. Para viabilizar a quantificação do processo de teletransporte, utiliza-se o conceito de Fidelidade.

\subsubsection{Fidelidade}

A fidelidade é definida como um valor que mede a semelhança entre os estados de entrada e de saída do teletransporte. Para um estado de entrada arbitrário, $\left|\psi_{\text {in }}\right\rangle$, e um estado de saída, o estado que foi teletransportado, definido pelo operador densidade $\hat{\rho}_{t e l}$, a fidelidade é definida como [21]:

$$
F=\left\langle\psi_{i n}\left|\hat{\rho}_{t e l}\right| \psi_{i n}\right\rangle
$$

Dessa forma, a fidelidade é 1 apenas se $\hat{\rho}_{t e l}=\left|\psi_{i n}\right\rangle\left\langle\psi_{i n}\right|$. Se os estados são completamente diferentes, ou seja, ortogonais entre si, a fidelidade é nula. No caso do teletransporte em variáveis discretas, apresentado na seção 2.3, o estado final é exatamente o estado de entrada e, portanto, a fidelidade é máxima $(F=1)$.

$$
\rho_{t e l}=\left|\psi_{t e l}\right\rangle\left\langle\psi_{t e l}\right|
$$

com

$$
\left|\psi_{t e l}\right\rangle=a\left|0_{3}\right\rangle+b\left|1_{3}\right\rangle=\left|\psi_{\text {in }}\right\rangle
$$

Isso acontece porque o exemplo serviu para introduzir os conceitos e etapas principais do teletransporte e não considerou em nenhum momento as perdas envolvidas em qualquer procedimento experimental. Apesar de ser definida em termos de um estado puro, $\left|\psi_{i n}\right\rangle$, e de um operador densidade, $\hat{\rho}_{t e l}$, é possível converter a fidelidade para medir o sucesso do teletransporte em outras representações, de acordo com o que for mais conveniente. Para o teletransporte em variáveis contínuas, o formalismo utilizado é o dos operadores de aniquilação/destruição e seus equivalentes fase/amplitude, pois 
tratamos de campos gaussianos de banda larga com uma amplitude coerente. O desenvolvimento da fidelidade para este formalismo segue o apresentado por van Loock et al. [14], e é válido para as duas abordagens, desde que se avalie as diferenças entre os operadores para cada caso.

A parte de um fator de $\pi$, a fidelidade em 2.6 é a função $Q$, ou de Husimi, do modo teleportado avaliado para um estado coerente dado por $\alpha_{i n}$. Podemos mostrar isso partindo da definição para a função Q segundo Scully e Zubairy [22]:

$$
Q\left(\alpha, \alpha^{*}\right)=\operatorname{Tr}\left[\rho \delta(\alpha-a) \delta\left(\alpha^{*}-a^{\dagger}\right)\right]
$$

Inserindo a unidade obtemos:

$$
\begin{aligned}
Q\left(\alpha, \alpha^{*}\right) & =\frac{1}{\pi} \operatorname{Tr} \int d^{2} \alpha^{\prime}\left[\rho \delta(\alpha-a)\left|\alpha^{\prime}\right\rangle\left\langle\alpha^{\prime}\right| \delta\left(\alpha^{*}-a^{\dagger}\right)\right] \\
& =\frac{1}{\pi} \operatorname{Tr} \int d^{2} \alpha^{\prime}\left\{\rho \delta\left(\alpha-\alpha^{\prime}\right)\left|\alpha^{\prime}\right\rangle\left\langle\alpha^{\prime}\right| \delta\left[\alpha^{*}-\left(\alpha^{\prime}\right)^{*}\right]\right\} \\
& =\frac{1}{\pi} \operatorname{Tr}(\rho|\alpha\rangle\langle\alpha|) \\
& =\frac{1}{\pi}\langle\alpha|\rho| \alpha\rangle
\end{aligned}
$$

A fidelidade fica então uma expressão da função Q do modo teletransportado (saída), mas avaliada para o estado de entrada:

$$
F=\pi Q_{t e l}\left(\alpha_{i n}\right)=\left\langle\alpha_{i n}\left|\rho_{t e l}\right| \alpha_{i n}\right\rangle
$$

A função Q definida como acima é expressa da seguinte forma quando envolve campos coerentes [14]:

$$
Q_{t e l}\left(\alpha_{i n}\right)=\frac{1}{2 \pi \sqrt{\sigma_{x} \sigma_{p}}} \exp \left[-(1-\Gamma)^{2}\left(\frac{x_{i n}^{2}}{2 \sigma_{x}}+\frac{p_{i n}^{2}}{2 \sigma_{p}}\right)\right]
$$

onde $\Gamma$ é o ganho aplicado por Bob no canal clássico que recebe de Alice, $\sigma_{x}$ e $\sigma_{p}$ são as variâncias da função $Q$ do modo teletransportado para as quadraturas correspondentes. Considerando ganho unitário $(\Gamma=1)$, obtemos:

$$
Q_{t e l}\left(\alpha_{i n}\right)=\frac{1}{2 \pi \sqrt{\sigma_{x} \sigma_{p}}}
$$

Assim, precisamos do espectro das funções $Q$ com as variâncias espectrais $\sigma_{x}(\Omega)=\sigma_{p}(\Omega)=$ $\frac{1}{2}+\frac{1}{4} V_{t e l, i n}^{X}(\Omega)$, onde a variância, $V_{t e l, i n}^{\hat{X}}$, é definida através de:

$$
\delta\left(\Omega-\Omega^{\prime}\right) V_{t e l, i n}^{\hat{X}} \equiv \frac{\left\langle\Delta\left[\hat{X}_{t e l}^{\dagger}(\Omega)-\hat{X}_{i n}^{\dagger}(\Omega)\right] \Delta\left[\hat{X}_{t e l}^{\dagger}\left(\Omega^{\prime}\right)-\hat{X}_{i n}^{\dagger}\left(\Omega^{\prime}\right)\right]\right\rangle}{\left\langle\Delta \hat{X}^{2}\right\rangle_{\text {vac uum }}}
$$

De forma análoga para a outra quadratura, $\hat{p}$. Calculando a fidelidade, para $\Gamma=1$, em termos das variâncias, obtemos:

$$
F=\frac{1}{2 \sqrt{\left(\frac{1}{2}+\frac{1}{4} V_{t e l, i n}^{\hat{X}}\right)\left(\frac{1}{2}+\frac{1}{4} V_{t e l, i n}^{\hat{P}}\right)}}
$$


No caso em que as variâncias das quadraturas $\hat{x}$ e $\hat{p}$ são iguais, como no caso de um OPO operado abaixo do limiar, podemos associá-las ao espectro de ruído da subtração de amplitudes da seguinte forma:

$$
V_{t e l, i n}^{\hat{X}}=V_{t e l, i n}^{\hat{P}}=2 S_{-}(\Omega)
$$

Após a manipulação algébrica temos então que, para o OPO operando abaixo do limiar, a fidelidade é, quando $\Gamma=1$ :

$$
F=\frac{1}{1+S_{-}(\Omega)}
$$

Com isso, a fidelidade pode ser calculada através do espectro de compressão de ruído produzido pela fonte de estados EPR. Nos capítulos a seguir utilizaremos essa relação para projetar os valores possíveis de fidelidade a serem alcançados pelo nosso sistema.

Precisamos agora definir valores mínimos de fidelidade acima dos quais pode-se considerar que o processo de teletransporte foi bem sucedido. Na literatura encontramos dois valores principais, o limite clássico e o limite de não clonagem, os quais passamos a esclarecer na sequência.

\subsubsection{O limite Clássico}

O limite clássico define um valor máximo para a fidelidade acima do qual emaranhamento deve ter sido utilizado em alguma medida. Este valor foi calculado para uma situação envolvendo o teletransporte de um único modo no artigo de Braunstein et al. [21]. Segundo o artigo, a fidelidade média máxima alcançada utilizando apenas canais de comunicação clássicos, sem o uso de emaranhamento como recurso é:

$$
F_{a v}=\frac{1}{2}
$$

Braunstein et al., basearam o cálculo supondo estados de vácuo. No entanto, afirmam que a argumentação não depende de que a média da distribuição Gaussiana seja nula, e que a estratégia envolvendo estados não-vácuo, como os que utilizaremos em nosso projeto, leva ao mesmo valor para a fidelidade máxima sem emaranhamento.

\subsubsection{O limite de Não clonagem}

Um segundo limite foi estabelecido por Grosshans e Grangier em um artigo de 2001 [23]. Os autores afirmam que o critério clássico não é suficiente, pois, embora qualquer valor acima dele implique necessariamente o uso de emaranhamento, este valor de fidelidade não pode garantir que não tenham sido feitas cópias do estado inicial durante o processo. Como o processo de teletransporte exige por definição que o estado inicial seja destruído e que não exista nenhuma cópia dele, atendendo, portanto, o teorema da não clonagem, um novo valor limite para a fidelidade precisa ser estabelecido. Segundo os autores, o valor para a fidelidade máxima é dado pela seguinte expressão, dependente do valor $M$, o número de cópias produzidas:

$$
F_{1 \rightarrow M} \leqslant \frac{M}{2 M-1}
$$

Assim, quando se produz uma cópia $(M=1$ original +1 cópia $=2)$, o máximo de 
fidelidade possível é $F=2 / 3$. Portanto, uma fidelidade acima deste valor representa não só que o teletransporte utilizou o recurso quântico do emaranhamento, mas também garante que nenhuma cópia foi produzida durante o processo. A impossibilidade de realizar cópias interferiria numa tentativa de espionar o sistema. Surge então o interesse de utilização do teletransporte como ferramenta de criptografia.

Definidas as idéias fundamentais do teletransporte, vamos estudar na sequência as ferramentas experimentais para a realização do teletransporte de informação quântica em cores distintas. 


\section{Capítulo 3}

\section{Componentes do Teletransporte Multicor}

O trabalho de pesquisa experimental no LMCAL envolveu o desenvolvimento de três componentes fundamentais para a presente proposta de teletransporte. Neste capítulo, apresentamos o trabalho realizado sobre estes componentes: as cavidades ópticas, na seção 3.1, os moduladores eletro-ópticos (EOMs), na seção 3.2, e a fonte de estados EPR, em nosso caso, um Oscilador Paramétrico Óptico (OPO), na seção 3.3.1. Cada seção contém uma uma breve explicação sobre o papel do componente no processo de teletransporte, teoria de funcionamento do componente, e os detalhes sobre o trabalho realizado, como projeto, construção, medidas para caracterização, e discussão dos resultados, de acordo com cada caso.

\subsection{Cavidades Ópticas}

Em nosso processo de teletransporte, as cavidade ópticas representam peças fundamentais em várias etapas. Precisaremos de 4 cavidades ópticas (além do OPO). Duas delas vão atuar como cavidades de análise, promovendo a rotação da elipse de ruído e permitindo a medida do ruído da quadratura de fase dos campos [24, 25]. Duas serão cavidades de filtro, para separar as bandas laterais da portadora do campo [26]. Na figura 3.1 temos duas ilustrações esquemáticas dos componentes das cavidade ópticas, nas duas configurações.
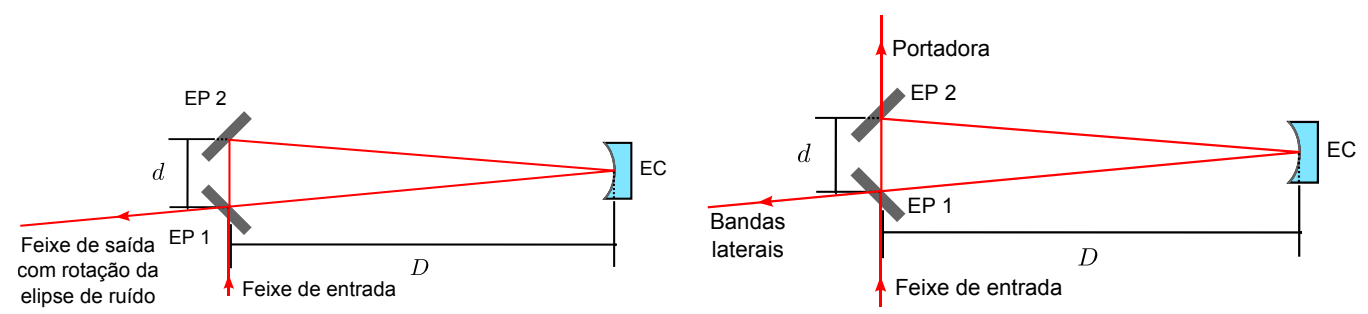

Figura 3.1: Esquema das cavidades de análise e filtro, respectivamente, mostrando a definição das grandezas relevantes. (EP-Espelho Plano, EC-Espelho Curvo) 


\subsubsection{Teoria do funcionamento das cavidades ópticas}

O fenômeno responsável pela ação das cavidades ópticas sobre os feixes refletidos e/ou transmitidos é a dependência dos coeficientes de reflexão e transmissão de uma cavidade óptica em função da frequência da luz incidente, da forma [25]:

$$
r(\Delta, \Omega)=-\frac{\sqrt{u}+i \frac{2(\Delta+\Omega)}{\gamma}}{1-i \frac{2(\Delta+\Omega)}{\gamma}}
$$

Nesta equação, escrevemos $\Delta=\omega_{0}-\omega_{c}$ como sendo a dessintonia entre a frequência de ressonância da cavidade e a frequência da onda portadora. O termo $\Omega$ é a distância em frequência acima e abaixo da frequência da portadora, descrevendo então as frequências das bandas laterais a partir da portadora. Nesta equação, $\gamma$ representa a largura de banda da cavidade e $u$ é o parâmetro de acoplamento, definido como a fração de luz que é refletida em exata ressonância.

Se escolhermos travar a cavidade sobre a frequência da onda portadora, $(\Delta=0)$, e ela tiver dois espelhos abertos com reflectâncias muito similares, a cavidade pode se transformar em um filtro, transmitindo a onda portadora e refletindo as bandas laterais. Basta que os coeficientes que atuam sobre as frequências das bandas laterais sejam $r(0, \Omega) \simeq r(0,-\Omega) \simeq 0$ e que o coeficiente que atua sobre a portadora, $r(0,0)$, seja o mais próximo da unidade. Na prática o espectro da onda transmitida terá a mesma largura de banda que a cavidade óptica.

Outra possibilidade é, por meio de escolhas adequadas de travamento e dos parâmetros dos espelhos das cavidades, utilizá-las para adicionar uma fase sobre o campo incidente e, com isso, projetar a quadratura de fase na quadratura de amplitude [27, 24]. Basta para isso que cada componente em frequência do campo receba um coeficiente de reflexão adequado.

Tanto para o uso das cavidades como filtro de bandas, ou como cavidades de análise, é necessário que a largura de banda das cavidades seja relativamente estreita, quando comparada com a largura de linha da onda portadora. É necessário também um sistema de sintonização adequado.

\subsubsection{O projeto das cavidades ópticas}

As cavidades que foram projetadas possuem o formato de anel, e seu projeto segue o esquema mostrado da figura 3.1. O suporte do espelho curvo é construído de forma que possa deslizar por quatro barras de metal. Isso permite que D assuma valores entre 6 e $47 \mathrm{~cm}$. Consequentemente, o caminho óptico de uma volta na cavidade, L, pode ter valores entre 9 e $97 \mathrm{~cm}$. Embora seja possível mover o espelho até a posição $D=0$, esta não é uma configuração desejável devido ao grande astigmatismo provocado pelo grande ângulo de incidência sobre o espelho curvo. O valor máximo de $47 \mathrm{~cm}$ é definido pelo comprimento das barras. São utilizadas quatro barras para estabilizar o sistema mecanicamente. Além disso, essas barras são feitas de Invar, uma liga de Níquel e Ferro com um coeficiente de dilatação de $1,2 \times 10^{-6} \mathrm{~K}^{-1}$, o que deve tornar o tamanho da cavidade óptica menos sensível a variações da temperatura ambiente. 
As cavidades terão diferentes espelhos, de acordo com seu uso. Na tabela 3.1 estão listados os espelhos e suas características ópticas para $1064 \mathrm{~mm}$, o comprimento de onda a ser trabalhado.

\begin{tabular}{|c|c|c|}
\hline & Análise & Filtro \\
\hline \hline EC & Côncavo (R=50 ou 200 $\mathrm{mm}), T_{1064}=0,0016 \%$ \\
\hline EP 1 & Plano, $T_{1064}=0,9 \%$ & Plano, $T_{1064}=0,9 \%$ \\
\hline EP 2 & Plano, $T_{1064}=0,0016 \%$ & Plano, $T_{1064}=0,9 \%$ \\
\hline
\end{tabular}

Tabela 3.1: Características dos espelhos para a construção das cavidades do teletransporte.

As cavidades apresentarão diferentes condições de estabilidade, dependendo do raio de curvatura dos espelhos que se escolha utilizar. Sendo o caminho óptico para elas definido exatamente como $L_{d i f}=d+\sqrt{4 D^{2}+d^{2}}$, a geometria das cavidades deve obedecer à seguinte desigualdade para que haja estabilidade óptica [28].

$$
0 \leq\left(1-\frac{L_{d i f}}{R}\right)^{2} \leq 1
$$

Se considerarmos que $d \approx 30 \sim$ mm é fixo, temos que o parâmetro $\mathrm{D}$ deve assumir os seguintes valores, de acordo com o raio de curvatura dos espelhos que se deseja utilizar:

\begin{tabular}{|c|c|}
\hline $\mathrm{R}(\mathrm{cm})$ & Condições de Estabilidade \\
\hline \hline 50 & $0 \leq D \leq 48,5 \mathrm{~cm}$ \\
\hline 200 & $0 \leq D \leq 198,5 \mathrm{~cm}$ \\
\hline
\end{tabular}

Como é possível perceber, o tamanho no qual é possível estender as cavidades (0-47 $\mathrm{cm}$ ) encontra-se dentro das regiões de estabilidade. Apenas com o espelho de $R=50 \mathrm{~cm}$ deve-se evitar o ponto em que $D=23,4 \mathrm{~cm}$. Na figura 3.2 temos um gráfico mostrando as regiões de estabilidade, de acordo com a desigualdade 3.2.
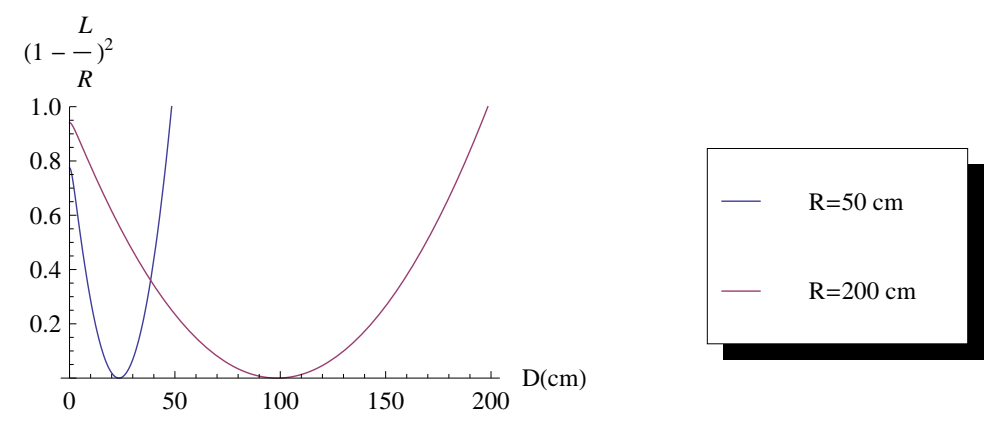

Figura 3.2: Gráfico de estabilidade das cavidades de análise e filtro de acordo com o raio de curvatura do espelho que se pretenda utilizar.

Com as transmitâncias e a geometria da cavidade, é possível estimar os valores teóricos (que não incluem as perdas espúrias), para a finesse, $\mathbb{F}$, a largura de banda, $\delta v$ e o intervalo espectral livre, $v_{F S R}$. Levando em conta um caminho óptico máximo $L_{\text {max }}=$ $97 \mathrm{~cm}$, definido pelo tamanho das barras de Invar, e um caminho óptico mínimo $L_{\text {min }}=$ $9 \mathrm{~cm}$, de forma que o espelho curvo fique a uma distância mínima razoável dos outros espelhos, os valores teóricos para a finesse, intervalo espectral livre e para a largura de banda se encontram na tabela 3.2.

Temos então as características previstas das cavidades de análise e de filtro. 


\begin{tabular}{|c|c|c|c|c|c|c|}
\hline & \multicolumn{3}{|c|}{ Cavidades de Análise } & \multicolumn{3}{c|}{ Cavidades de Filtro } \\
\cline { 1 - 5 }$L(\mathrm{~cm})$ & $\mathbb{F}$ & $v_{F S R}(\mathrm{MHz})$ & $\delta v(\mathrm{MHz})$ & $\mathbb{F}$ & $v_{F S R}(\mathrm{MHz})$ & $\delta v(\mathrm{MHz})$ \\
\hline 93 & \multirow{2}{*}{$\sim 740$} & $\sim 300$ & $\sim 0,4$ & \multirow{2}{*}{$\sim$} & $\sim 300$ & $\sim 0,8$ \\
\cline { 4 - 5 } & & $\sim 3300$ & $\sim 4,5$ & & $\sim 3300$ & $\sim 9$ \\
\hline
\end{tabular}

Tabela 3.2: Valores teóricos para $\mathbb{F}, v_{F S R}$ e $\delta v$, de acordo com os limites da geometria das cavidades de análise e de filtro.

\subsubsection{Construção e caracterização preliminar das cavidades ópticas}

Após o projeto, as peças foram fabricadas pela oficina mecânica do Instituto de Física da USP. Na figura 3.3 encontram-se fotografias de uma das cavidades após a montagem de todos os componentes.
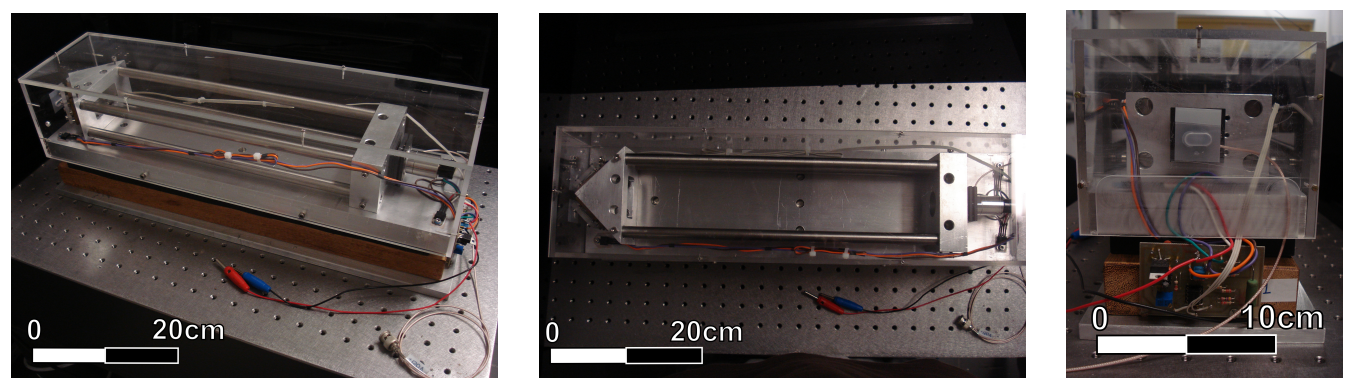

Figura 3.3: Fotografias de uma das cavidades ópticas já montada.

Para que seja possível travar as cavidades é importante que o tamanho do caminho óptico permaneça constante durante sua operação. A variação da temperatura e a consequente dilatação dos materiais pode atrapalhar neste sentido. O uso de barras de Invar como suporte mecânico das peças já age para diminuir estes efeitos. No entanto, mesmo com as barras de Invar, uma variação de $1^{\circ} \mathrm{C}$ representa uma alteração de aproximadamente $600 \mathrm{~nm}$, quando a cavidade está o mais comprida possível. Esta alteração ainda é relevante, pois é da ordem do comprimento de onda da luz na cavidade operando em $1064 \mathrm{~nm}$. Para melhorar a estabilidade das cavidades com relação às variações térmicas, foram instalados nelas circuitos elétricos que as aquecem e controlam a temperatura, diminuindo a oscilação da temperatura das cavidades com a temperatura ambiente. A eficiência deste processo foi testada e os circuitos se mostraram capazes de responder às variações da temperatura ambiente. A temperatura das cavidades se mostrou estável numa faixa da ordem de décimos de grau, enquanto a temperatura ambiente mudava em $4^{\circ} \mathrm{C}$.

Uma das cavidades foi utilizada brevemente como parte de outro experimento do laboratório e foi possível verificar que ela se mostrou mais estável mecanicamente do que a atual cavidade de filtro que possuímos no laboratório.

Os próximos passos são a caracterização das propriedades ópticas das cavidades e a construção do sistema de travamento. Depois destas etapas, as cavidades estarão prontas para a sua instalação no projeto de teletransporte.

\subsection{Moduladores eletro-ópticos}

Para realizarmos o teletransporte, é necessário manipular características da luz em duas etapas. Num primeiro momento, Vitor precisa produzir o estado a ser teletransportado. 


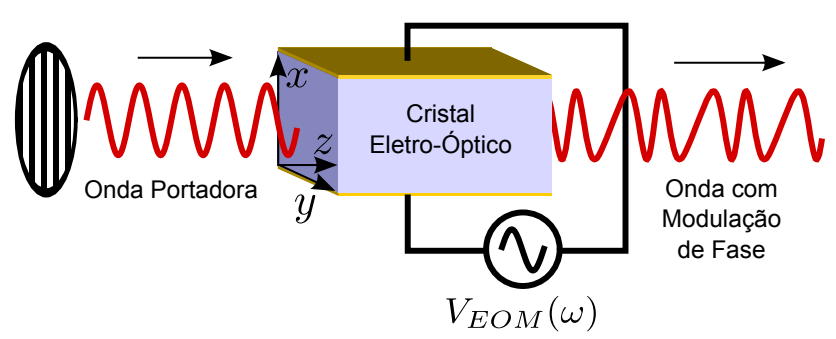

Figura 3.4: Esquema de funcionamento de um EOM transversal em situação de modulação de fase.

Depois, Bob deve ser capaz de imprimir as informações clássicas enviadas por Alice no seu feixe EPR. Nestas duas situações, precisamos ser capazes de alterar as duas quadraturas da luz, intensidade e fase. O equipamento que promove esta manipulação é o modulador eletro-óptico (EOM).

\subsubsection{Teoria de funcionamento de um EOM}

Os moduladores eletro-ópticos são dispositivos que funcionam baseados na alteração eletricamente induzida do índice de refração ou birrefringência natural de certos cristais [28]. Através dessa característica, grandezas como fase, intensidade e estado de polarização podem ser alteradas e moduladas em função de uma tensão de entrada. Os EOMs são compostos basicamente por um cristal com propriedades eletro-ópticas coberto em faces opostas por materiais condutores, que formam dois eletrodos. Na figura 3.4 mostra-se um esquema de funcionamento de um EOM onde o campo elétrico é aplicado na direção transversal à propagação da luz, numa situação de modulação de fase. Pelo esquema construtivo de um EOM, dois eletrodos com um meio dielétrico entre eles, fica claro que a propriedade elétrica mais importante de um EOM é a sua capacitância. Em situações de modulação em alta frequência esta característica pode ser relevante, uma vez que a alta capacitância pode fazer com que o EOM atue como um filtro passa alta. Isso implica em que as tensões sofridas pelo cristal serão atenuadas caso isso ocorra, e alguma forma de contornar esta dificuldade pode ser necessária.

Quando um feixe de luz passa por um EOM, ao aplicarmos uma tensão modulada em seus terminais, o índice de refração do material sofrerá uma modulação. Esta alteração provocará uma alteração na velocidade da luz dentro do cristal que, em última instância, representará uma modulação da fase na onda que sai do EOM. Alguns cuidados são necessários para que ocorra apenas modulação de fase. Em geral, os cristais eletro-ópticos são birrefringentes. Por causa disso, ao incidirmos um feixe de luz com um determinado estado de polarização, este feixe de luz sairá, em geral, com seu estado de polarização com uma alteração modulada. Isso porque a modulação dos índices de refração atua em todos os planos cristalinos do cristal, mas não necessariamente com a mesma intensidade. Em algumas situações a modulação do estado de polarização é interessante, mas, no nosso caso, estamos interessados em modular apenas a fase. A condição para que isso ocorra é, portanto, que a luz incidente seja linearmente polarizada e que o seu eixo de polarização esteja alinhado a um dos eixos principais do cristal. Com isso, este feixe de luz será influenciado pela modulação de apenas um dos índices de refração do cristal.

Matematicamente, o efeito de um EOM modulando fase pode ser representado como a transposição de fótons da frequência da portadora para frequências das bandas laterais. Considerando um feixe coerente definido por um número complexo $\alpha_{0}=\left|\alpha_{0}\right| e^{i \omega_{0} t}$, 
o campo após a modulação será:

$$
\alpha_{\text {mod }}=\alpha_{0} \cdot e^{i \phi(t)} \simeq \alpha_{0} \cdot(1+i \phi(t))=\alpha_{0}+i \alpha_{0} \phi(t)
$$

Onde levamos em conta que a modulação de fase é muito pequena, $\phi(t) \ll 2 \pi^{1}$. A modulação $\phi(t)$ possui como transformada de Fourier:

$$
\phi(t)=\int_{-\infty}^{\infty} \phi(\Omega) e^{i \Omega t} d \Omega
$$

Levando em conta que $\phi^{*}(\Omega)=\phi(-\Omega)$, modulação afeta tanto a banda superior quanto a inferior. Tendo em vista que a atuação pelos moduladores nestas bandas laterais é limitado no espectro de frequências, representamos a modulação nestas regiões com uma largura de banda denotada por $\delta \Omega_{\bmod }$.

$$
\phi_{\Omega}(t)=\int_{\Omega-\delta \Omega_{m o d}}^{\Omega+\delta \Omega_{m o d}} \phi(\Omega) e^{i \Omega t} d \Omega
$$

O campo modulado fica então descrito como:

$$
\alpha_{\text {mod }}=\alpha_{0}+i \alpha_{0}\left(\phi_{\Omega}(t)+\phi_{-\Omega}(t)\right)
$$

Ao controlarmos $\phi(t)$, podemos alterar as bandas laterais do campo, produzindo a modulação necessária nas etapas do teletransporte.

\subsubsection{Procedimento de caracterização dos EOMs}

O laboratório possui quatro unidades de EOM, de dois modelos distintos, duas unidades LM 0202 e duas unidades PM 25, ambos do fabricante Linus. Para o seu uso no teletransporte, é necessário caracterizar o comportamento destes equipamentos dentro das condições de alta frequência (15 MHz) em que se pretende utilizá-los. Este comportamento é caracterizado pela razão entre o atraso de fase inserido no feixe de luz, $\delta \phi(\omega)$, e a tensão, $V_{E O M}(\omega)$, necessária para produzir tal efeito. Definimos assim o ganho do EOM para uma determinada polarização de entrada como:

$$
G(\omega)=\frac{\delta \phi(\omega)}{V_{E O M}(\omega)}
$$

Consideramos que ambas as grandezas variam dependendo da frequência de modulação. A tensão é diretamente medida através de um osciloscópio e uma ponta de prova ligada diretamente sobre o EOM. A fase, no entanto, apresenta um desafio maior para a medida, já que fotodetectores são sensíveis apenas à intensidade da luz. Por isso, utilizamos um interferômetro de Mach-Zehnder para medir a fase introduzida pelos EOMs num feixe de luz. Na figura 3.5 encontra-se um diagrama na montagem experimental utilizada para medir a fase.

\footnotetext{
${ }^{1}$ Para estados coerentes, o o ruído quântico padrão associado à fase é proporcional ao inverso do número de fótons: $\Delta \phi=\frac{1}{2 \sqrt{N}}$. Num estado coerente, levando em conta um comprimento de onda de 1064 $\mathrm{nm}$, um tempo de integração na detecção de $2,5 \mu \mathrm{s}$, e potências usualmente da ordem de miliwatts, o número de fótons é da ordem de $10^{10}$ fótons. Assim, precisamos que o ruído de fase adicionado seja da ordem de $10^{-5}$ radianos para que seja comparável ao ruído quântico padrão. Muito menor, portanto, do que $2 \pi$.
} 


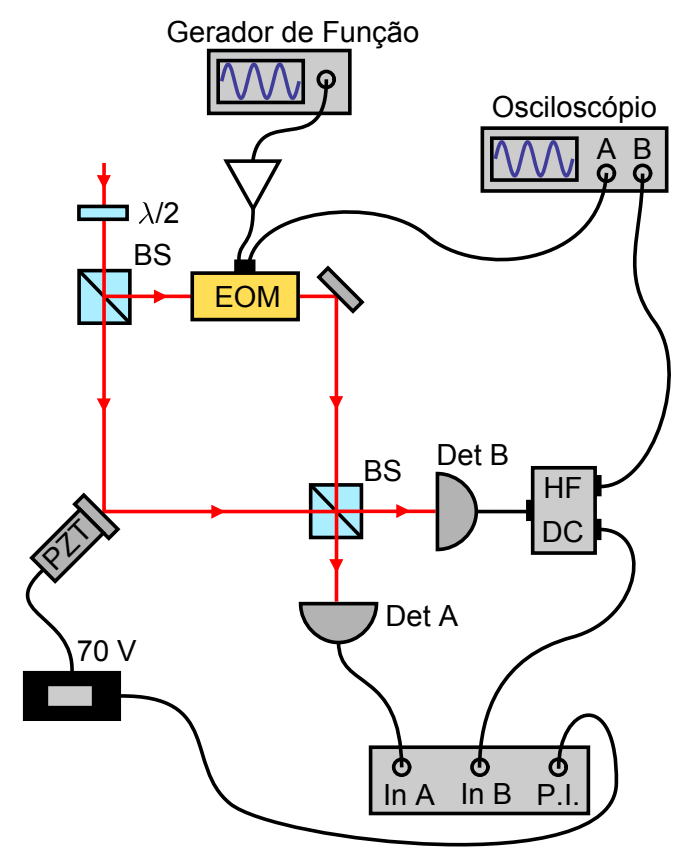

Figura 3.5: Montagem experimental do interferômetro de Mach-Zehnder para medir o atraso de fase introduzido pelos EOMs.

Num interferômetro de Mach-Zehnder, um feixe de luz é dividido em um divisor de feixe (BS). Através de dois espelhos, estes feixes são reunidos e interferem sobre um outro divisor de feixe gerando dois feixes de saída. Num dos braços do interferômetro, um dos espelhos está montado sobre um PZT ${ }^{2}$. O PZT possui função em dois momentos. Primeiro, ele recebe de um gerador de função uma onda dente de serra em baixa frequência $(10 \mathrm{~Hz})$, amplificada para as altas tensões que ele necessita (70 V). Nesta configuração (não mostrada no esquema), diz-se que ele está em modo de varredura. Isso porque ele desloca o espelho, alterando o comprimento deste braço do interferômetro em vários comprimentos de onda. Ou seja, a fase é varrida na ordem de dezenas de radianos. Esta configuração é utilizada para otimizar o alinhamento do interferômetro através da medida do contraste em cada um dos detectores:

$$
\begin{aligned}
& k_{A}=\frac{V_{A}^{\text {max }}-V_{A}^{\text {min }}}{V_{A}^{\text {max }}+V_{A}^{\text {min }}} \\
& k_{B}=\frac{V_{B}^{\text {max }}-V_{B}^{\text {min }}}{V_{B}^{\text {max }}+V_{B}^{\text {min }}}
\end{aligned}
$$

Quanto mais perto de um for o contraste, melhor alinhamento dos feixes. Nas medidas, apenas contrastes maiores de 0,9 foram considerados aceitáveis.

Para medir o ganho precisamos conhecer o funcionamento físico do interferômetro de Mach-Zehnder, com modulação de fase em um dos braços. A teoria nos diz que a tensão medida no detector B, por exemplo, deve ser modelada como um valor de tensão médio, $V_{B}^{\text {med }}=\frac{\left(V_{B}^{\text {max }}+V_{B}^{\text {min }}\right)}{2}$, somado a um termo dependente com uma função senoidal da diferença de fase entre os braços do interferômetro. Termo este que é proporcional à amplitude, $V_{B}^{a m p}=\frac{\left(V_{B}^{\max }-V_{B}^{\min }\right)}{2}$ :

$$
V_{B}=V_{B}^{m e d}+V_{B}^{a m p} \cdot \sin (\phi)
$$

${ }^{2}$ PZT é uma sigla para Titanato Zirconato de Chumbo, uma substância química de fórmula $\mathrm{Pb}\left[Z r_{x} T i_{1-x}\right] O_{3}, 0<\mathrm{x}<1$, com propriedades piezoelétricas. No esquema da figura 3.5, e no decorrer do texto, a sigla PZT representa um dispositivo piezoelétrico. 


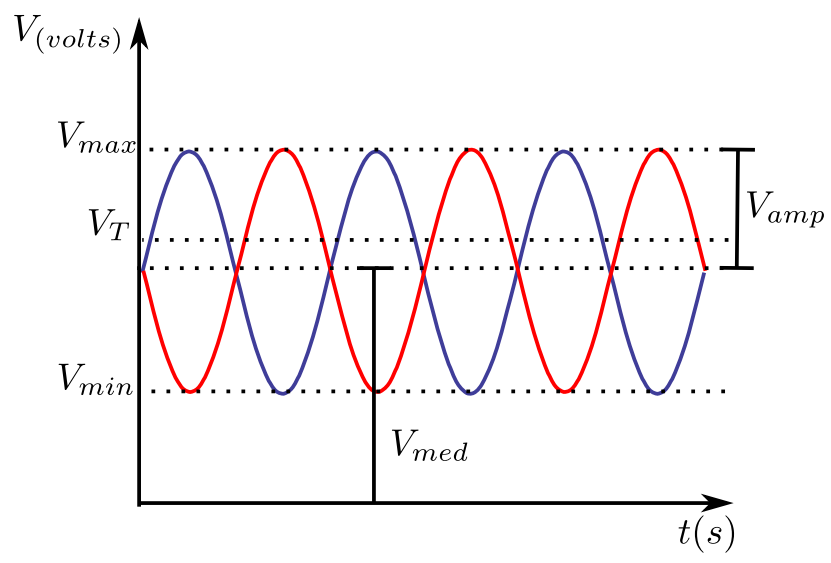

Figura 3.6: Ilustração da tela de um osciloscópio mostrando os sinais dos dois detectores de um interferômetro de Mach-Zehnder numa situação de varredura de fase.

onde $\phi$ é a diferença de fase.

Na figura 3.6 mostra-se uma ilustração do sinal dos dois detectores de um interferômetro Mach-Zehnder, quando se realiza uma varredura de fase com o PZT.

O sistema de travamento mantém o interferômetro travado em uma fase específica, a fase de travamento, $\phi_{T}$. O travamento foi realizado utilizando um controlador de retroalimentação proporcional-integral, utilizando como sinal de erro a diferença entre os sinais dos dois braços do interferômetro.

Com o sistema travado, mas, por enquanto, sem a modulação da fase, podemos relacionar a fase de travamento com a tensão de travamento:

$$
V_{B}^{T}=V_{B}^{m e d}+V_{B}^{a m p} \cdot \sin \left(\phi_{T}\right)
$$

E assim, a fase de travamento é:

$$
\phi_{T}=\arcsin \left(\frac{V_{B}^{T}-V_{B}^{\text {med }}}{V_{B}^{a m p}}\right)
$$

Ao modularmos a fase com o EOM enquanto o sistema está travado em uma fase específica, a fase total será a soma das duas $\phi=\delta \phi+\phi_{T}$, e a tensão no detector será então:

$$
V_{B}=V_{B}^{m e d}+V_{B}^{a m p} \cdot \sin \left(\phi_{T}+\delta \phi\right)
$$

Como as oscilações de tensão geradas pela modulação de fase são pequenas comparadas com o valor médio da tensão, é interessante realizar a medida no osciloscópio em modo AC (Alternate Current), onde o offset é descontado. Como a medida é feita na fase de travamento, a tensão média durante a medida é a tensão de travamento, $V_{B}^{T}$. É esta tensão que o osciloscópio desconta ao fazer a medida no modo AC. Ao medirmos a amplitude das oscilações no osciloscópio, temos então o seguinte resultado:

$$
\begin{gathered}
v_{B}=V_{B}-V_{B}^{T} \\
v_{B}=V_{B}^{\text {med }}-V_{B}^{T}+V_{B}^{a m p} \cdot \sin \left(\phi_{T}+\delta \phi\right) .
\end{gathered}
$$

Ao isolarmos a modulação de fase desta equação, obtemos:

$$
\delta \phi=\arcsin \left(\frac{v_{B}-V_{B}^{m e d}+V_{B}^{T}}{V_{B}^{a m p}}\right)-\phi_{T} .
$$


E substituindo a expressão para a fase de travamento, $\phi_{T}$,

$$
\delta \phi=\arcsin \left(\frac{v_{B}-V_{B}^{m e d}+V_{B}^{T}}{V_{B}^{a m p}}\right)-\arcsin \left(\frac{V_{B}^{T}-V_{B}^{m e d}}{V_{B}^{a m p}}\right)
$$

Considerando que a tensão de travamento é muito próxima da tensão média, e que a amplitude da tensão de modulação é muito menor do que a amplitude da tensão média, a equação acima pode ser aproximada por:

$$
\delta \phi=\frac{v_{B}}{V_{B}^{a m p}} .
$$

Avaliamos as duas expressões experimentalmente e a aproximação se mostrou excelente, não afetando o resultado dentro do erro experimental considerado. Em face disso, a expressão simplificada foi utilizada para os cálculos subsequentes.

Dessa forma, temos condições de medir todos os fatores que determinam o que definimos como o ganho na equação 3.3. Vejamos os detalhes técnicos do processo de medida. Olhando o esquema da figura 3.5, vemos que o feixe de luz inicial passa por uma lâmina de meia-onda. Ela é necessária para controlar a direção de polarização da luz. O modelo LM 0202 é capaz de modular não só a fase, mas também a intensidade e o estado de polarização da luz, dependendo da orientação da polarização da luz de entrada. Para que funcione como um modulador de fase apenas, a direção de polarização do feixe de entrada deve estar alinhada a um dos dois planos ópticos dos cristais do EOM. Assim, como preparação para a medida, é necessário minimizar a modulação de polarização pelo EOM, ajustando a direção de polarização da luz através da lâmina de meia-onda.

Já o modelo PM 25 é construído para ser utilizado como um modulador de fase apenas. Por ser construído com duas janelas de Brewster, é necessário ajustar a direção de polarização da luz de entrada para minimizar a reflexão na janela de entrada. $\mathrm{O}$ ângulo de transmissão máxima das janelas de Brewster é alinhado na construção com um dos planos ópticos do cristal, o que garante que este modelo module apenas a fase quando a direção de polarização da luz de entrada está ajustada para máxima transmissão.

O PZT também é utilizado no momento da medida, para travar o sistema em fase zero. O interferômetro de Mach-Zehnder é muito sensível a alterações na relação de fase entre seus dois braços. Pequenas alterações no caminho óptico, como aquelas introduzidas por vibrações do solo, ondas sonoras, ou variações térmicas, são mensuráveis por este sistema. Por isso, para fazer a medida, é necessário um sistema de travamento de fase, que compense estas alterações indesejáveis. O travamento ocorre em torno do zero na diferença de fase entre os braços, na lateral dos picos de interferência, onde a própria inclinação entre a diferença dos caminhos fornece a resposta para o controlador P.I. (Proporcional e Integral). O equipamento de travamento recebe o sinal dos dois detectores, faz a subtração e retorna para o PZT um sinal proporcional e integral com relação à diferença entre os dois sinais. Este sinal de travamento é amplificado para a tensão de trabalho do PZT e chega ao PZT, onde provoca alteração da posição do espelho que deve corrigir eventuais desvios do zero do interferômetro.

Estando o interferômetro travado, insere-se a modulação sobre o EOM. O sinal senoidal de alta frequência (10-20 MHz) é produzido por um gerador de funções e, após ser amplificado, chega ao EOM. Note-se que esta modulação não é compensada pelo sistema de travamento por dois motivos. Primeiro por que a oscilação é muito rápida para que o sistema mecânico (e massivo) do espelho com o PZT possa responder a tempo. 
Segundo, porque existe a filtragem da alta frequência em um dos detectores, e o sistema de travamento recebe a componente de alta frequência em apenas um dos canais.

A medida é feita então através de duas pontas de prova. Uma colocada diretamente sobre a entrada do sinal de modulação no EOM, para medir $V_{E O M}$, e a outra na saída de ata frequência (HF) do detector para medir $v_{B}$. Os dois sinais foram visualizados num osciloscópio, e as amplitudes foram medidas através da função do osciloscópio que mede a tensão máxima das ondas mostradas no osciloscópio. As medidas foram feitas variando a frequência de modulação em passos de $1 \mathrm{MHz}$, de 10 a $20 \mathrm{MHZ}$. Através da equação 3.4, calculamos a fase para cada tensão e frequência, de cada EOM. Em seguida, construíram-se gráficos da fase, $\delta \phi$ em função da tensão de modulação, $V_{E O M}$. Para todas as frequências nos dois moduladores o comportamento da fase com a tensão de modulação foi linear. Na figura 3.7 temos exemplos do resultado para os dois modelos na frequência de $15 \mathrm{MHz}$.

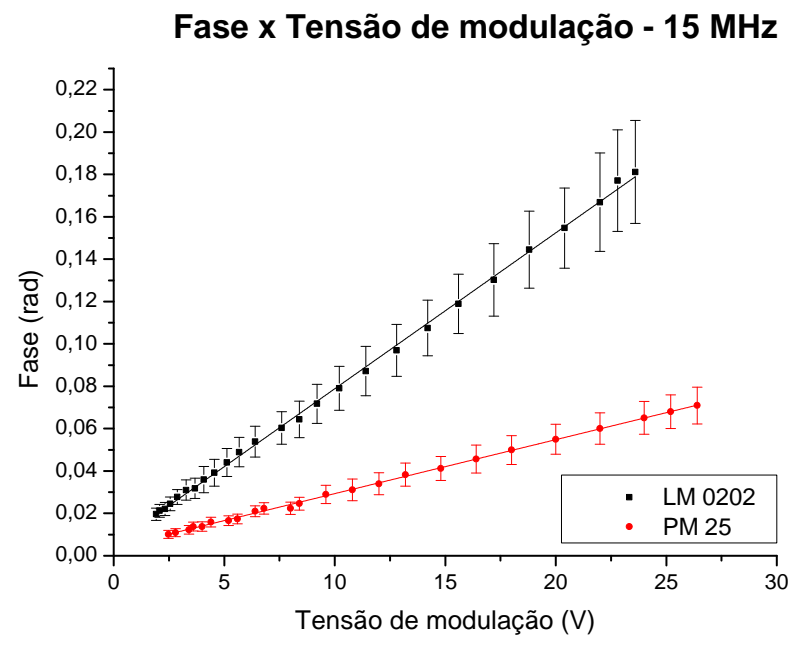

Figura 3.7: Exemplo do ajuste feito para a relação entre fase e tensão de modulação sobre o EOM.

Observamos que as equações de reta possuíam um coeficiente linear da mesma ordem de grandeza do coeficiente angular. Quando calculamos quanto este coeficiente representaria em tensão medida no osciloscópio, encontramos $(2,7 \pm 0,4) \mathrm{mV}$ para o PM 25 e $(3,1 \pm 0,4) \mathrm{mV}$ para o LM 0202. Como a equação teórica para o ganho (equação 3.3) não possui termo linear, atribuímos este coeficiente para um erro sistemático na medida, devido ao uso da função de medida do valor máximo no osciloscópio. Desprezando este termo, o coeficiente angular das retas corresponde ao ganho que procuramos. Os valores dos ganhos para os dois moduladores pode ser observado na figura 3.8 . 


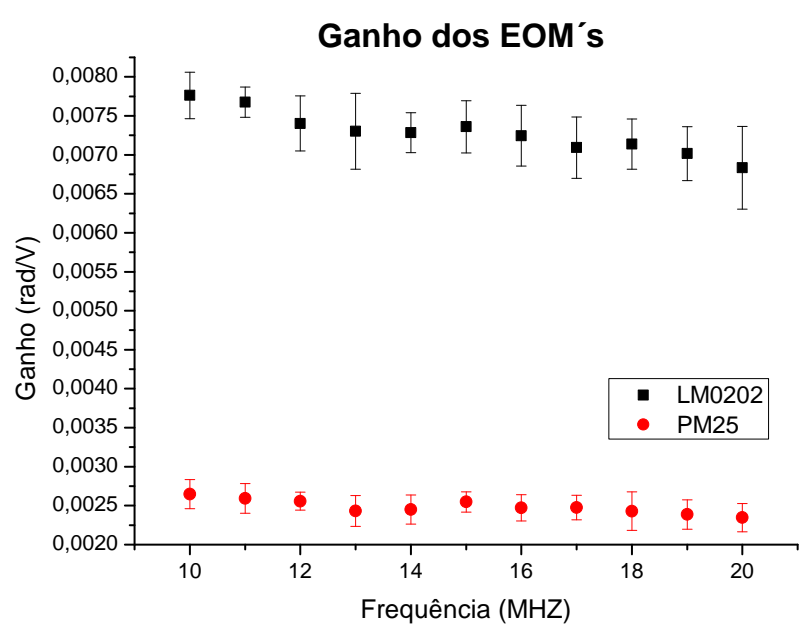

Figura 3.8: Gráficos do ganho dos EOMs em função da frequência de modulação.

Através desse gráfico, percebemos que o ganho tende a diminuir com o aumento da frequência. Como pretendemos utilizar os moduladores numa frequência de $15 \mathrm{MHz}$, na tabela 3.3 são mostrados os valores dos ganhos para esta frequência com as incertezas calculadas para os coeficientes no ajuste das retas.

\begin{tabular}{|c|c|}
\hline \multicolumn{2}{|c|}{ Ganho dos EOMs para a frequência de $15 \mathrm{MHz}$} \\
\hline \hline LM 0202 & $(7,4 \pm 0,3) \times 10^{-3} \mathrm{rad} /$ Volt \\
\hline PM 25 & $(2,5 \pm 0,1) \times 10^{-3} \mathrm{rad} /$ Volt \\
\hline
\end{tabular}

Tabela 3.3: Resultados das medidas de caracterização dos EOMs para 15 MHz.

A medida das perdas por transmissão nos EOMs também fez parte da caracterização. Foram encontrados valores de 3\% para o modelo PM 25 e 9\% para o LM 0202.

Com estes resultados esperamos ser capazes de produzir os efeitos desejados com os EOMs na modulação dos feixes de luz, etapa necessária tanto na preparação do estado a ser teletransportado por Vitor, como na reconstrução do estado por Bob.

\subsection{A fonte de estados EPR}

O sistema de teletransporte utilizará como fonte de estados EPR um Oscilador Paramétrico Óptico - OPO. Estes sistemas são compostos por um cristal com propriedades não lineares dentro de uma cavidade óptica. Quando um feixe de luz incide num cristal não linear, dentro de certas condições, é possível que ocorra um processo de conversão paramétrica descendente. Neste processo, um campo eletromagnético de frequência $\omega_{0}$, chamado de bombeio, é transformado pela interação com o cristal em dois outros campos, de frequências $\omega_{1}$ e $\omega_{2}$, chamados de sinal e complementar. Em nosso experimento, o feixe de bombeio terá frequência na região verde do espectro visível e os feixes sinal e complementar na região do infravermelho.

A conservação de energia é obedecida, já que as frequências dos três campos se relacionam da forma:

$$
\omega_{0}=\omega_{1}+\omega_{2}
$$


Os efeitos não lineares costumam ser muito fracos. Uma forma de contornar esta dificuldade é colocar o cristal dentro de uma cavidade óptica. Quando em ressonância, os campos dentro de uma cavidade interferem de forma construtiva sobre si mesmos, resultando no aprisionamento do campo dentro da cavidade e, or causa disso, podem atingir amplitudes muito maiores do que o campo de alimentação externo. Assim, o efeito não linear pode ser observado mais facilmente. Os OPOs podem ser construídos para serem ressonantes para qualquer um dos três campos, para dois deles ou para os três campos ao mesmo tempo. Estes OPOs são chamados respectivamente de Unicamente Ressonante (SROPO), Duplamente Ressonante (DROPO) ou Triplamente Ressonante (TROPO), e variam entre si com relação a várias características. Uma dessas características é o emaranhamento que ocorre devido à interação quântica entre os campos em um OPO, justamente o fenômeno necessário para formar o canal quântico do teletransporte. Devido à ressonância, os campos ficam aprisionados por um certo tempo dentro da cavidade, o que aumenta o tempo de interação e, com ele, as correlações entre os campos ressonantes. Em 2006, foi observado em nosso laboratório que um OPO triplamente ressonante operado acima do limiar gera emaranhamento entre os três campos (emaranhamento tripartite) [29]. Este OPO continua em funcionamento e poderia, a princípio, ser utilizado como fonte EPR para uso no teletransporte. No entanto, na medida em que o emaranhamento é distribuído para o feixe de bombeio, as correlações entre os feixes gêmeos ficam diminuídas. Como precisamos de máximo emaranhamento para a realização do teletransporte, decidiu-se pela construção de um novo OPO, duplamente ressonante entre os feixes gêmeos.

Os meios não lineares utilizados para a construção do OPO são cristais não centrosimétricos, apresentando uma alta não linearidade do tipo $\chi^{(2)}$ [28]. Entre as substâncias usualmente utilizadas estão, por exemplo, o titanil fosfato de potássio, $\mathrm{KTiOPO}$ ou KTP, e o niobato de lítio, $\mathrm{LiN} \mathrm{bO}_{3}$. Os cristais para uso dentro de cavidades ópticas podem ser fabricados com diversos tratamentos nas superfícies por onde se pretende que o feixes passem. Cristais monolíticos apresentam as duas faces ópticas tratadas para agir como espelhos, integrando em um único elemento a cavidade óptica e o meio não linear. Estes sistemas são muito estáveis mecanicamente, mas pouco flexíveis, uma vez que a geometria da cavidade é definida na fabricação do cristal. Por outro lado, quando o cristal não possui nenhuma face espelhada, são necessários dois espelhos externos para formar a cavidade. Nestes casos, em geral, as duas faces ópticas do cristal são tratadas para serem antirrefletoras, evitando perdas por reflexão dentro da cavidade. Estes sistemas são mais flexíveis, mas menos estáveis que o caso monolítico. Uma solução intermediária é o uso de um cristal semimonolítico, com apenas uma das superfícies ópticas com tratamento refletor. Atinge-se então um compromisso entre flexibilidade de geometria e a estabilidade da montagem. Neste caso, a face não espelhada precisa da mesma forma receber tratamento antirrefletor.

Na próxima subseção, 3.3.1, apresentaremos uma dedução teórica da relação de potências de um OPO duplamente ressonante. O resultado é importante na caracterização inicial deste tipo de OPO. Na seção seguinte, 3.3.2, mostro os resultados da construção e caracterização de um DROPO, que foi construído em nosso laboratório em meados de dezembro de 2012. A caracterização mostra que o OPO não atingiu os objetivos esperados. Por isso, a seção 3.3.3 estabelece os cálculos prévios necessários à construção já em andamento de um novo OPO, utilizando novos cristal e espelhos. 


\subsubsection{Teoria clássica do OPO Duplamente Ressonante}

A caracterização inicial de um OPO envolve a medida da relação entre as potências de entrada e saída do DROPO. Para isso, é preciso uma relação teórica para comparação e estimativa dos parâmetros. Na literatura encontra-se uma variedade de resultados para a mesma relação. Alguns autores simplesmente afirmam que a relação é linear, semelhante ao resultado para um laser, sem, no entanto, apresentar argumentos suficientes para tal afirmação [30, 31, 28]. Alguns artigos fornecem a resposta utilizando aproximações em primeira ordem, mas não apresentam a dedução detalhada [32, 33]. Por fim, encontra-se também uma relação obtida sem o uso de aproximações que, por ser transcendental, acaba sendo de pouca utilidade prática [34].

Usando uma estratégia análoga à apresentada por Debuisschert et al. [35] para o OPO Triplamente Ressonante, apresentamos um estudo teórico do Oscilador Paramétrico Óptico Duplamente Ressonante - DROPO para a obtenção da relação entre a potência de entrada e a potência de saída, cujo resultado está em concordância com Fabre et al. [32].

Um oscilador paramétrico óptico é formado genericamente por uma cavidade óptica, formada por dois ou mais espelhos, e por um cristal que compõe o meio não linear. Os espelhos permitem a ressonância do campo e o aumento da potência dentro da cavidade. Dessa forma os fracos efeitos não lineares podem ser alcançados com mais facilidade do que apenas com o meio não linear. O efeito não linear buscado corresponde à transformação do feixe de bombeio com frequência $\omega_{0}$ em dois outros feixes, chamados historicamente de sinal e complementar, de frequências $\omega_{1}$ e $\omega_{2}$, respectivamente.

Em termos de amplitudes complexas dos campos, os ganhos que estes sofrem quando de uma passagem pelo comprimento do cristal podem ser expressos em função da constante $\chi$, que é proporcional à susceptibilidade não linear $\chi^{(2)}$ e ao comprimento do cristal, $l$. Levando em conta que o efeito é muito pequeno, podemos considerar apenas termos de primeira ordem em $\chi$. Denotando as amplitudes na entrada do cristal como $\alpha_{i}(0)$, no meio do cristal como $\alpha_{i}$ e no final como $\alpha_{i}(l)$ (com i=0,1,2), as equações que representam uma passagem dos feixes pelo cristal são:

$$
\left\{\begin{array} { l } 
{ \alpha _ { 1 } ( l ) = \alpha _ { 1 } ( 0 ) + 2 i \chi \alpha _ { 0 } \alpha _ { 2 } ^ { * } } \\
{ \alpha _ { 2 } ( l ) = \alpha _ { 2 } ( 0 ) + 2 i \chi \alpha _ { 0 } \alpha _ { 1 } ^ { * } } \\
{ \alpha _ { 0 } ( l ) = \alpha _ { 0 } ( 0 ) + 2 i \chi \alpha _ { 1 } \alpha _ { 2 } }
\end{array} \quad \left\{\begin{array}{l}
\alpha_{1}=\alpha_{1}(0)+i \chi \alpha_{0} \alpha_{2}^{*} \\
\alpha_{2}=\alpha_{2}(0)+i \chi \alpha_{0} \alpha_{1}^{*} \\
\alpha_{0}=\alpha_{0}(0)+i \chi \alpha_{1} \alpha_{2}
\end{array}\right.\right.
$$

onde 1 corresponde ao campo do feixe de bombeio, 1 ao campo do feixe sinal e 2 ao campo do feixe complementar. Para esta abordagem simplificada, consideramos que o acordo de fase é perfeito, ou seja $\triangle k=k_{0}-k_{1}-k_{2}=0$.

Supondo uma cavidade de comprimento $L$, em uma volta completa cada campo sofre um deslocamento de fase dado por:

$$
\phi_{j}=\frac{\omega_{j}}{c}\left(n_{j} l+L\right)
$$

Numa situação estacionária, os ganhos e as perdas de cada campo devem ser equacionados. Fazendo isso, obtemos as equações para os campos após uma volta completa na cavidade: 


$$
\begin{aligned}
\alpha_{0} & =t_{0} \alpha_{0}^{i n}+i \chi \alpha_{1} \alpha_{2} \\
\alpha_{1}\left[1-r_{1} e^{i \phi_{1}}\right] & =2 i \chi \alpha_{0} \alpha_{2}^{*} r_{1} e^{i \phi_{1}} \\
\alpha_{2}\left[1-r_{2} e^{i \phi_{2}}\right] & =2 i \chi \alpha_{0} \alpha_{1}^{*} r_{2} e^{i \phi_{2}}
\end{aligned}
$$

, de forma que $t_{i}$ e $r_{i}$ são os coeficientes de transmissão e reflexão de amplitude para os campos elétricos, respectivamente.

Note-se que neste caso tratamos de um OPO duplamente ressonante em relação aos dois feixes gerados, o sinal e o complementar. A cavidade não é ressonante para o feixe de bombeio.

Para a manipulação das equações faremos uma série de suposições e mudanças de variáveis para facilitar a análise. Considerando uma situação de quase ressonância, podemos definir a dessintonia $\delta \phi_{j}$ da forma:

$$
\phi_{j}=2 p_{j} \pi+\delta \phi_{j}, \text { sendo } p_{j} \text { um inteiro. }
$$

Considerando que $\left|\delta \phi_{j}\right| \ll 2 \pi$, podemos desenvolver a exponencial em primeira ordem, o que nos dá $e^{i \phi_{j}}=1+\delta \phi_{j}$. Além disso, levando em conta que as transmissões de intensidade são pequenas para os feixes sinal e complementar, podemos fazer as seguintes aproximações para as reflexões e transmissões de amplitude:

$$
\begin{aligned}
r_{j} & =1-\gamma_{j} \\
t_{j} & =\sqrt{2 \gamma_{j}}
\end{aligned}
$$

Podemos ainda introduzir as perdas espúrias na forma de $\mu_{j}$ e definirmos um coeficiente de perdas totais $\gamma_{j}^{\prime}=\gamma_{j}+\mu_{j}$.

E por fim, definimos a dessintonia relativa como sendo:

$$
\triangle_{j}=\frac{\delta \phi_{j}}{\gamma_{j}^{\prime}}
$$

Com todas estas alterações, as equações 3.6, 3.7 e 3.8 ficam:

$$
\begin{aligned}
\alpha_{0} & =t_{0} \alpha_{0}^{i n}+i \chi^{*} \alpha_{1} \alpha_{2} \\
\alpha_{1} \gamma_{1}^{\prime}\left[1-i \triangle_{1}\right] & =2 i \chi \alpha_{0} \alpha_{2}^{*} \\
\alpha_{2} \gamma_{2}^{\prime}\left[1-i \triangle_{2}\right] & =2 i \chi \alpha_{0} \alpha_{1}^{*}
\end{aligned}
$$

Multiplicando a equação 3.10 pelo complexo conjugado da equação 3.11, pode-se isolar a parte complexa, que deve ser nula para uma condição de estabilidade. A condição para que a parte complexa seja nula e, portanto, para que haja oscilação dos campos na cavidade, é que:

$$
\triangle_{1}=\triangle_{2}=\triangle
$$

Supomos ainda que as perdas da cavidade são similares para os dois feixes infravermelhos $\gamma_{1}^{\prime}=\gamma_{2}^{\prime}=\gamma^{\prime}$.

Multiplicando a equação 3.10 pelo complexo conjugado da equação 3.11 obtemos: 


$$
\left|\alpha_{0}\right|^{2}=\frac{\gamma^{\prime 2}\left(1+\triangle^{2}\right)}{4|\chi|^{2}}
$$

Na condição de limiar, praticamente não há campo sinal ou complementar na cavidade. Neste caso, a equação 3.9 fica expressa como:

$$
\alpha_{0}=t_{0} \alpha_{0}^{i n}
$$

Juntando este resultado com a equação 3.12, e fazendo a dessintonia igual a zero, obtemos para a condição de limiar em ressonância:

$$
\left|\alpha_{0}^{i n}\right|_{L i m}^{2}=\frac{\gamma^{\prime 2}}{4 t_{0}^{2}|\chi|^{2}}
$$

Na situação acima do limar, vale a equação 3.9. Isolando $\alpha_{2}$ de 3.11 e substituindo em 3.9, temos:

$$
t_{0} \alpha_{0}^{i n}=\alpha_{0}\left(1+\frac{2 \chi^{2}\left|\alpha_{1}\right|^{2}}{\gamma^{\prime}(1-i \triangle)}\right)
$$

Tirando o módulo quadrado, obtemos

$$
t_{0}^{2}\left|\alpha_{0}^{i n}\right|^{2}=\left|\alpha_{0}\right|^{2}\left(1+\frac{4 \chi^{2}\left|\alpha_{1}\right|^{2}}{\gamma^{\prime}\left(1+\triangle^{2}\right)}+\frac{4 \chi^{4}\left|\alpha_{1}\right|^{4}}{\gamma^{\prime}\left(1+\triangle^{2}\right)}\right)
$$

Utilizando a equação 3.12 para substituir $\left|\alpha_{0}\right|^{2}$ e manipulando, temos:

$$
\frac{\left|\alpha_{0}^{i n}\right|^{2}}{\left|\alpha_{0}^{i n}\right|_{L i m}^{2}}=1+\triangle^{2}+\frac{\gamma^{\prime}\left|\alpha_{1}\right|^{2}}{t_{0}^{2}\left|\alpha_{0}^{i n}\right|_{L i m}^{2}}+\frac{1}{4}\left(\frac{\gamma^{\prime}\left|\alpha_{1}\right|^{2}}{t_{0}^{2}\left|\alpha_{0}^{i n}\right|_{L i m}^{2}}\right)^{2}
$$

Expressando o campo infravermelho através daquele que sai da cavidade como de $\left|\alpha_{1}^{\text {out }}\right|^{2}=2 \gamma\left|\alpha_{1}\right|^{2}$, ficamos com:

$$
\frac{\left|\alpha_{0}^{i n}\right|^{2}}{\left|\alpha_{0}^{i n}\right|_{\text {Lim }}^{2}}=1+\Delta^{2}+\frac{1}{2} \frac{\gamma^{\prime}}{\gamma t_{0}^{2}} \frac{\left|\alpha_{1}^{\text {out }}\right|^{2}}{\left|\alpha_{0}^{\text {in }}\right|_{\text {Lim }}^{2}}+\frac{1}{16}\left(\frac{\gamma^{\prime}}{\gamma t_{0}^{2}}\right)^{2}\left(\frac{\left|\alpha_{1}^{\text {out }}\right|^{2}}{\left|\alpha_{0}^{\text {in }}\right|_{\text {Lim }}^{2}}\right)^{2}
$$

Levando em conta que os módulos quadrados das amplitudes dos campos são equivalentes ao fluxo de fótons, podemos relacioná-los às potências através de:

$$
P=\hbar \omega|\alpha|^{2}
$$

Então, podemos fazer as substituições: 


$$
\begin{gathered}
\sigma=\frac{P_{0}^{i n}}{P_{\text {Lim }}^{\text {in }}}=\frac{\left|\alpha_{0}^{i n}\right|^{2}}{\left|\alpha_{0}^{i n}\right|_{\text {Lim }}^{2}} \\
\sigma_{1}=\frac{P_{1}^{\text {out }}}{P_{\text {Lim }}^{\text {in }}}=\frac{\omega_{1}\left|\alpha_{1}^{\text {out }}\right|^{2}}{\omega_{0}\left|\alpha_{0}^{i n}\right|_{\text {Lim }}^{2}}
\end{gathered}
$$

Obtemos:

$$
\sigma=1+\triangle^{2}+\frac{1}{2 t_{0}^{2}} \frac{\gamma^{\prime}}{\gamma} \frac{\omega_{0}}{\omega_{1}} \sigma_{1}+\left(\frac{1}{4 t_{0}^{2}} \frac{\gamma^{\prime}}{\gamma} \frac{\omega_{0}}{\omega_{1}}\right)^{2} \sigma_{1}^{2}
$$

Resolvendo a equação de segundo grau e utilizando o resultado com solução positiva:

$$
\sigma_{1}=4 t_{0}^{2}\left(\frac{\gamma}{\gamma^{\prime}} \frac{\omega_{0}}{\omega_{1}}\right)\left[\sqrt{\sigma-\triangle^{2}}-1\right]
$$

Em termos das potências que medimos fora da cavidade, temos então,

$$
P_{1}^{\text {out }}=4 t_{0}^{2}\left(\frac{\gamma}{\gamma^{\prime}} \frac{\omega_{0}}{\omega_{1}}\right) P_{\operatorname{Lim}}^{i n}\left(\sqrt{\frac{P_{i n}}{P_{L i m}^{i n}}}-1\right)
$$

Por fim, considerando que o comprimento de onda dos feixes gêmeos é praticamente o dobro do relativo ao bombeio, e somando as potências dos dois feixes, temos:

$$
P_{\text {total }}^{\text {out }}=4 t_{0}^{2}\left(\frac{\gamma}{\gamma^{\prime}}\right) P_{\text {Lim }}^{\text {in }}\left(\sqrt{\frac{P_{\text {in }}}{P_{\text {Lim }}^{\text {in }}}}-1\right)
$$

Esta equação mostra como a potência de geração dos feixes sinal e complementar varia com a raiz quadrada da potência de bombeio.

\subsubsection{Construção e caracterização do DROPO}

A construção do OPO em nosso laboratório envolveu os esforços meus e de minha colega estudante de doutorado Paula Sampaio Meirelles em vários processos preparatórios, em especial na compra e projeto de peças e materiais durante todo o ano de 2011. Ao final do ano recebemos a visita do então estudante de doutorado do laboratório Kastler-Brossel, em Paris, e hoje pós-doutorando em nosso grupo, Renné Medeiros Araújo, que então tomou a frente da construção. A equipe conseguiu finalizar a construção do OPO, obtendo a oscilação do OPO em meados de Dezembro de 2011.

Este OPO foi construído na geometria linear, como esquematizado na figura 3.9. Utilizou-se um cristal de KTP, semimonolítico, da marca Litton, com $1 \mathrm{~cm}$ de comprimento, $3 \mathrm{~mm}$ de altura e $3 \mathrm{~mm}$ de largura. A face espelhada do cristal possui uma transmitância de $T_{1064}=2,5 \times 10^{-4}$ para comprimentos de onda de $1064 \mathrm{~nm}$ e é também altamente refletora para o $532 \mathrm{~nm}$, com uma transmitância de $T_{532}=0,03$. A outra face do cristal é tratada para ser antirrefletora, com o objetivo de eliminar ao máximo as perdas intracavidade. Para completar a cavidade do OPO, utilizamos um espelho com a face interna também altamente refletora para $1064 \mathrm{~nm}$. Embora não tão refletora quanto a 


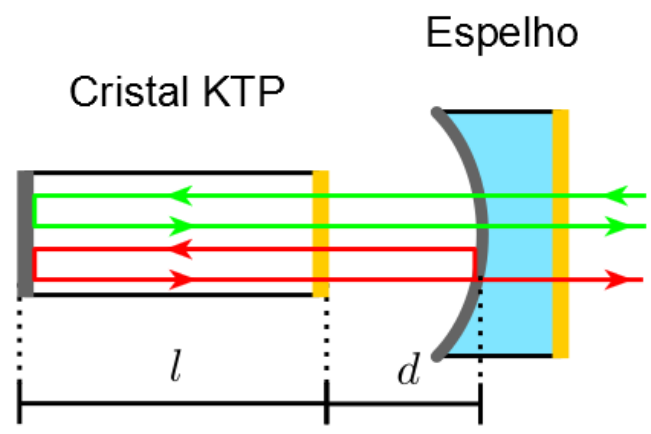

Figura 3.9: Esquema dos elementos ópticos do OPO, mostrando as coberturas refletoras (cinza) e antirrefletoras (amarelo) para o infravermelho.
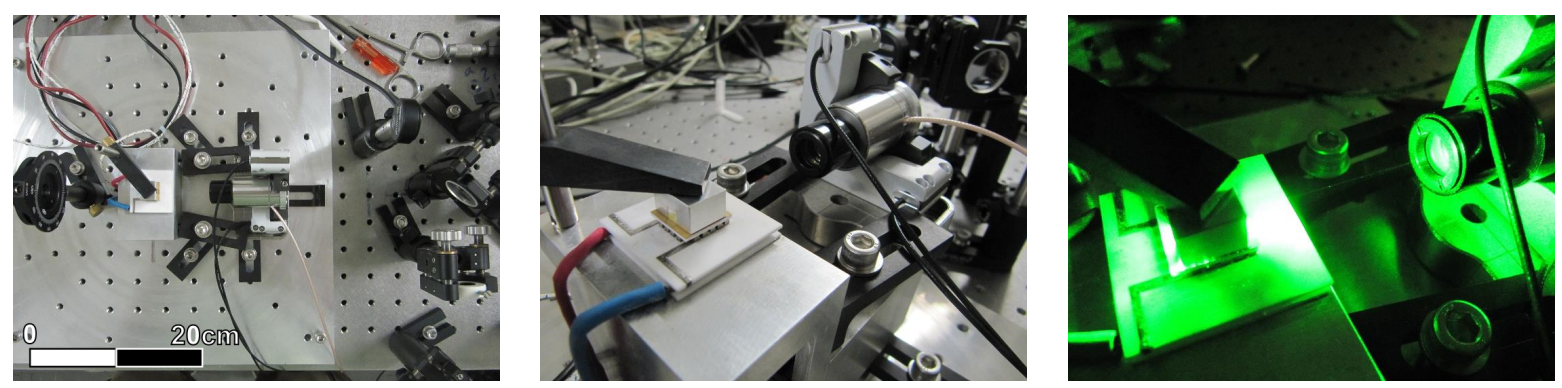

Figura 3.10: Fotografias do DROPO construído. Na primeira imagem temos uma vista superior, na segunda uma vista lateral e na terceira uma vista lateral aproximada do OPO com o feixe de bombeio incidindo na cavidade. Observa-se o cristal dentro de um bloco de alumínio para dissipação do calor. O espelho externo é acoplado a um dispositivo piezoelétrico (PZT) para permitir o controle do tamanho da cavidade e consequente varredura e travamento.

face do cristal, sua transmitância de $T_{1064}=0,0336$ é suficiente para permitir a saída dos feixes gêmeos para uso no teletransporte. Para $532 \mathrm{~nm}$, esta face é um pouco refletora, com a transmitância em $T_{532}=0,829$, e assim permite a entrada do feixe de bombeio. A face externa deste espelho possui uma cobertura antirrefletora para ambos os comprimentos de onda. Devido às configurações de transmitâncias dos espelhos, 0 OPO é ressonante para os feixes gêmeos, mas não é ressonante para o feixe de bombeio, caracterizando-se então como um OPO duplamente ressonante.

Com um raio de curvatura de $50 \mathrm{~mm}$, o espelho foi posicionado a uma distância aproximada de $40 \mathrm{~mm}$ da face antirrefletora do cristal, formando uma cavidade quasiconcêntrica. Este espelho foi montado sobre um PZT, para permitir variar e controlar o tamanho da cavidade do OPO na escala micrométrica. Com esta configuração, calculamos o acordo de modo para $1064 \mathrm{~nm}$ com o objetivo de obter uma cintura de $51 \mu \mathrm{m}$, posicionada na face refletora do cristal e um comprimento de Rayleigh de $z_{0}=7 \mathrm{~cm}$. $\mathrm{O}$ acordo de modo para $532 \mathrm{~nm}$ foi calculado para que o comprimento de Rayleigh coincidisse com o do modo infravermelho, resultando numa cintura de $36 \mu \mathrm{m}$. Na figura 3.10, podem-se observar fotografias do DROPO terminado e em funcionamento.

Após um alinhamento sistemático e cuidadoso, obtivemos a oscilação do OPO, ou seja, a criação de feixes gêmeos infravermelhos através do bombeamento com feixe de luz verde. Na figura 3.11 observa-se uma captura de tela do osciloscópio ligado ao detector, mostrando a presença de picos de geração de feixes gêmeos na medida em que o PZT varre o comprimento da cavidade. 

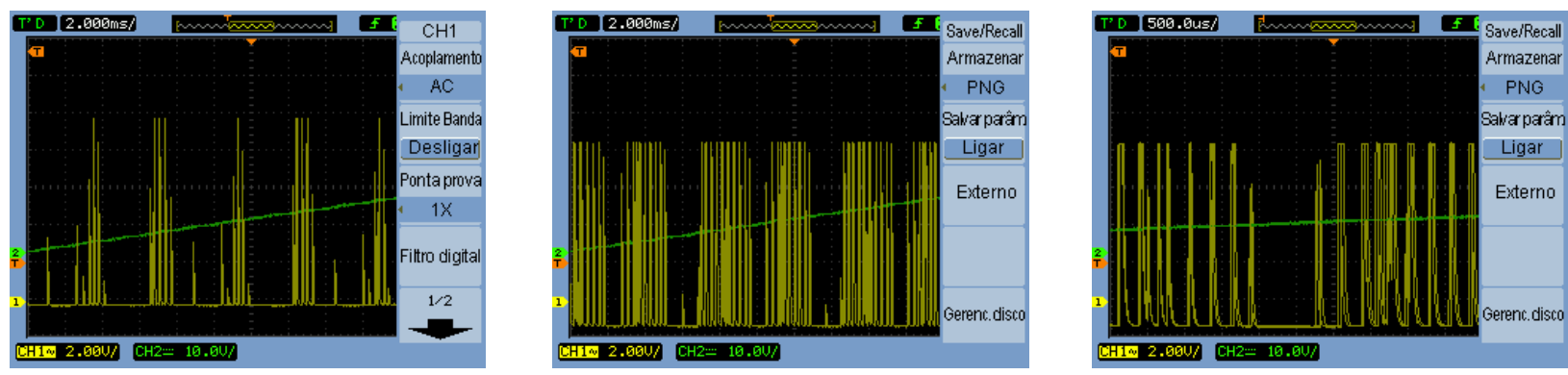

Figura 3.11: Capturas de tela do osciloscópio mostrando os picos de luz infravermelha detectados durante a varredura da cavidade do OPO. Na primeira imagem o OPO se encontra perto do limiar de oscilação. Na segunda, com o aumento da potência, percebe-se a ampliação do pente de frequências e a saturação do detector, conforme a geração de luz infravermelha é aumentada. Na última imagem temos uma ampliação da escala para melhor visualização dos picos.

\subsubsection{A potência de limiar do DROPO}

Após a obtenção da oscilação do DROPO, o limiar de oscilação foi minimizado através da otimização do alinhamento e obtivemos uma potência de limiar final de $P_{t h}^{(2)}=129 \mathrm{~mW}$. Em outro OPO já em uso em nosso laboratório, a potência de limiar é de $P_{t h}^{(3)}=70 \mathrm{~mW}$ à temperatura ambiente [36]. Como este OPO é triplamente ressonante, é esperado que possua um limiar mais baixo. As expressões teóricas para os limiares dos OPOs são:

$$
\begin{aligned}
& P_{t h}^{(2)}=\frac{\gamma^{\prime 2}}{2 t_{0}^{2}|\chi|^{2}} \\
& P_{t h}^{(3)}=\frac{\gamma_{0}^{\prime 2} \gamma_{1}^{\prime} \gamma_{2}^{\prime}}{8 \gamma_{0}|\chi|^{2}}
\end{aligned}
$$

Sendo que a equação para o limiar do DROPO foi obtida na seção 3.3.1 (equação 3.13), levando em conta que na situação experimental o feixe de bombeio passa duas vezes pelo cristal. A equação para o TROPO se encontra na referência [35].

Atribuindo os valores teóricos aos coeficientes para o os dois $\mathrm{OPOs}^{3}$, obtemos a seguinte razão:

$$
\frac{P_{t h}^{(2)}}{P_{t h}^{(3)}}=30 \cdot \frac{\left|\chi_{(3)}^{\prime}\right|^{2}}{\left|\chi_{(2)}^{\prime}\right|^{2}}=\frac{129}{70}=1,8
$$

Onde o coeficiente de acoplamento independente do cristal dado por $\left|\chi^{\prime}\right|^{2}=|\chi|^{2} / l^{2}$. Como resultado desta análise, observamos que

$$
\chi_{(2)}^{\prime} \simeq 4 \chi_{(3)}^{\prime}
$$

A diferença entre os dois coeficientes está relacionada às diferentes configurações espaciais dos feixes nos dois OPOs. Enquanto no TROPO o comprimento de Rayleigh calculado pela geometria da cavidade é de $z_{0}=22 \mathrm{~mm}$, no DROPO buscou-se otimizar

\footnotetext{
${ }^{3}$ Os valores dos coeficientes $\gamma_{i}^{\prime}$ para o TROPO foram calculados através dos dados para as finesses. Estas, bem como os outros parâmetros necessários, foram obtidos de [36].
} 


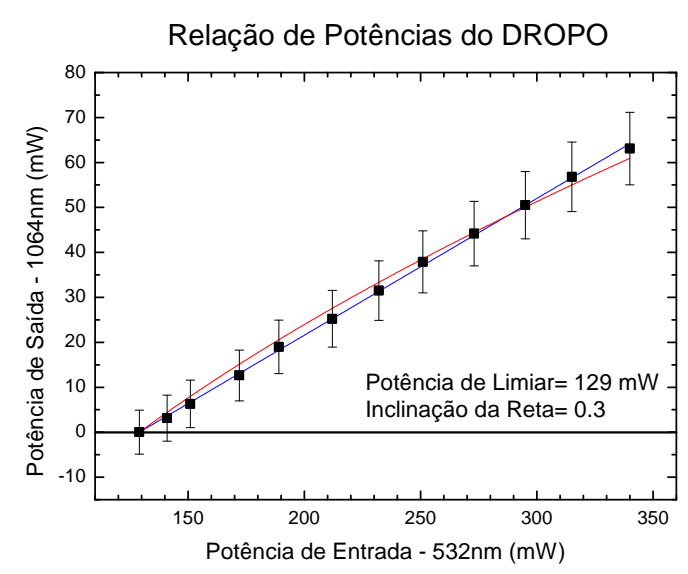

Figura 3.12: Relações de potência do DROPO. A linha azul é um ajuste linear e a linha vermelha é o ajuste da relação 3.14, proporcional à raiz quadrada da potência de entrada.

o acordo de modo, aproximando o comprimento de Rayleigh do comprimento do cristal, fazendo $z_{0}=7 \mathrm{~mm}$. A razão entre os dois valores fica próxima de 4 , o que explica a diferença entre os coeficientes de acoplamento. A relevância deste resultado é que, estando os dois coeficientes dentro da mesma ordem de grandeza, o DROPO se mostra compatível com a potência de bombeio disponível em nosso laboratório $(600 \mathrm{~mW})$.

\subsubsection{Relações de Potência do DROPO}

Em seguida, medimos a potência de saída do OPO, formada pelos dois feixes sinal e complementar, em função da potência de entrada (bombeio) no OPO. Para realizar a medida, o OPO foi colocado em varredura, e o valor em tensão do maior dos picos no osciloscópio foi considerado como relativo à potência dos feixes. A conversão do valor de tensão medido no osciloscópio em potência levou em conta o ganho líquido do detector $^{4}, 0,453 \mathrm{~V} / \mathrm{mW}$, e a transmissividade do filtro necessário para evitar a saturação do detector, $T=0,35$. A potência do feixe de bombeio foi medida com medidor de potência ${ }^{5}$. Os resultados das medidas são mostrados no gráfico da figura 3.12.

Os pontos experimentais poderiam sugerir que a relação é linear. De fato, é possível encontrar várias referências que afirmam a linearidade da relação [30, 31, 28]. No entanto, nenhuma destas referências faz a dedução da equação. Levando em conta apenas a primeira ordem da aproximação, a dedução fornece, de fato, uma relação em que a potência de saída depende da raiz quadrada da potência de entrada, conforme a equação 3.14, demonstrada no capítulo 3.3.1, e também como afirmado nos artigos de C. Fabre, P. F. Cohadon e C. Schwob [33, 32]. Tendo em vista a margem de erro experimental, não se pode afirmar qual das duas expressões teóricas melhor descreve o fenômeno físico.

\subsubsection{Finesse do DROPO}

A finesse de uma cavidade óptica é medida da qualidade da cavidade. Pode ser definida como a razão entre o intervalo espectral livre e a largura de banda da cavidade [37].

\footnotetext{
${ }^{4}$ Detector modelo PDA 36A, fabricado pela Thorlabs. O detector possui sensibilidade de resposta de $0,3 \mathrm{~mA} / \mathrm{mW}$ e, com a chave de ganho na posição " 0 ", uma resposta de ganho de $1,51 \mathrm{~V} / \mathrm{mA}$. Nesta situação a incerteza na medida é de $2 \%$.

${ }^{5}$ Medidor de potência modelo PM100D com sensor modelo S121C, ambos fabricados pela Thorlabs. A incerteza do aparelho nestas condições de medida é de $3 \%$.
} 


$$
\mathbb{F}=\frac{F S R}{B W}
$$

A finesse máxima teórica é calculada, considerando espelhos de alta reflexão, através da fórmula:

$$
\mathbb{F}=\frac{2 \pi}{T}
$$

Onde $\mathbb{F}$ é a finesse e $T$ é a transmitância do espelho de saída, correspondendo ao caso ideal em que todas as perdas da cavidade são perdas úteis, formando o feixe de luz transmitido para fora da cavidade. Como a transmitância do espelho de saída é de 0,0336, a finesse teórica máxima fica em $\mathbb{F}=187$.

A finesse é experimentalmente determinada através da medida da largura de banda e do intervalo espectral livre no osciloscópio, durante a varredura da cavidade. O melhor resultado medido para a finesse, obtido após vários ajustes, foi $\mathbb{F}=133$. Isso implica em 1,3 \% de perdas espúrias. Nesta configuração, as perdas úteis correspondem a apenas $72 \%$ das perdas totais. Estes valores comprometeram a viabilidade de se utilizar este OPO para o projeto de teletransporte. Vejamos como podemos chegar a esta conclusão.

\subsubsection{A compressão e a fidelidade teóricas para um OPO}

A fidelidade do teletransporte em banda larga é tão maior quanto maior for o squeezing (ou compressão) produzido pela fonte de estados emaranhados. Este squeezing depende de alguns fatores construtivos, de acordo com o espectro de subtração de ruídos de intensidade [38], mostrado abaixo:

$$
S_{\hat{p}-}=1-\frac{\gamma}{\gamma^{\prime}}\left(\frac{1}{1+\Omega^{\prime 2}}\right)
$$

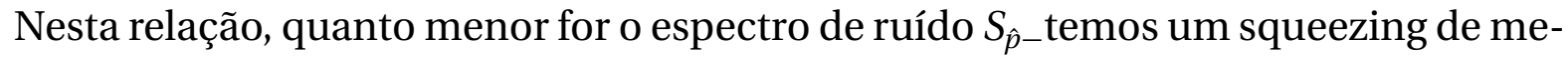
lhor qualidade. Ao manipularmos a equação 3.17 para incluir valores que podemos medir, chegamos à:

$$
S_{\hat{p}-}=1-\frac{T}{T+A}\left(\frac{1}{1+\left(\frac{2 \pi v_{\text {análise }}}{v_{F S R}(T+A)}\right)^{2}}\right)
$$

Onde $T=0,0336$ é a transmitância do espelho de saída, $A$ corresponde às perdas espúrias, $v_{\text {análise }}=15 \mathrm{MHz}$ é a frequência de análise que pretendemos utilizar para a medida e $v_{F S R}=2,62 \mathrm{GHz}$ é o intervalo espectral livre da cavidade do OPO. O valor do ruído da subtração das intensidades fica então em $S_{\hat{p}-}=54 \%$. Logo abaixo, mostrase um gráfico de espectros de ruído da subtração de quadraturas de intensidade para vários valores de perdas espúrias.

Utilizaremos o valor do ruído da subtração das intensidades para estimar a fidelidade máxima possível com este sistema. Consideraremos que o OPO opera acima mas ainda próximo do limiar de operação. Assim podemos considerar que

$$
V_{t e l, i n}^{\hat{X}} \simeq V_{t e l, i n}^{\hat{P}}=2 S_{-}(\Omega)
$$

E, seguindo a análise da seção 2.4.1, baseada no artigo de von Loock et al. [14], a fidelidade é então: 


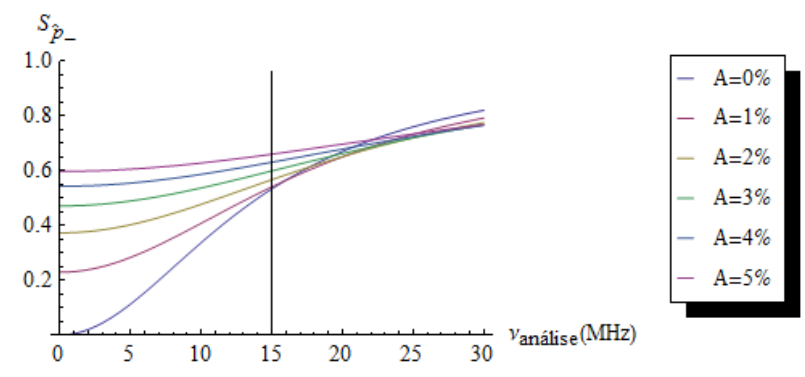

Figura 3.13: Espectro de ruído de subtração de quadraturas de intensidade em função das perdas espúrias. De baixo para cima, aumentam-se as perdas espúrias de $0 \%$ até $5 \%$. A linha vertical marca a frequência de análise que pretendemos utilizar (15 MHz).

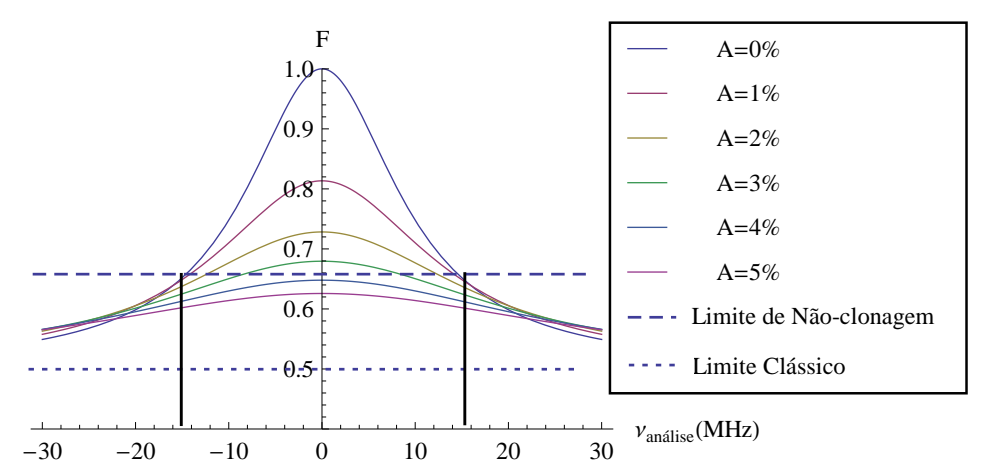

Figura 3.14: Fidelidade do teletransporte para o OPO de acordo com o percentual de perdas espúrias com relação ao campo total dentro da cavidade, "A". Mostra-se também os limites para o teletransporte clássico, $F \leq \frac{1}{2}$ [21], e o limite de não clonagem, $F \geq \frac{2}{3}$ [23]. A linhas verticais representam a frequência de análise que pretendemos utilizar.

$$
F=\frac{1}{1+S_{-}}
$$

E utilizando o valor obtido anteriormente para o ruído de subtração das intensidades, a fidelidade teórica máxima para o teletransporte com este OPO é $F_{\text {max }}=65 \%$. Na figura 3.14, temos um gráfico da fidelidade máxima em função da frequência de análise. Como ainda teremos perdas na detecção, os valores sao muito baixos para a realização bem sucedida do teletransporte. É possível perceber que com este OPO estaríamos trabalhando no limite para conseguir obter uma fidelidade acima do limite de não clonagem, que é de $2 / 3 \simeq 0,66$.

Como as tentativas de diminuição das perdas espúrias através do alinhamento não foram bem sucedidas, investigamos outras possíveis causas. Descobrimos, por fim, que a face antirrefletora do cristal estava com manchas, o que indica uma deterioração da cobertura antirrefletora. Estas manchas explicam os valores demasiadamente grandes para as perdas espúrias. O uso deste cristal para compor um OPO para teletransporte fica inviabilizado. O laboratório possui outro cristal possível de ser utilizado para compor um OPO. No entanto, como ele não é semi-monolítico, foi necessário projetar um novo OPO. 


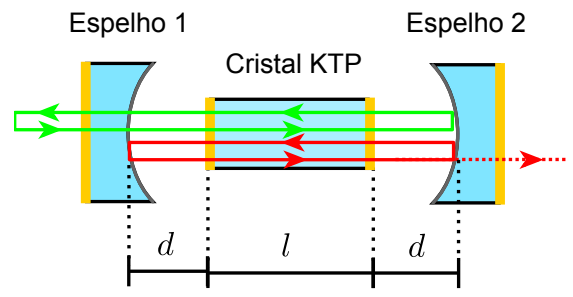

Figura 3.15: Esquema do novo DROPO.

\subsubsection{O projeto do novo OPO}

O cristal que vamos utilizar para a construção do novo OPO é também um cristal de KTP, da marca Raicol. Como as duas faces desse cristal são antirrefletoras, foram adquiridos novos espelhos para serem utilizados em conjunto com ele. O novo OPO será simétrico, configurado como na figura 3.15.

As coberturas dos espelhos possuem duas configurações de acordo com a tabela 3.4.

\begin{tabular}{|c|c|c|c|c|}
\hline Espelho & \multicolumn{2}{|c|}{1} & \multicolumn{2}{c|}{2} \\
\hline Face & Externa & Interna & Interna & Externa \\
\hline \hline$T_{532}$ & $99,9 \%$ & $97,4 \%$ & $0,0148 \%$ & n. a. \\
\hline$T_{1064}$ & n. a. & $0,0169 \%$ & $5,12 \%$ & $99,9 \%$ \\
\hline
\end{tabular}

Tabela 3.4: Coeficientes de transmissão de intensidade dos novos espelhos fornecidos pelo fabricante (ATFilms).

Os espelhos foram adquiridos com raios de curvatura pequenos, entre $1 \mathrm{~cm}$ e $5 \mathrm{~cm}$. O objetivo é diminuir o tamanho da cavidade, o que proporciona uma maior largura de banda para o OPO e consequentemente um maior squeezing. Supondo uma cavidade simétrica, onde $l=12 \mathrm{~mm}$ é o comprimento do cristal e $d$ é a distância dos espelhos às faces do cristal, podemos estimar as características clássicas da cavidade. A estabilidade da cavidade é dada pela equação 3.2, $\operatorname{com} L_{d i f}=2 d+l / n=2 d+\frac{12 \mathrm{~mm}}{1,78}$ correspondendo ao comprimento de difração da cavidade, e $R$ o raio de curvatura dos espelhos.

Na figura 3.16, mostra-se as curvas para o critério de estabilidade do OPO, $\left(1-\frac{L_{d i f}}{R}\right)^{2}$, em função da distância dos espelhos às faces do cristal. São mostradas três curvas, uma para cada raio de curvatura dos espelhos adquiridos. Para que a cavidade seja estável, é necessário que o valor do critério fique entre zero e um, podendo ser também igual a estes valores.

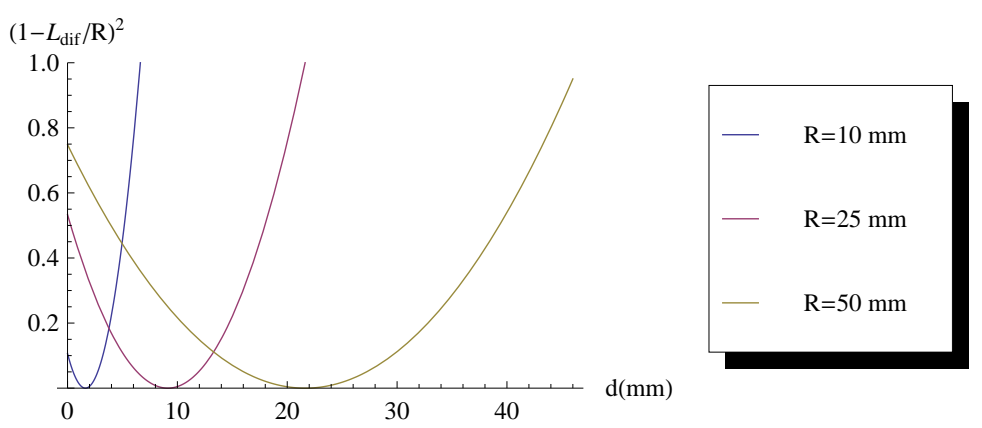

Figura 3.16: Valores para o critério de estabilidade da cavidade do OPO para espelhos com raio de curvatura igual a $10 \mathrm{~mm}, 25 \mathrm{~mm}$ e $50 \mathrm{~mm}$. 
Na tabela 3.5 temos os intervalos de estabilidade para cada um dos raios de curvatura dos espelhos.

\begin{tabular}{|c|c|}
\hline $\mathrm{R}(\mathrm{mm})$ & Condições de estabilidade \\
\hline \hline 10 & $0 \leq d \leq 6,63 \mathrm{~mm}$ \\
\hline 25 & $0<\leq d \leq 21,6 \mathrm{~mm}$ \\
\hline 50 & $0 \leq d \leq 46,6 \mathrm{~mm}$ \\
\hline
\end{tabular}

Tabela 3.5: Condições de estabilidade para o novo OPO.

Para que o processo de conversão paramétrica ocorra no cristal de forma eficiente, é necessário que os feixes estejam corretamente focalizados dentro dele. Podemos controlar a focalização do feixe no cristal através do comprimento de difração, $z_{0}$. Na distância entre a cintura e o valor de $z_{0}$, o feixe pode ser considerado com uma onda plana. Assim, é desejável que o comprimento de difração seja ao menos a metade do tamanho efetivo do cristal $\left(z_{0}=\frac{l_{\text {eff }}}{2}=3,4 \mathrm{~mm}\right)$ [28], onde o tamanho efetivo, levando em conta os efeitos da difração, é $l_{\text {eff }}=\frac{l}{n}$. Assim, teríamos uma onda aproximadamente plana nesta região, com a cintura no centro do cristal, e dois comprimentos de Rayleigh, um para cada lado a partir do centro. Um cálculo mais preciso foi feito por Boyd\&Kleinman, que otimiza a conversão paramétrica e mostra que a relação ideal entre o comprimento de difração e o comprimento do cristal é [28]:

$$
z_{0}=\frac{l_{\text {eff }}}{5,68}
$$

Uma vez que o comprimento do cristal é de $12 \mathrm{~mm}$, sabemos que o valor para o comprimento de difração ideal é $z_{0}=1,2 \mathrm{~mm}$. Abaixo deste valor, a difração aumenta muito e o acordo de fase fica comprometido. Para calcular comprimento de difração em função da configuração do OPO utilizamos a expressão abaixo:

$$
4 z_{0}^{2}=\left(2 R-L_{d i f}\right) L_{d i f}
$$

O comportamento de $z_{0}$ com a distância dos espelhos às faces do cristal é mostrado na figura3.17.

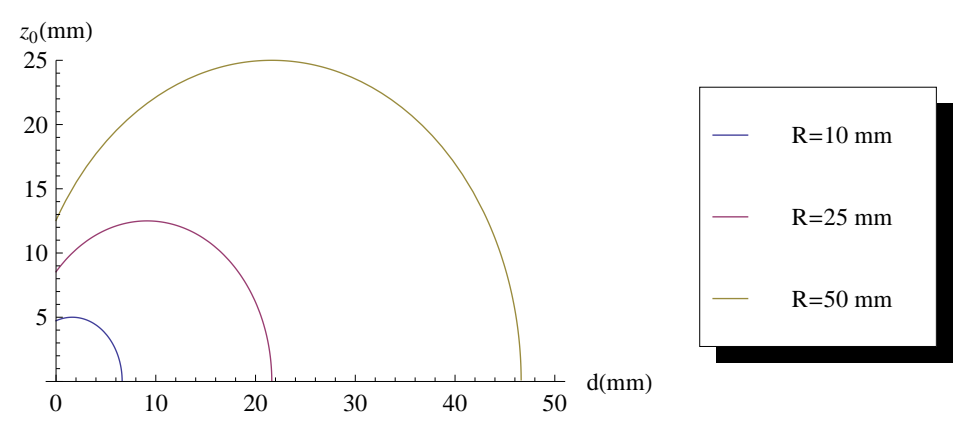

Figura 3.17: Comprimento de difração em função da distância dos espelhos às faces do cristal.

Queremos que o comprimento de difração do OPO fique entre os valores definidos pelos dois critérios. Na tabela são mostradas as faixas que $d$ pode assumir para tanto. 


\begin{tabular}{|c|c|c|}
\hline & \multicolumn{2}{|c|}{$\mathrm{d}(\mathrm{mm})$} \\
\hline $\mathrm{R}(\mathrm{mm})$ & $z_{0}=\frac{l_{\text {eff }}}{2}$ & $z_{0}=\frac{l_{\text {eff }}}{5.68}$ \\
\hline 10 & \multicolumn{2}{|c|}{$5,3<d<6,5$} \\
\hline 25 & \multicolumn{2}{|c|}{$21,2<d<21,6$} \\
\hline 50 & \multicolumn{2}{|c|}{$46,4<d<46,6$} \\
\hline
\end{tabular}

Tabela 3.6: Faixas de distâncias dos espelhos às faces do cristal para que o OPO atenda aos critérios de Boyd\&Kleinman e Confocal.

Todas estas faixas para $d$ atendem ao critério de estabilidade para a cavidade do OPO, sendo que para cada um deles teremos uma largura de banda diferente e, por consequência, diferentes fidelidades possíveis.

Fazendo as perdas espúrias nulas, $\mu=0$, na equação 3.18, podemos estimar o valor do ruído mínimo para uma frequência de análise de $v_{\text {análise }}=15 \mathrm{MHz}$. Temos então, utilizando os valores para $d$ obtidos através do critério de Boyd\&Kleinman, os resultados para o valor do ruído para a subtração das intensidades, e para a fidelidade máxima mostrados na tabela 3.7.

\begin{tabular}{|c|c|c|c|}
\hline$R(\mathrm{~mm})$ & $d(\mathrm{~mm})$ & $S_{\hat{p}_{-}}^{\text {min }}$ & $F^{\text {max }}$ \\
\hline \hline 10 & 6,5 & $4,5 \%$ & $96 \%$ \\
\hline 25 & 21,6 & $14 \%$ & $87 \%$ \\
\hline 50 & 46,6 & $34 \%$ & $75 \%$ \\
\hline
\end{tabular}

Tabela 3.7: Valores de ruído mínimo e da fidelidade máxima para teletransporte com o novo OPO, de acordo com o espelho que se escolha utilizar.

O espelho que permite atingir uma maior fidelidade é o com $R=10 \mathrm{~mm}$. Na figura 3.18 temos um exemplo de gráfico da fidelidade teórica em função da frequência de análise para este espelho. Nota-se claramente que teremos uma situação favorável para superar o limite de não clonagem e alcançar altas fidelidades, se compararmos com os resultados para o OPO antigo. Os fatores que contribuem para isso são uma cavidade menor, possibilitado pelos pequenos raios de curvatura escolhidos, juntamente com o uso de espelhos com uma transmitância para o infravermelho um pouco maior, de 3\% para $5 \%$, sendo que ambos os fatores contribuem para que o novo OPO possua uma maior largura de banda.

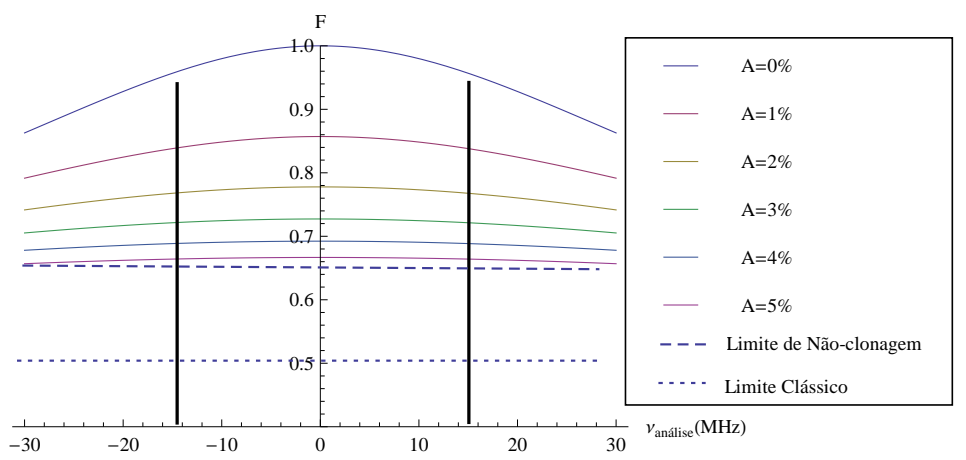

Figura 3.18: Fidelidade teórica em função da frequência de análise. Foram utilizados como parâmetros, $R=10 \mathrm{~mm}, d=6,5 \mathrm{~mm}$ e $T_{1064}=5 \%$. O parâmetro "A" corresponde às possíveis perdas espúrias da cavidade. As linhas pretas verticais representam a frequência de análise, $15 \mathrm{MHz}$. 


\section{Capítulo 4}

\section{O Projeto de Teletransporte do LMCAL}

No capítulo anterior foram apresentados três elementos fundamentais para o projeto de teletransporte de informação quântica do LMCAL, as cavidades ópticas, os moduladores eletro-ópticos e o OPO. Tendo introduzido o funcionamento destes componentes, passamos neste capítulo a mostrar como eles serão integrados no processo geral de teletransporte. O processo será descrito teoricamente, levando em conta a necessidade de expressar o emaranhamento nas bandas laterais do espectro dos campos envolvidos. Detalhes particulares de nossa abordagem experimental, especialmente aqueles envolvendo a necessidade das cavidades ópticas, também serão incluídos. Na figura 4.1 mostramos um diagrama detalhado do projeto de teletransporte, e deverá servir de referência visual para o restante do capítulo.

\subsection{Teoria do teletransporte com bandas laterais}

\subsubsection{Descrição do campo eletromagnético com bandas laterais}

O teletransporte em variáveis contínuas descrito na seção 2.2 é uma dedução teórica de como o teletransporte pode ser realizado. Nesta descrição, o emaranhamento foi produzido considerando os campos compostos por apenas uma frequência. Toda a intensidade do campo está localizada em apenas uma frequência, e podemos representar esta localização como uma função delta de Dirac no espectro das frequências. A figura 4.2 mostra uma ilustração desta representação, no lado esquerdo. A frequência onde se concentra o transporte de energia do campo é chamada de frequência da onda portadora.

Os campos eletromagnéticos, no entanto, possuem uma natureza mais complexa. É preciso uma descrição que leve em conta, em primeira instância, as flutuações do vácuo quântico que existem em todas as frequências. As regiões do espectro acima e abaixo da frequência da portadora são chamadas de bandas laterais. Na figura 4.2, a imagem à direita ilustra o ruído quântico relativo ao vácuo, presente em todas as frequências do espectro. Por abranger todo o espectro, este ruído é chamado de ruído branco. A existência de bandas laterais do campo permite a produção de emaranhamento entre essas porções do espectro e, subsequentemente, a realização de teletransporte com base neste tipo de emaranhamento.

A eletrônica de detecção possui uma capacidade espectral limitada de medir as bandas laterais. A largura da banda de detecção é de $600 \mathrm{KHz}$, centralizada sobre a frequência de demodulação do sistema [36]. Em nosso caso, a frequência de demodulação será 


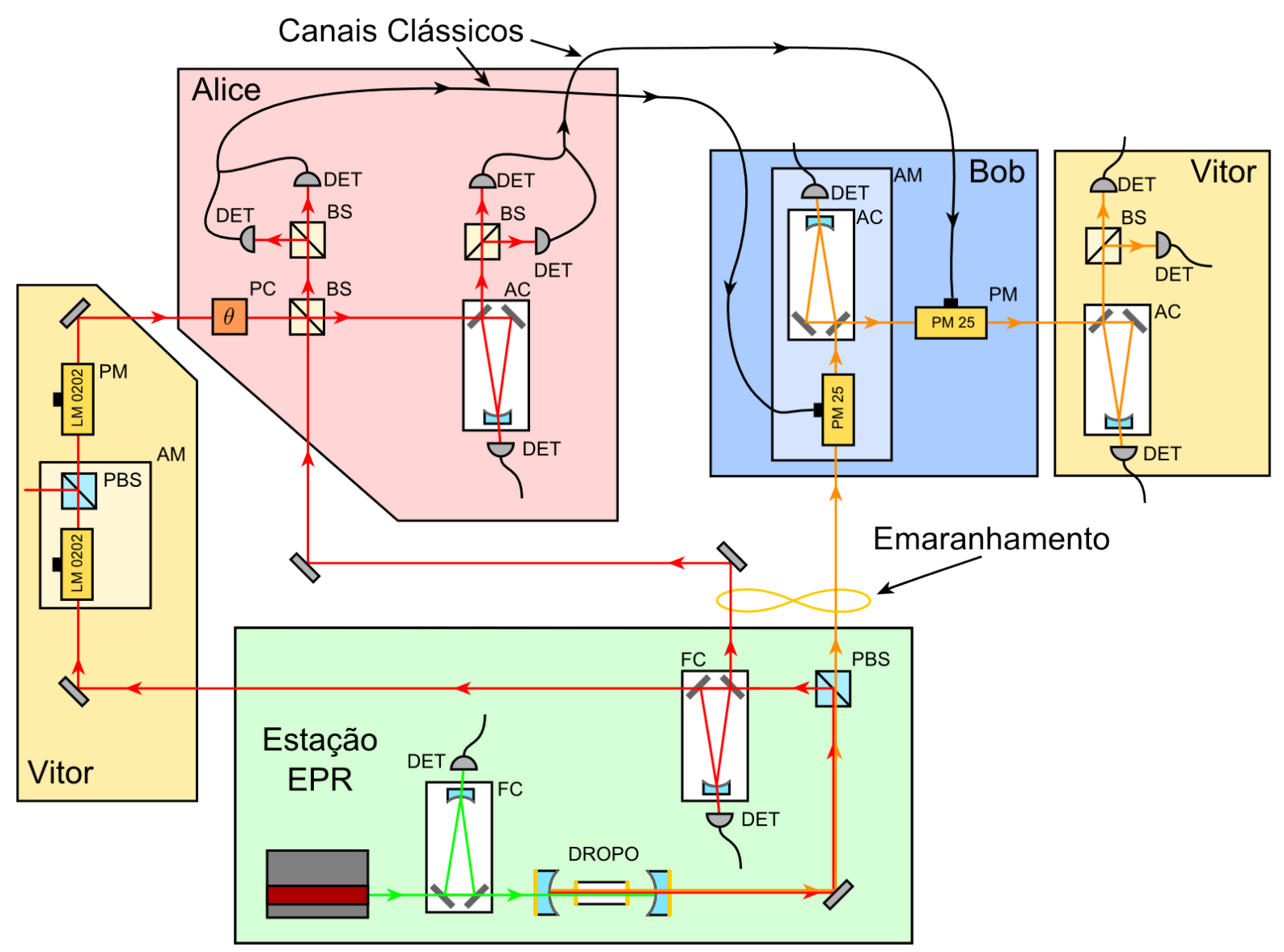

Figura 4.1: Esquema detalhado do projeto de teletransporte de informação quântica do LMCAL. As siglas representam: AC-Cavidade de Análise, FC-Cavidade de Filtro, DET-Detector, BS-Divisor de Feixes, PBS-Divisor de Feixes Polarizador, PM-Modulador de Fase, AM-Modulador de Amplitude, DROPO - Oscilador Paramétrico Óptico Duplamente Ressonante, PC-Controlador de Fase. 


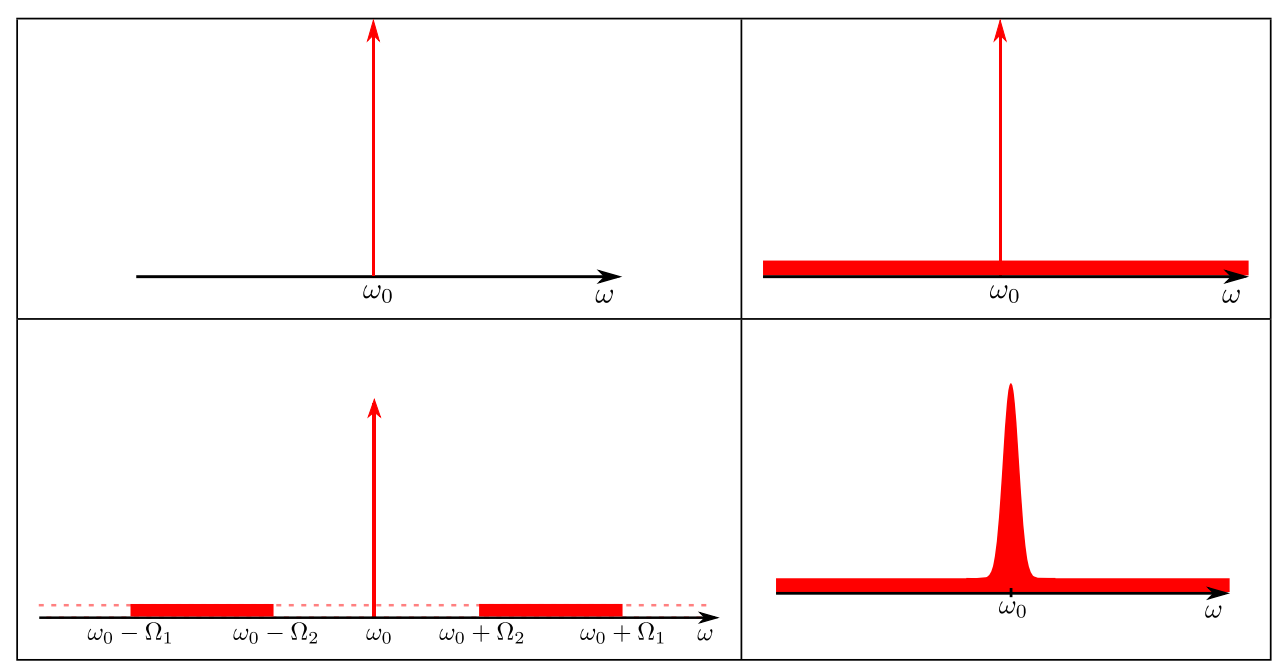

Figura 4.2: Espectros ilustrativos para diferentes descrições do campo eletromagnético. Acima à esquerda, um campo monomodo contendo apenas a onda portadora. Acima à direita, um campo monomodo com adição de ruído. Abaixo à esquerda, uma descrição da onda portadora com as bandas laterais, limitadas pelo sistema de detecção. Esta é a representação que iremos utilizar nas descrições matemáticas. No canto inferior direito, à titulo de ilustração, temos uma representação mais fiel da onda portadora. Ela é descrita por uma função gaussiana no espectro das frequências, que permite definir uma largura de banda para o campo da portadora.

igual à frequência de modulação aplicada sobre os EOMs, ou seja, 15 MHz. Esta descrição é a mais próxima do experimento que pretendemos realizar. Uma ilustração do espectro levando em conta a largura limitada das bandas laterais se encontra na imagem inferior da figura 4.2. Em nosso experimento, o OPO produzirá um estado EPR com emaranhamento entre os fótons presentes nestas bandas laterais.

Passemos então à descrição matemática do campo eletromagnético com suas bandas laterais.

A descrição matemática destes campos envolve a quantização do campo eletromagnético. Ao utilizarmos a descrição quântica do campo, este passa agora a ser descrito por operadores. O formalismo completo da quantização do campo eletromagnético pode ser encontrado em $[39,22,18]$. Usualmente, os operadores utilizados são os operadores de aniquilação e destruição, $\hat{a}$ e $\hat{a}^{\dagger}$.

O campo elétrico de um único modo do campo eletromagnético pode ser expresso através de operadores de criação e aniquilação, como na equação 2.5:

$$
\hat{E}_{x}=\mathscr{E}_{0}\left(\hat{a} e^{-i \omega_{0} t}+\hat{a}^{\dagger} e^{i \omega_{0} t}\right) \operatorname{sen}(k z)
$$

A descrição das bandas laterais é introduzida com a transformada de Fourier dos operadores somada ao termo da onda portadora.

$$
\hat{a}(t)=\int_{-\infty}^{\infty} \hat{a}_{\Omega} e^{i \Omega t} d \Omega+\alpha_{0}
$$

Onde vale a relação de comutação:

$$
\left[\hat{a}(t), \hat{a}^{\dagger}\left(t^{\prime}\right)\right]=\delta\left(t-t^{\prime}\right)
$$

Dessa forma, $\Omega$ representa as bandas laterais acima e abaixo da portadora no espectro de frequência. Como consideramos apenas uma porção limitada do espectro, $\Omega$ possui uma largura finita e podemos dizer que $\Omega \ll \omega_{0}$. Por sua vez, $\alpha_{0}$ representa o campo da 
portadora que é tratado nesta descrição como um campo clássico.

Os limites experimentais para a detecção de frequências adicionam algumas limitações quanto às regiões do espectro que podem ser medidas. Como mostrado na imagem inferior da figura 4.2, a detecção acessa apenas duas bandas laterais à frequência da portadora. Matematicamente, esta situação é descrita como:

$$
\hat{a}(t)=\underbrace{\int_{-\Omega_{1}}^{-\Omega_{2}} \hat{a}_{-\Omega} e^{i \Omega t} d \Omega}_{\text {banda inferior }}+\underbrace{\int_{\Omega_{1}}^{\Omega_{2}} \hat{a}_{\Omega} e^{i \Omega t} d \Omega}_{\text {banda superior }}+\underbrace{\alpha_{0}}_{\text {portadora }}
$$

Considerando $\Omega$ como sendo a frequência central à cada banda, ou seja, $\Omega=\frac{\Omega_{1}+\Omega_{2}}{2}$, obtemos os operadores para as bandas laterais:

$$
\hat{a}(t)=\underbrace{\hat{a}_{-\Omega}(t)}_{\text {bandainferior }}+\underbrace{\hat{a}_{+\Omega}(t)}_{\text {banda superior }}+\underbrace{\alpha_{0}}_{\text {portadora }}
$$

Fazendo uso destes operadores de aniquilação e destruição, podemos definir os operadores de quadratura $\hat{x}$ e $\hat{p}$ da seguinte forma. Partindo do operador número, temos:

$$
\hat{a}^{\dagger} \hat{a}=\underbrace{\alpha_{0}^{*}\left(\hat{a}_{-\Omega}+\hat{a}_{+\Omega}\right)+\alpha_{0}\left(\hat{a}_{-\Omega}^{\dagger}+\hat{a}_{+\Omega}^{\dagger}\right)}_{\text {Parte oscilante em } \Omega(\mathrm{AC})}+\underbrace{\alpha_{0}^{*} \alpha_{0}}_{\text {Parte contínua (DC) }}+\underbrace{O(2)}_{\text {Negligenciável }}
$$

Se expressarmos a portadora como $\alpha_{0}=\left|\alpha_{0}\right| e^{i \phi}$, podemos escrever a parte oscilante como:

$$
\left|\alpha_{0}\right|\left(\hat{a}^{\dagger} \hat{a}\right)_{o s c}=\left|\alpha_{0}\right|\left[\hat{a}_{-\Omega} e^{-i \phi}+\hat{a}_{+\Omega} e^{-i \phi}+\hat{a}_{-\Omega}^{\dagger} e^{i \phi}+\hat{a}_{+\Omega}^{\dagger} e^{i \phi}\right]
$$

Definimos então o operador posição $\hat{x}$ como sendo:

$$
\hat{x}=\frac{1}{2}\left[\hat{a}_{-\Omega} e^{-i \phi}+\hat{a}_{+\Omega} e^{-i \phi}+\hat{a}_{-\Omega}^{\dagger} e^{i \phi}+\hat{a}_{+\Omega}^{\dagger} e^{i \phi}\right]
$$

Realizando uma mudança de fase de $\pi / 2$, temos que $e^{i \phi} \rightarrow e^{i\left(\phi+\frac{\pi}{2}\right)}=i e^{i \phi}$ e $e^{-i \phi} \rightarrow$ $e^{-i\left(\phi+\frac{\pi}{2}\right)}=-i e^{i \phi}$, então, podemos definir o operador momento, $\hat{p}$ :

$$
\hat{p}=\frac{i}{2}\left[-\hat{a}_{-\Omega} e^{-i \phi}-\hat{a}_{+\Omega} e^{-i \phi}+\hat{a}_{-\Omega}^{\dagger} e^{i \phi}+\hat{a}_{+\Omega}^{\dagger} e^{i \phi}\right]
$$

Ao ajustarmos a fase $\phi$ para que seja nula, podemos ter uma melhor percepção do significado destes operadores:

$$
\begin{gathered}
2 \hat{x}=\hat{a}_{+\Omega}^{\dagger}+\hat{a}_{+\Omega}+\hat{a}_{-\Omega}^{\dagger}+\hat{a}_{-\Omega}=\hat{x}_{+}+\hat{x}_{-} \\
2 \hat{p}=i\left[\hat{a}_{+\Omega}^{\dagger}-\hat{a}_{+\Omega}\right]+i\left[\hat{a}_{-\Omega}^{\dagger}-\hat{a}_{-\Omega}\right]=\hat{p}_{+}+\hat{p}_{-}
\end{gathered}
$$

Onde os símbolos $+\mathrm{e}-$ são relativos às bandas laterais superior e inferior, respectivamente. Através destes operadores, podemos continuar na descrição do teletransporte com bandas laterais. 


\subsubsection{Produção dos feixes EPR}

O teletransporte precisa de um sistema de feixes emaranhados como canal quântico. O emaranhamento se expressa através da compressão em quadraturas do feixe EPR. No caso:

$$
\begin{aligned}
& \Delta^{2}\left(\hat{x}_{A}-\hat{x}_{B}\right)<S Q L \\
& \Delta^{2}\left(\hat{p}_{A}+\hat{p}_{B}\right)<S Q L
\end{aligned}
$$

Onde SQL é o Standard Quantum Limit, o ruído mínimo que o princípio de incerteza exige para quadraturas conjugadas. Este tipo de emaranhamento é produzido pela fonte de estados EPR, lembrando que neste caso o emaranhamento é produzido sobre as bandas laterais, ou seja, $\hat{x}_{A}=\left(\hat{x}_{+}^{A}+\hat{x}_{-}^{A}\right) / 2, \hat{x}_{B}=\left(\hat{x}_{+}^{B}+\hat{x}_{-}^{B}\right) / 2, \hat{p}_{A}=\left(\hat{p}_{+}^{A}+\hat{p}_{-}^{A}\right) / 2 \mathrm{e}$ $\hat{p}_{B}=\left(\hat{p}_{+}^{B}+\hat{p}_{-}^{B}\right) / 2$.

\subsubsection{Preparação do estado a ser teletransportado}

Após a geração dos feixes, o feixe A (sinal) é enviado primeiramente para Vitor. O campo do feixe A é intenso, uma vez que a geração dos feixes EPR pelo OPO ocorrerá acima do limiar. Vitor aproveitará a alta intensidade da portadora para modular sobre ela o feixe a ser teletransportado. Para isso, ele precisa separar as bandas laterais, contendo as correlações EPR com o campo B, do campo da portadora. O feixe com as correlações nas bandas laterais possui idealmente apenas vácuo na frequência onde antes estava a portadora. Ele é enviado para Alice, que o irá utilizar para fazer a medida de Bell. A portadora que foi separada das bandas correlacionadas possui agora vácuo não correlacionado nas bandas laterais, e pode ser utilizada por Vitor como matéria-prima na produção do estado a ser teletransportado.

O aproveitamento da portadora do feixe EPR A para produzir o estado a ser teletransportado é importante no sucesso do experimento. Como estes dois feixes serão interferidos na medida de Bell, é importante que eles tenham a mesma frequência. No entanto, o OPO, como fonte de estados EPR, foi muito utilizado como fonte sintonizável de luz Laser. Assim, a frequência dos feixes de saída do OPO é particular da configuração da operação do OPO naquele instante. A sintonização de um outro OPO para gerar um feixe com a mesma frequência do feixe A seria uma opção bastante complicada. Ainda uma outra possibilidade, a simples divisão do feixe A em um divisor de feixes é descartada pois com ela as correlações seriam enfraquecidas, devido a unidade de ruído de vácuo adicionada no divisor de feixes.

A separação é então feita através do uso de uma cavidade óptica configurada como um filtro de bandas. A cavidade deve ter uma largura de banda menor do que a soma das distâncias das bandas laterais à portadora $(B W<\Omega)$. Em nosso caso, para a largura de banda da cavidade de filtro, $B W=0,8-9 \mathrm{MHz}$, e a frequênia de análise planejada é de $\Omega=15 \mathrm{MHz}^{1}$.

\footnotetext{
${ }^{1}$ A escolha desta frequência de análise não é arbitrária. À princípio, quanto menor a frequência de análise, melhor a fidelidade do teletransporte. Mas há um limite inferior, a largura de banda da cavidade de filtro. Ela delimita o que será transmitido junto com a portadora, e assim, as bandas laterais do feixe refletido que estão dentro desta faixa não são correlacionadas com o outro feixe EPR. A geometria de nossas cavidades de filtro permitem larguras de banda de até 0,8 MHz. Este seria nosso limite inferior. $\mathrm{O}$ limite superior é definido pela largura de banda do OPO. Como apenas as frequências dos campos dentro desta banda interagem no OPO, somente esta faixa limitada é que apresenta emaranhamento. Por isso, quanto maior a largura de banda do OPO, melhor é o emaranhamento e maior a fidelidade possível de ser alcançada. O OPO construído apresentava uma largura de banda de $\sim 20 \mathrm{MHz}$, considerado insuficiente.
} 
Ao sintonizar a cavidade sobre o pico de intensidade da portadora, a cavidade age como um filtro, transmitindo a portadora e refletindo as bandas externas à sua largura de banda. O feixe refletido contendo as bandas laterais emaranhadas com o feixe B é enviado para Alice, que o utilizará na medida de Bell. O operador de aniquilação que descreve o feixe refletido incorpora então o fator $r(\Delta, \Omega)$, que representa o coeficiente de reflexão de amplitude do campo eletromagnético, conforme a equação 3.1.

Se colocarmos a cavidade em ressonância com a portadora, $\Delta=0$ e então, o operador de aniquilação para o campo refletido será:

$$
\hat{a}_{A}=r(0,-\Omega) \hat{a}_{-\Omega}(t)+r(0, \Omega) \hat{a}_{\Omega}(t)+r(0,0) \alpha_{A}+\sqrt{1-r^{2}} \hat{a}_{v a c}
$$

Com os dados experimentais das cavidades, mostrados nas tabelas 3.13.2, podemos calcular os valores teóricos para os coeficientes $r(\Delta, \Omega)$ através da fórmula 3.1

\begin{tabular}{|c|c|c|}
\hline$\delta v(\mathrm{MHz})$ & $|r(\Delta=0, \Omega= \pm 15 \mathrm{MHz})|$ & $|r(\Delta=0, \Omega=0)|$ \\
\hline \hline 0,8 & 0,9996 & 0 \\
\hline 9 & 0,9534 & 0 \\
\hline
\end{tabular}

Devido a esses resultados, podemos fazer $r(0,-\Omega)=r(0, \Omega)=1$. Assim, após a reflexão pela cavidade, e considerando a contribuição do vácuo pequena, temos:

$$
\hat{a}_{A}=\hat{a}_{-\Omega}(t)+\hat{a}_{\Omega}(t)+r \alpha_{A}
$$

E o feixe transmitido pela cavidade é um estado coerente. Este feixe é então utilizado por Vitor para a produção do campo a ser teletransportado. Seguindo as definições de operadores, o estado inicial é denotado de forma semelhante aos operadores da seção 2.3, $\hat{x}_{i n}$ e $\hat{p}_{i n}$. Sua produção, no entanto, envolve agora a modulação da onda portadora em frequências que estejam dentro das bandas laterais, ou seja, dentro do intervalo $\Omega_{1} \longleftrightarrow \Omega_{2}$, como descrito na seção anterior.

\subsubsection{Medida de Bell com bandas laterais}

Da mesma forma como na seção 2.3, a medida de Bell feita por Alice envolve a mistura dos dois campos por ela recebidos em um divisor de feixes. Expressando os campos a serem medidos em função dos operadores posição e momento, temos:

$$
\hat{a}_{A}=\hat{x}_{A}+i \hat{p}_{A}+r \alpha_{A}
$$

Onde tomamos $\alpha_{A}$ como sendo real. Da mesma forma, o campo a ser teletransportado fica:

$$
\hat{a}_{i n}=\hat{x}_{i n}+i \hat{p}_{i n}+\alpha_{i n}
$$

Denominando as saídas do divisor de feixes com os índices $u$ e $v$, os respectivos campos ficam:

$$
\begin{aligned}
& \hat{a}_{u}=\left(\hat{a}_{A}+e^{i \theta} \hat{a}_{i n}\right) / \sqrt{2} \\
& \hat{a}_{v}=\left(\hat{a}_{A}-e^{i \theta} \hat{a}_{i n}\right) / \sqrt{2}
\end{aligned}
$$

Com o projeto do novo OPO podemos obter uma largura de banda de aproximadamente $35 \mathrm{MHz}$. Duas frequências dentro desta faixa ainda precisam ser evitadas, 12 e $24 \mathrm{MHz}$, pois $12 \mathrm{MHz}$ é a frequência utilizada pelo sistema de travamento da cavidade de dobramento do laser de bombeio e, por isso, contém excesso de ruído, assim como o seu harmônico superior, $24 \mathrm{MHz}$. 
A fase $\theta$ é adicionada ao campo de entrada e pode ser ajustada de acordo com o desejado. Duas situações são interessantes de serem analisadas, $\theta=0$ e $\theta=\pi / 2$.

- $\theta=0$

Nesta condição, os campos de saída são:

$$
\begin{aligned}
& \hat{a}_{u}=[\left(\hat{x}_{A}+\hat{x}_{i n}\right)+i \underbrace{\left(\hat{p}_{A}+\hat{p}_{i n}\right)}_{\text {medida de } \hat{p}}+\underbrace{\left(r \alpha_{A}+\alpha_{i n}\right)}_{\text {intensidade máxima }}] / \sqrt{2} \\
& \hat{a}_{v}=[\underbrace{\left(\hat{x}_{A}-\hat{x}_{i n}\right)}_{\text {medida de } \hat{x}}+i\left(\hat{p}_{A}-\hat{p}_{i n}\right)+\underbrace{\left(r \alpha_{A}-\alpha_{i n}\right)}_{\text {intensidade mínima }}] / \sqrt{2}
\end{aligned}
$$

- $\theta=\pi / 2$

Podemos fazer $\theta=\pi / 2$ e $\alpha=\Gamma \alpha_{A}=\alpha_{i n}$, seguindo a estratégia utilizada por J. Zhang e K. Peng [40]. Assim, os campos de saída do divisor de feixes ficam:

$$
\begin{aligned}
& \hat{a}_{u}=\left[\hat{a}_{A}+i \hat{a}_{i n}+\alpha(1+i)\right] / \sqrt{2} \\
& \hat{a}_{v}=\left[\hat{a}_{A}-i \hat{a}_{i n}+\alpha(1-i)\right] / \sqrt{2}
\end{aligned}
$$

Neste $\operatorname{caso}(\theta=\pi / 2)$, ao calcularmos o termo proporcional à fotocorrente nos detectores, $I_{i}=\hat{a}_{i}^{\dagger} \hat{a}_{i}$, temos:

$$
\begin{gathered}
I_{u}=\alpha^{2}+\frac{\alpha}{2}\left[(1+i) \hat{a}_{A}^{\dagger}+(1-i) \hat{a}_{i n}^{\dagger}+(1-i) \hat{a}_{A}+(1+i) \hat{a}_{i n}\right]+O(2) \\
I_{u}=\alpha^{2}+\frac{\alpha}{2}\left[(1-i) \hat{a}_{A}^{\dagger}+(1+i) \hat{a}_{i n}^{\dagger}+(1+i) \hat{a}_{A}(1-i) \hat{a}_{i n}\right]+O(2)
\end{gathered}
$$

Por fim, através da eletrônica, as fotocorrentes são somadas e subtraídas, e, desconsiderando os termos de ordem superior, fornecem:

$$
\begin{gathered}
I_{u}+I_{u}=\alpha\left[\hat{a}_{A}^{\dagger}+\hat{a}_{i n}^{\dagger}+\hat{a}_{A}+\hat{a}_{i n}\right]=\alpha\left(\hat{x}_{A}+\hat{x}_{i n}\right) \\
I_{u}-I_{u}=\alpha\left[i \hat{a}_{A}^{\dagger}-i \hat{a}_{i n}^{\dagger}-i \hat{a}_{A}+i \hat{a}_{i n}\right]=\alpha\left(\hat{p}_{A}-\hat{p}_{i n}\right)
\end{gathered}
$$

As vantagens de se utilizar uma fase $\theta=0$ é que a medida não depende da intensidade dos campos. A desvantagem é que se faz necessária uma cavidade óptica estabilizada para realizar a rotação de elipse e fazer a medida da quadratura de soma de fases. Quando se escolhe $\theta=\pi / 2$, a vantagem é que a medida é direta, e o sistema é fácil de travar, necessitando, no entanto, que os campos estejam muito bem balanceados para que ela funcione.

Estas informações sobre as duas quadraturas medidas por Alice são então enviadas para Bob por dois canais clássicos, um para cada quadratura.

\subsubsection{O efeito do canal quântico}

Por fim, o teletransporte é realizado após Bob receber seu feixe EPR e também as informações clássicas enviadas por Alice. Para realizar o teletransporte, Bob precisa aplicar modificações em seu feixe EPR, modificações estas baseadas nas informações clássicas recebidas. As modificações são implementadas através de Moduladores Eletro Ópticos, em duas etapas como explicado a seguir.

O campo recebido por Bob sendo descrito por:

$$
\mathscr{E}(t)=\alpha_{B}+\int a_{\Omega} e^{i \Omega t} d \Omega
$$


O efeito da modulação será multiplicar o termo da portadora por uma modulação dependente do tempo, que, por ser muito pequena, pode ser aproximada em primeira ordem:

$$
e^{i \phi(t)} \simeq 1+i \phi(t)
$$

Assim, o campo modulado fica:

$$
\mathscr{E}(t)=\alpha_{B}+\alpha_{B} i \phi(t)+\int a_{\Omega} e^{i \Omega t} d \Omega
$$

A modulação $\phi(t)$ possui como transformada de Fourier:

$$
\phi(t)=\int \phi(\Omega) d \Omega
$$

Levando em conta que $\phi(-\Omega)=\phi^{*}(\Omega)$, a modulação se apresenta também em duas bandas, superior e inferior:

$$
\mathscr{E}(t)=\alpha_{B}+i \alpha_{B}\left(\phi_{\Omega}(t)+\phi_{-\Omega}(t)\right)+\hat{a}_{-\Omega}^{B}(t)+\hat{a}_{\Omega}^{B}(t)
$$

Ou, se fizermos:

$$
\begin{gathered}
\hat{p}_{\varepsilon}=\alpha_{B}\left(\phi_{\Omega}(t)+\phi_{-\Omega}(t)\right), \mathrm{e} \\
\hat{x}_{B}+i \hat{p}_{B}=\hat{a}_{-\Omega}^{B}(t)+\hat{a}_{\Omega}^{B}(t)
\end{gathered}
$$

obtemos o campo modulado em termos de operadores de amplitude e fase:

$$
\mathscr{E}(t)=\alpha_{B}+i \hat{p}_{\varepsilon}+\hat{x}_{B}+i \hat{p}_{B}
$$

O primeiro passo é produzir modulação de fase com o EOM, para que $\hat{p}_{B}$ seja cancelado. Note-se que $\hat{p}_{\varepsilon}$ é a parte eletronicamente filtrada de $\phi(t)$ na frequência $\Omega$. Para fazer o cancelamento, utilizo o valor medido na saída $u$ da medida de Bell, proporcional à amplitude do campo, adicionando este valor ao campo de Bob através de $\hat{p}_{\varepsilon}$ :

$$
\mathscr{E}(t)=\alpha_{B}+i\left(\hat{p}_{A}+\hat{p}_{i n}\right)+\hat{x}_{B}+i \hat{p}_{B}
$$

Rearranjando, temos:

$$
\mathscr{E}(t)=\alpha_{B}+i \hat{p}_{i n}+i\left(\hat{p}_{A}+\hat{p}_{B}\right)+\hat{x}_{B}
$$

O próximo passo é a rotação de $\pi / 2$ da elipse através de uma cavidade óptica. Com isso, consegue-se projetar operadores de amplitude em operadores de fase e vice-versa. O efeito é obtido através da reflexão do feixe em uma cavidade óptica travada num valor específico de dessintonia entre a ressonância da cavidade e a frequência da portadora de tal forma que os coeficientes de reflexão assumam os seguintes valores:

$$
\begin{gathered}
r(\Delta, 0)=i \\
r(\Delta, \Omega) \simeq r(\Delta,-\Omega)=1
\end{gathered}
$$

Ao aplicarmos estes coeficientes à relação do campo refletido, 4.2, ou seja, uma fase de $\pi / 2$ aplicada à portadora, o campo fica da seguinte forma após a reflexão:

$$
\mathscr{E}(t)=i\left(\alpha_{B}+\hat{p}_{i n}+\left(\hat{p}_{A}+\hat{p}_{B}\right)-i \hat{x}_{B}\right)
$$


Sendo o estado multiplicado por uma fase global, que é descartada na medida, passamos então à mais um deslocamento de fase, dessa vez proporcional à medida da quadratura de fase, como medido por Alice na saída $v$, do divisor de feixes. Adiciona-se então através da modulação variações de fase como:

$$
\hat{x}_{\varepsilon}=\alpha_{B}\left(\theta_{\Omega}(t)+\theta_{-\Omega}(t)\right)=i\left(\hat{x}_{A}-\hat{x}_{i n}\right)
$$

E obtemos então:

$$
\mathscr{E}(t)=\alpha_{B}+\hat{p}_{i n}+\left(\hat{p}_{A}+\hat{p}_{B}\right)-i \hat{x}_{B}+i\left(\hat{x}_{A}-\hat{x}_{i n}\right)
$$

E rearranjando, obtemos um campo que é similar ao campo de entrada, somado a dois outros termos relativos aos dois feixes EPR:

$$
\mathscr{E}_{\text {tel }}(t)=\alpha_{B}-i \underbrace{\left(\hat{x}_{i n}+i \hat{p}_{i n}\right)}_{\text {Estado original }}+\underbrace{\left(\hat{p}_{A}+\hat{p}_{B}\right)+i\left(\hat{x}_{A}-\hat{x}_{B}\right)}_{\text {Quadraturas comprimidas }}
$$

Assim, obtemos na saída do sistema o estado de entrada inicial, multiplicado por uma fase global, junto é claro com a nova portadora e os resquícios dos operadores dos feixes EPR. Observamos que quanto melhor a compressão obtida na produção do feixe EPR, mais próximos de zero serão os termos que surgem junto com estado inicial e, portanto, melhor será a semelhança do estado de saída com o estado de entrada. Ou seja, se fizermos

$$
\begin{aligned}
& \left(\hat{p}_{A}+\hat{p}_{B}\right) \rightarrow 0 \\
& \left(\hat{x}_{A}-\hat{x}_{B}\right) \rightarrow 0
\end{aligned}
$$

obteremos o estado inicial nas bandas laterais do feixe de saída.

$$
\mathscr{E}_{\text {tel }}(t) \rightarrow \alpha_{B}-i\left(\hat{x}_{i n}+i \hat{p}_{i n}\right)
$$

No TROPO construído em nosso laboratório foi possível obter feixes de luz emaranhados que diferem em até $4,8 \mathrm{~nm}$ [7]. A técnica utiliza o controle fino da temperatura do cristal para fazer com que os feixes sinal e complementar ressoem em modos com comprimentos de onda distintos. Espera-se que através da técnica o novo OPO produza feixes EPR com diferença de comprimento de onda similar.

Fica então demonstrado como planejamos executar o teletransporte de informação quântica para campos de cores distintas. 


\section{Capítulo 5}

\section{Conclusão}

Através deste trabalho, vários avanços foram alcançados no desenvolvimento do projeto de teletransporte de informação quântica do LMCAL.

As quatro cavidades ópticas necessárias foram construídas e dão sinais de ótima estabilidade mecânica, suportando, inclusive, variações da temperatura ambiente, uma característica desejável para facilitar o travamento e viabilizar seu uso simultâneo no teletransporte.

Os moduladores eletro-ópticos foram caracterizados, apresentando os seguintes valores de ganho, para uma frequência de modulação de $15 \mathrm{MHz}:(7,4 \pm 0,3) \times 10^{-3} \mathrm{rad} / \mathrm{Volt}$ para o modelo LM $0202 \mathrm{e}(2,5 \pm 0,1) \times 10^{-3} \mathrm{rad} /$ Volt para o modelo PM 25 .

Um oscilador paramétrico óptico foi projetado e construído e, infelizmente, teve que ser desmontado por não atender às expectativas com relação ao nível de perdas espúrias. Um valor de $1,3 \%$ para as perdas espúrias representa neste caso $38 \%$ das perdas totais da cavidade. Um valor muito alto, com consequências sobre o nível de compressão possível de ser obtido entre os dois feixes gerados e, por consequência sobre a fidelidade máxima possível de ser obtida no teletransporte. Com este OPO, os cálculos indicaram um valor máximo de compressão para o ruído de uma das quadraturas comprimidas de $S_{\hat{p}-}=55 \%$, implicando uma fidelidade máxima de $65 \%$, sem considerar as perdas de detecção.

Um novo OPO foi projetado e encontra-se em fase de construção. Com a aquisição de novos espelhos, otimizados para a construção de um OPO com maior largura de banda, a teoria mostrou que a fidelidade máxima sem perdas para a frequência de análise é de $96 \%$.

Com a compreensão de onde cada parte se encaixa no todo do projeto, fica mais claro quais os passos necessários para atingir o objetivo de realizar o teletransporte. Após a construção e caracterização do novo OPO, faltam ainda uma boa parte do desenvolvimento da eletrônica, incluindo construir e testar o controle de travamento das cavidades ópticas, aprontar os sistemas de detecção e demodulação e instalar o sistema de modulação de Vitor. Com a eletrônica pronta, entramos na parte de testes e por fim, de realização do teletransporte. 
54 CONCLUSÃO 


\section{Referências Bibliográficas}

[1] C. H. Bennett, G. Brassad, C. Crépeau, R. Jozsa, A. Peres, and W. K. Wootters. Teleporting an unknown quantum state via dual classical and Einstein-Podolsky-Rosen channels. Phys. Rev. Lett., 70:1895 - 1899, 1993. iii, v, 1, 3, 5, 7

[2] D. Bouwmeester, Jian-Wei Pan, K. Mattle, M. Eibl, H. Weinfurter, and A. Zeilinger. Experimental quantum teleportation. Nature, 390:575, 1997. iii, v, 1, 11

[3] A. Furusawa, J. L. Sørensen, S. L. Braunstein, C. A. Fuchs, H. J. Kimble, and E. S. Polzik. Unconditional quantum teleportation. Science, 282:706, 1998. iii, v, 1, 3, 11, 12

[4] Yoon-Ho Kim, Sergei P. Kulik, and Yanhua Shih. Quantum teleportation of a polarization state with a complete Bell state measurement. Phys. Rev. Lett., 86:1370-1373, Feb 2001. iii, v, 1, 11

[5] A. S. Villar, L. S. Cruz, K. N. Cassemiro, M. Martinelli, and P. Nussenzveig. Generation of bright two-color continuous variable entanglement. Phys. Rev. Lett., 95:243603, 2005. iii, v, 1

[6] A. S. Villar, K. N. Cassemiro, K. Dechoum, A. Z. Khoury, M. Martinelli, and P. Nussenzveig. Entanglement in the above-threshold optical parametric oscillator. J. Opt. Soc. Am. B, 24:249, 2007. iii, v, 1

[7] A. S. Coelho, F. A. S. Barbosa, K. N. Cassemiro, A. S. Villar, M. Martinelli, and P. Nussenzveig. Three-color entanglement. Science, 326(5954):823-826, 2009. iii, v, 1, 51

[8] A. Einstein, B. Podolsky, and N. Rosen. Can quantum-mechanical description of physical reality be considered complete? Phys. Rev., 47:777-780, 1935. 1

[9] Alain Aspect, Jean Dalibard, and Gérard Roger. Experimental test of Bell's inequalities using time- varying analyzers. Phys. Rev. Lett., 49:1804-1807, Dec 1982. 1

[10] M. A. Rowe, D. Kielpinski, V. Meyer, C. A. Sackett, W. M. Itano, C. Monroe, and D. J. Wineland. Experimental violation of a Bell's inequality with efficient detection. $\mathrm{Na}$ ture, 409(6822):791-794, Feb 2001. 1

[11] Yuji Hasegawa, Rudolf Loidl, Gerald Badurek, Matthias Baron, and Helmut Rauch. Violation of a Bell-like inequality in single-neutron interferometry. Nature, 425(6953):45-48, Sep 2003. 1

[12] Z. Y. Ou, S. F. Pereira, H. J. Kimble, and K. C. Peng. Realization of the EinsteinPodolsky-Rosen paradox for continuous variables. Phys. Rev. Lett., 68:3663, 1992. 1 
[13] Z.Y. Ou, S.F. Pereira, and H.J. Kimble. Realization of the Einstein-Podolsky-Rosen paradox for continuous variables in nondegenerate parametric amplification. $A p$ plied Physics B, 55:265-278, 1992. 1

[14] P. van Loock, Samuel L. Braunstein, and H. J. Kimble. Broadband teleportation. Phys. Rev. A, 62:022309, Jul 2000. 1, 11, 15, 16, 38

[15] Samuel L. Braunstein. A fun talk on teleportation. Site, February 1995. www.research.ibm.com/quantuminfo/teleportation/braunstein.html. Acesso em 12/01/2013. 4

[16] W. K. Wootters and W. H. Zurek. A single quantum cannot be cloned. Nature, 299(5886):802-803, 1982. 4

[17] E. Rieffel and W. Polak. An introduction to quantum computing for non-physicists. ACM Comput. Surv., 32(3):300-335, September 2000. 8

[18] C. Gerry and P. Knight. Introductory Quantum Optics. Cambridge University Press, 2004. 8, 11, 45

[19] N. Lütkenhaus, J. Calsamiglia, and K.-A. Suominen. Bell measurements for teleportation. Phys. Rev. A, 59:3295-3300, May 1999. 11

[20] Samuel L. Braunstein and H. J. Kimble. Teleportation of continuous quantum variables. Phys. Rev. Lett., 80(4):869-872, Jan 1998. 11

[21] Samuel L. Braunstein, Christopher A. Fuchs, and H. J. Kimble. Criteria for continuous-variable quantum teleportation. Journal of Modern Optics, 47(23):267-278, 2000. 15, 17, 39

[22] M. O. Scully and M. S. Zubairy. Quantum Optics. Cambridge University Press, Cambridge, United Kingdom, 1997. 16, 45

[23] Frédéric Grosshans and Philippe Grangier. Quantum cloning and teleportation criteria for continuous quantum variables. Phys. Rev. A, 64:010301, Jun 2001. 17, 39

[24] Alessandro S. Villar. The conversion of phase to amplitude fluctuations of a light beam by an optical cavity. American Journal of Physics, 76(10):922-929, 2008. 19, 20

[25] F. A. S. Barbosa. Em preparação. Tese de doutorado, Instituto de Física da Universidade de São Paulo, 2013. 19, 20

[26] Nicolai B. Grosse, Syed Assad, Moritz Mehmet, Roman Schnabel, Thomas Symul, and Ping Koy Lam. Observation of entanglement between two light beams spanning an octave in optical frequency. Phys. Rev. Lett., 100:243601, Jun 2008. 19

[27] A.S. Villar, M. Martinelli, and P. Nussenzveig. Testing the entanglement of intense beams produced by a non-degenerate optical parametric oscillator. Optics Communications, 242(4-6):551 - 563, 2004. 20

[28] A. Yariv. Quantum Electronics. John Wiley \& Sons, New York, 1989. 21, 23, 30, 31, 37,41 
[29] A. S. Villar, M. Martinelli, C. Fabre, and P. Nussenzveig. Direct production of tripartite pump-signal-idler entanglement in the above-threshold optical parametric oscillator. Phys. Rev. Lett., 97:140504, 2006. 30

[30] R.L. Byer, M.K. Oshman, J.F. Young, and S.E. Harris. Visible CW parametric oscillator. Applied Physics Letters, 13(3):109-111, 1968. cited By (since 1996) 16. 31, 37

[31] D. C. Gerstenberger and R. W. Wallace. Continuous-wave operation of a doubly resonant lithium niobate optical parametric oscillator system tunable from 966 to 1185 nm. J. Opt. Soc. Am. B, 10(9):1681-1683, Sep 1993. 31, 37

[32] C Fabre, PF Cohadon, and C Schwob. CW optical parametric oscillators: Single mode operation and frequency tuning properties. QUANTUM AND SEMICLASSICAL OPTICS, 9(2):165-172, APR 1997. 31, 37

[33] Claude Fabre. Advanced photonics with second-order optically nonlinear processes., chapter Classical and quantum aspects of C.W. parametric interactions in a cavity., pages 293-318. NATO science series. Partnership sub-series 3, High technology. Kluwer, 1998. 31, 37

[34] Emmanuel Rosencher and Claude Fabre. Oscillation characteristics of continuouswave optical parametric oscillators: Beyond the mean-field approximation. J. Opt. Soc. Am. B, 19(5):1107-1116, May 2002. 31

[35] T. Debuisschert, A. Sizmann, E. Giacobino, and C. Fabre. Type-ii continuous-wave optical parametric oscillators oscillation and frequency-tuning characteristics. $J$. Opt. Soc. Am. B, 10(9):1668-1680, Sep 1993. 31, 36

[36] A. S. Coelho. Emaranhamento tripartite no oscilador paramétrico Ótico. Dissertação de mestrado, Instituto de Física da Universidade de São Paulo, 2009. 36, 43

[37] Eugene Hecht. Optics. Addison Wesley, 4. ed edition, 2002. 37

[38] Alessandro de Souza Villar. Emaranhamento Multicolor entre Feixes Intensos de Luz. PhD thesis, Instituto de Física da Universidade de São Paulo, 2007. 38

[39] D. F. Walls and G. Milburn. Quantum Optics. Springer, 1993. 45

[40] Jing Zhang and Kunchi Peng. Quantum teleportation and dense coding by means of bright amplitude-squeezed light and direct measurement of a Bell state. Phys. Rev. A, 62:064302, Nov 2000. 49 